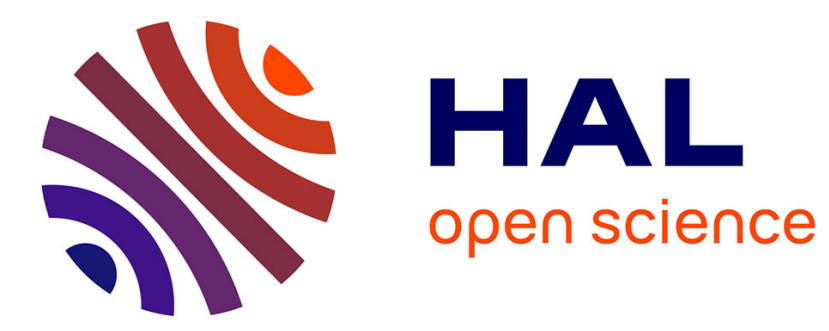

\title{
Pyrene/coumarine-subphthalocyanine conjugates as light harvesting systems with intramolecular energy transfer
}

\author{
Vivian Lioret, Yoann Rousselin, Richard Decreau
}

\section{To cite this version:}

Vivian Lioret, Yoann Rousselin, Richard Decreau. Pyrene/coumarine-subphthalocyanine conjugates as light harvesting systems with intramolecular energy transfer. Dyes and Pigments, 2020, 183, pp.108696. 10.1016/j.dyepig.2020.108696 . hal-03476777

\section{HAL Id: hal-03476777 \\ https://hal.science/hal-03476777}

Submitted on 13 Dec 2021

HAL is a multi-disciplinary open access archive for the deposit and dissemination of scientific research documents, whether they are published or not. The documents may come from teaching and research institutions in France or abroad, or from public or private research centers.
L'archive ouverte pluridisciplinaire HAL, est destinée au dépôt et à la diffusion de documents scientifiques de niveau recherche, publiés ou non, émanant des établissements d'enseignement et de recherche français ou étrangers, des laboratoires publics ou privés. 


\section{Manuscript Details}

\section{Manuscript number}

Title
DYPI_2020_1212

Pyrene/coumarine-subphthalocyanine conjugates as light harvesting systems with intramolecular energy transfer

Research paper

\section{Article type}

\section{Abstract}

A series of subphthalocyanine-antenna dyads have been successfully designed, synthetized and characterized by $1 \mathrm{H}$ NMR, 13C-NMR, high-resolution mass spectroscopy, and X-ray diffraction studies with one dyad. Pyrene and coumarine have been appended at the axial position of the subphthalocyanine scaffold using different types of linkers. Photophysical properties of the new compounds have been measured in toluene, tetrahydrofuran, chloroform, dimethyl sulfoxide and methanol. Energy transfer efficiencies between antenna and the subphthalocyanine platform have been investigated and almost quantitative energy transfer occurs in the antenna-platform 5.

\section{Keywords}

Corresponding Author

Corresponding Author's Institution

Order of Authors

Suggested reviewers subphthalocyanine; pyrene; coumarine; dyad; fluorescence; intramolecular energy transfer

Richard decreau

University of Burgundy Franche Comté

Vivian Lioret, Yoann Rousselin, Richard decreau

Mogens Nielsen, Timothy Bender, Christopher Ziegler

\section{Submission Files Included in this PDF}

File Name [File Type]

5-Cover Letter.pdf [Cover Letter]

5-Highlight.pdf [Highlights]

05.draft.pdf [Manuscript File]

5-checkcif(1).pdf [Figure]

5-declaration-of-competing-interests(1).pdf [Conflict of Interest]

5-SI_final version.pdf [Supplementary Material]

\section{Submission Files Not Included in this PDF}

\section{File Name [File Type]}

5-Graphical Abstract.PNG [Graphical Abstract]

To view all the submission files, including those not included in the PDF, click on the manuscript title on your EVISE Homepage, then click 'Download zip file'. 
Dyes and Pigments

Editors of Dyes and Pigments

Dijon, May 27th, 2020

Dear Editor,

We would like to submit a manuscript entitled "Pyrene/coumarine-subphthalocyanine conjugates as light harvesting systems with intramolecular energy transfer" for publication in Dyes and Pigments.

This study reports the syntheses of several dyads of fluorophores and subsequent studies of intramolecular energy transfers. In such dyads the acceptor is a subphthalocyanine, the donor is either a coumarin or a pyrene, and the nature of the linker between both has been varied. Next, upon careful purification and characterization of the conjugates including X-ray diffraction studies for two candidates, subsequent photophysical studies have been engaged. Upon fluorescence spectroscopy, fluorescence quantum yields have been measured and subsequent energy transfer between both moieties within each dyad has been also measured. Up to five different organic solvents have been examined to carry out such studies. One out of three dyads underwent almost quantitative energy transfer efficiency (E.T.E.).

Overall this study is a blend of organic synthesis of new subphthalocyanine-based fluorophore dyads, and photophysical studies addressing the energy transfer between two fluorophores.

We hope this study will be of interest for readers of Dyes and Pigments.

Sincerely,

Richard A. Decréau

Dr Richard A. Decréau ; Associate Professor ; Institut de Chimie Moléculaire de l'Université de Bourgogne (ICMUB), UMR 6302 CNRS-Université de Bourgogne, BP 47 870, F-21 078 Dijon Cedex, France ; Richard.Decreau@u-bourgogne.fr 


\section{Highlight}

Required : 85 characters. Here : 85 characters

The Energy Transfer Efficiency was studied in four new subphthalocyanine-fluorophore conjugates

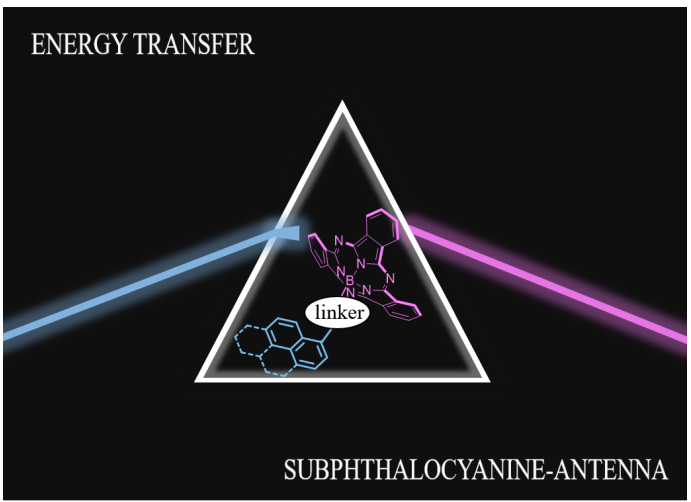




\title{
Pyrene/coumarine-subphthalocyanine conjugates as light harvesting systems with intramolecular energy transfer
}

\author{
Vivian Lioret ${ }^{\mathrm{a}}$, Yoann Rousselin ${ }^{\mathrm{a}}$, Richard A. Decréau ${ }^{\mathrm{a},{ }^{*}}$ \\ a ICMUB Institute, University Bourgogne - Franche Comté, 9 Avenue Alain Savary, Sciences Mirande, 21078 Dijon, France \\ *Corresponding author. E-mail address: Richard.Decreau@u-bourgogne.fr (R.A. Decréau).
}

\begin{abstract}
A series of subphthalocyanine-antenna dyads have been successfully designed, synthetized and characterized by ${ }^{1} \mathrm{H}-\mathrm{NMR},{ }^{13} \mathrm{C}-\mathrm{NMR}$, high-resolution mass spectroscopy and $\mathrm{X}$-ray diffraction for some of them. Pyrene and coumarine have been appended at the axial position of the subphthalocyanine scaffold using different types of linkers. Photophysical properties of the new compounds have been measured in toluene, tetrahydrofuran, chloroform, dimethyl sulfoxide and methanol. Energy transfer efficiencies between antenna and the subphthalocyanine platform have been investigated and almost quantitative energy transfer occurs in the antennaplatform 5.
\end{abstract}

Keywords: Subphtalocyanine, Pyrene, Coumarine, Dyad, Fluorescence, Intramolecular Energy Transfer

\section{Introduction}

Energy transfer is a crucial process in nature, but also in more artificial applications, such as the conversion of solar energy into electricity, in optoelectronic devices[1] or in the detection of analytes[2,3]. Over the past decades, this area of research has become a fertile field for the association of two or more chromophores together. The interaction of different partners and the exchange of energy between them has become an attractive investigation domain. Numerous conjugated polyazamacrocycles, such as porphyrins[4, 5], phthalocyanines[6] or naphthalocyanines[4] have been employed as partners for photophysical or electronic studies. Among them, subphthalocyanines, which are lower homologues of phthalocyanines having a central Boron (III) atom, are another important class of chromophores. They are conic-shaped macrocycles, with a 14- $\pi$ electron aromatic core. This scaffold is used in many fields, such as organic material[7], photodynamic therapy [8] or optoelectronic[9, 10]. Most functionalizations of the SubPc moieties are done by substitution of the axial halogen.

In order to study energy transfers with subphthalocyanines, pyrene and coumarine have been chosen to absorb light in the UV-blue region of the visible spectrum. Although a few pyreneSubPc dyads have already been described in the literature[11], we specifically investigated the efficiency of the energy transfer between these two units as a function of the nature of the linker. For this purpose, the SubPc platform has been functionalized at the axial position [12,13] (and not at the iso-indolic position, which may otherwise affect the electronic properties of the 
platform) by the pyrene, choosing chemical modifications, such as a triple bond, a B-O-R or a B-O- $\mathrm{CH}_{2}-\mathrm{R}$ as a linker. Coumarine was also linked to the SubPc platform by a B-O-R link.

The photophysical behavior of these antenna-SubPc dyads were explored using fluorescence spectroscopy. SubPc are also known to be good singlet oxygen generator under light exposure[14], yet, we did not measured their ability to perform such generation.

\section{Experimental}

\subsection{Materials and equipments}

${ }^{1} \mathrm{H}$ and ${ }^{13} \mathrm{C}$ NMR spectra were recorded on a Bruker Avance III $500 \mathrm{MHz}$ spectrometer. Chemical shifts are expressed in parts per million (ppm) from the residual non-deuterated solvent signal. J values are expressed in Hz. HPLC-MS analyses were performed on a ThermoDionex Ultimate 3000 instrument equipped with a diode array detector (Thermo-Dionex, FLD 3400-RS). High-resolution mass spectra (HRMS) were recorded on a LTQ Orbitrap XL (THERMO) equipped with an electrospray (ESI) source. For single crystal X-ray diffraction analyzes, all experimental data procedure and refinement are detailed in Supplementary Information. Data CCDC- 2005981 and 2005982 contain the supplementary crystallographic data for this paper for compound $\mathbf{4}$ and $\mathbf{6}$ respectively. These data can be obtained free of charge from The Cambridge Crystallographic Data Centre via www.ccdc.cam.ac.uk/data request/cif

\subsection{Fluorescence quantum yield}

UV-Visible measurements were performed on an Agilent Cary 60 using a glass cuvette $(1 \times 1 \times 3$ $\mathrm{cm}$ ). Fluorescence spectroscopic studies (emission/excitation spectra) were performed on a HORIBA Jobin Yvon Fluorolog spectrophotometer (software FLuorEssence) at $25^{\circ} \mathrm{C}$ (using a temperature control system combined with water circulation), with standard fluorometer cells (Labbox, LB Q, light path: $10 \mathrm{~mm}$, width: $10 \mathrm{~mm}$, chamber volume: $3.5 \mathrm{~mL}$ ). Fluorescence quantum yields were calculated by relative method using rhodamine $6 \mathrm{G}$ in ethanol $\left(\Phi_{\mathrm{F}}=0.96\right.$, $488 \mathrm{~nm})$. Emission Spectra were recorded for an absorbance at excitation wavelength comprised between 0.02 and 0.09 . Fluorescence quantum yield $\left(\Phi_{\mathrm{F}}\right)$ were determined using the following equation:

$$
\Phi_{F}=\Phi_{F}(S t d) \times\left(\frac{\eta}{\eta(S t d)}\right)^{2} \times\left(\frac{1-10^{-A b s}}{1-10^{-A b s(S t d)}}\right) \times\left(\frac{A(S t d)}{A}\right)
$$

With:

Std corresponds to standard

$\Phi_{\mathrm{F}}$ and $\Phi_{\mathrm{F}}(\mathrm{Std})$ : fluorescence quantum yields

$\eta$ and $\eta$ (Std): refractive index of solvent 
Abs and Abs (Std): absorbance at excitation wavelength (488 nm)

$\mathrm{A}$ and $\mathrm{A}(\mathrm{Std})$ : areas under the fluorescence curves

\subsection{Synthesis}

\subsubsection{Synthesis of compound $\mathbf{1}$}

To a solution of phthalonitrile $(1.06 \mathrm{~g}, 8.27 \mathrm{mmol})$ in dry dichlorobenzene (DCB, 45 $\mathrm{mL})$, under nitrogen atmosphere, was slowly added $\mathrm{BCl}_{3}(20 \mathrm{~mL}, 1 \mathrm{M}$ in hexane, $20 \mathrm{mmol})$ and the reaction was heated at $70^{\circ} \mathrm{C}$ to remove hexane. After $30 \mathrm{~min}$ at $70^{\circ} \mathrm{C}$, a condenser was added and the reaction mixture was heated at $180^{\circ} \mathrm{C}$ for 1.5 hours. The color went from light milky yellow to dark purple. Then the reaction mixture was cooled down and a precipitate was formed. The solid was filtrated, washed with methanol and pentane and dried under vacuum to afford compound 1 (700 mg, 58\%). ${ }^{1} \mathrm{H}$ NMR (500 MHz, $\left.\mathrm{CDCl}_{3}, 300 \mathrm{~K}\right): \delta(\mathrm{ppm}) 7.95$ (m, 6H), 8.90 (m, 6H). HR-MS ESI: m/z $431.0966[\mathrm{M}+\mathrm{H}]^{+}$(calcd for $\mathrm{C}_{24} \mathrm{H}_{13} \mathrm{BClN}_{6}{ }^{+}$: 431.0978). HP-LC analysis: retention time 5.83 .

\subsubsection{Synthesis of compound 2}

1-pyrenecarboxaldehyde (1 g, $4.3 \mathrm{mmol})$ and dry THF $(20 \mathrm{~mL})$ were mixed together. Sodium borohydride $(165 \mathrm{mg}, 4.3 \mathrm{mmol})$ was added in small portions, together with small portions of methanol to help the solubilization (total volume of added methanol $10 \mathrm{~mL}$ ). An orange solution was obtained. The reaction was then quenched with a $2 \%$ concentrated hydrochloric acid solution. The solvent was removed under reduced pressure. The white powder obtained was dissolved in dichloromethane, washed with water and the organic phase was dried with magnesium sulfate. The solvent was removed under reduced pressure and the resulting solid was subjected to silica gel column chromatography (eluent: DCM) to afford compound 2 (0.88 g, 88\%). ${ }^{1} \mathrm{H}$ NMR (500 MHz, $\left.\mathrm{CDCl}_{3}, 300 \mathrm{~K}\right): \delta(\mathrm{ppm}) 1.90$ (s, 1H), 5.40 (s, 2H), $7.98-8.10(\mathrm{~m}, 4 \mathrm{H}), 8.15(\mathrm{~m}, 2 \mathrm{H}), 8.20(\mathrm{~m}, 2 \mathrm{H}), 8.37$ (d, $J=9.2 \mathrm{~Hz}, 1 \mathrm{H}) .{ }^{13} \mathrm{C}$ NMR $(125$ $\left.\mathrm{MHz}, \mathrm{CDCl}_{3}, 300 \mathrm{~K}\right): \delta$ (ppm) 64.04, 123.16, 124.88, 124.92, 125.13, 125.43, 125.46, 126.16, 126.20, 127.55, 127.64, 128.08, 128.97, 130.94, 131.41, 131.44, 133.92. HR-MS ESI: m/z $247.0762[\mathrm{M}+\mathrm{O}-\mathrm{H}]^{-}$(calcd for $\left.\mathrm{C}_{17} \mathrm{H}_{10} \mathrm{O}_{2}^{-}: 247.0765\right)$. HP-LC analysis: retention time 4.78 .

\subsubsection{Synthesis of compounds $\mathbf{3}, \mathbf{4}$ and $\mathbf{6}$}

General procedure. The synthetic method reported here to append aryloxy/alkoxy structures at the axial position of the SubPc platform was reminiscent of that we reported for phenoxy moities.[15] To a solution of compound 1 (50 mg, 0,116 mmol) in toluene (5 mL) was added the corresponding antenna $(0,58 \mathrm{mmol})$. The reaction mixture was heated under refluxing conditions during 2-5 days and monitored by LCMS. The solvent was then removed under reduced pressure and the crude product was subjected to silica gel column chromatography. 


\section{Compound $\mathbf{3}$}

Compound $\mathbf{3}$ was synthesized following the general procedure, where the chosen antenna was compound 2 (134 mg). The reaction mixture was heated under refluxing conditions for 5 days. Target compound $\mathbf{3}$ was obtained after purification of the crude product by silica gel column chromatography using the $\mathrm{DCM} / \mathrm{MeOH}$ mixture $(95 / 5 \mathrm{vol}$.) as an eluent to afford the desired product 3 (52 mg, 74\%). ${ }^{1} \mathrm{H}$ NMR (500 MHz, $\left.\mathrm{CDCl}_{3}, 300 \mathrm{~K}\right): \delta(\mathrm{ppm}) 3,40(\mathrm{~m}, 2 \mathrm{H}), 5.29$ (s, $1 \mathrm{H}), 7.08(\mathrm{~d}, J=7.8 \mathrm{~Hz}, 1 \mathrm{H}), 7.28(\mathrm{~d}, J=9.2 \mathrm{~Hz}, 1 \mathrm{H}), 7.75-7.88(\mathrm{~m}, 10 \mathrm{H}), 7.99(\mathrm{~d}, J=7.6$ $\mathrm{Hz}, 2 \mathrm{H}), 8.76(\mathrm{~m}, 6 \mathrm{H}) .{ }^{13} \mathrm{C} \mathrm{NMR}\left(125 \mathrm{MHz}, \mathrm{CDCl}_{3}, 300 \mathrm{~K}\right): \delta$ (ppm) 60.55, 122.09, 122.78 , $124.28,124.48,124.86,124.93$, 125.24, 125.64, 126.89, 127.22, 127.35, 127.87, 129.69, 130.56, 130.64, 131.01, 131.15, 132.35, 151.43. HR-MS ESI: m/z 627.2069 [M+H] ${ }^{+}($calcd for $\mathrm{C}_{41} \mathrm{H}_{24} \mathrm{BN}_{6} \mathrm{O}^{+}$: 627.2099). HP-LC analysis: retention time $6.68 \mathrm{~min}$.

\section{Compound 4}

Compound 4 was synthesized following the general procedure where the chosen antenna was 1-hydroxypyrene $(127 \mathrm{mg})$. The reaction mixture was heated under refluxing conditions for 2 days. The final product was obtained after purification of the crude mixture by silica gel column chromatography using DCM as an eluent to afford the desired product 4 (32 $\mathrm{mg}, 45 \%)$. ${ }^{1} \mathrm{H}$ NMR $\left(500 \mathrm{MHz}, \mathrm{CDCl}_{3}, 300 \mathrm{~K}\right): \delta(\mathrm{ppm}) 5.88(\mathrm{~d}, J=8.3 \mathrm{~Hz}, 1 \mathrm{H}), 6.88(\mathrm{~d}, J=9.1 \mathrm{~Hz}, 1 \mathrm{H})$, $7.60(\mathrm{dd}, J=8.7,1.8 \mathrm{~Hz}, 2 \mathrm{H}), 7.74(\mathrm{~d}, J=1.7 \mathrm{~Hz}, 2 \mathrm{H}), 7.79(\mathrm{t}, J=7.6 \mathrm{~Hz}, 1 \mathrm{H}), 7.86-7.91(\mathrm{~m}$, $7 \mathrm{H}), 7.93(\mathrm{dd}, J=7.5,1.2 \mathrm{~Hz}, 1 \mathrm{H}), 8.81-8.86(\mathrm{~m}, 6 \mathrm{H}) .{ }^{13} \mathrm{C} \mathrm{NMR}\left(125 \mathrm{MHz}, \mathrm{CDCl}_{3}, 300 \mathrm{~K}\right)$ : $\delta(\mathrm{ppm}) 116.13,120.67,122.41,124.08,124.20,124.67,125.21,125.23,125.44,125.82$, $126.11,126.21,127.19,130.02$, 131.13, 131.15, 131.36, 131.38, 147.10, 151.57. HR-MS ESI: $\mathrm{m} / \mathrm{z} 613.1908[\mathrm{M}+\mathrm{H}]^{+}\left(\right.$calcd for $\mathrm{C}_{40} \mathrm{H}_{21} \mathrm{BN}_{6} \mathrm{O}^{+}$: 613.1943). HP-LC analysis: retention time 7.36 $\min$.

\section{Compound 6}

Compound 6 was synthesized following the general procedure, where the chosen antenna was 7-hydroxycoumarine $(94 \mathrm{mg}$ ). The reaction mixture was heated under refluxing conditions for 2 days. Target compound $\mathbf{6}$ was obtained after subjecting the crude mixture to silica gel column chromatography using DCM as an eluent to afford the desired product $6(41 \mathrm{mg}, 64 \%) .{ }^{1} \mathrm{H}$ NMR (500 MHz, $\left.\mathrm{CDCl}_{3}, 300 \mathrm{~K}\right): \delta(\mathrm{ppm}) 5.27(\mathrm{~d}, \mathrm{~J}=2.2 \mathrm{~Hz}, 1 \mathrm{H}), 5.33(\mathrm{dd}, \mathrm{J}=8.5,2.3 \mathrm{~Hz}$, $1 \mathrm{H}), 6.08(\mathrm{~d}, \mathrm{~J}=9.4 \mathrm{~Hz}, 1 \mathrm{H}), 6.83(\mathrm{~d}, \mathrm{~J}=8.4 \mathrm{~Hz}, 1 \mathrm{H}), 7.36(\mathrm{~d}, \mathrm{~J}=9.4 \mathrm{~Hz}, 1 \mathrm{H}), 7.93(\mathrm{~m}, 6 \mathrm{H})$, $8.87(\mathrm{~m}, 6 \mathrm{H}) .{ }^{13} \mathrm{C} \mathrm{NMR}\left(125 \mathrm{MHz}, \mathrm{CDCl}_{3}, 300 \mathrm{~K}\right): \delta$ (ppm) 161.25, 156.62, 155.03, 151.61, 143.30, 131.07, 130.22, 128.29, 122.48, 116.31, 113.35, 113.11, 106.41, 77.41, 77.16, 76.91 . 
HR-MS ESI: $\mathrm{m} / \mathrm{z} 557.1527[\mathrm{M}+\mathrm{H}]^{+}$(calcd for $\mathrm{C}_{33} \mathrm{H}_{18} \mathrm{BN}_{6} \mathrm{O}_{3}{ }^{+}:$557.1528). HP-LC analysis: retention time $5.68 \mathrm{~min}$.

\subsubsection{Synthesis of compound $\mathbf{5}$}

To a solution of ethynylpyrene $(100 \mathrm{mg}, 0.44 \mathrm{mmol})$ in THF $(4 \mathrm{~mL})$ was added phenylmagnesium bromide $(0.33 \mathrm{~mL}, 1.0 \mathrm{M})$, then the solution was stirred for 1 hour at $60^{\circ} \mathrm{C}$. Then, a solution of compound 1 (95 mg, $0.22 \mathrm{mmol}$ ) in THF ( $4 \mathrm{~mL}$ ) was added to the reaction mixture. After heating at $60^{\circ} \mathrm{C}$ for $16 \mathrm{~h}$, the solvent was removed under reduced pressure and the crude product was purified by silica gel column chromatography (eluent: DCM) to afford compound 5 (60 mg, 44\%). ${ }^{1} \mathrm{H}$ NMR $\left(500 \mathrm{MHz}, \mathrm{CDCl}_{3}, 300 \mathrm{~K}\right): \delta(\mathrm{ppm}) 7.41(\mathrm{~d}, J=8.1 \mathrm{~Hz}$, $1 \mathrm{H}), 7.60(\mathrm{~d}, J=9.1 \mathrm{~Hz}, 1 \mathrm{H}), 7.73(\mathrm{~d}, J=8.2 \mathrm{~Hz}, 1 \mathrm{H}), 7.81(\mathrm{~d}, J=8.9 \mathrm{~Hz}, 1 \mathrm{H}), 7.85-7.90$ $(\mathrm{m}, 3 \mathrm{H}), 7.93(\mathrm{~m}, 6 \mathrm{H}), 8.04(\mathrm{ddd}, J=8.3,5.2,1.2 \mathrm{~Hz}, 2 \mathrm{H}), 8.92(\mathrm{~m}, 6 \mathrm{H}) .{ }^{13} \mathrm{C} \mathrm{NMR}(125 \mathrm{MHz}$, $\left.\mathrm{CDCl}_{3}, 300 \mathrm{~K}\right): \delta$ (ppm) 117.13, 122.32, 124.08, 124.14, 125.35, 125.36, 125.51, 126.09, 127.16, 127.97, 128.05, 129.61, 129.86, 130.93, 130.99, 131.12, 131.15, 131.67, 150.70. HRMS ESI: m/z $621.1980[\mathrm{M}+\mathrm{H}]^{+}$(calcd for $\mathrm{C}_{42} \mathrm{H}_{22} \mathrm{BN}_{6}{ }^{+}$: 621.1994). HP-LC analysis: retention time $7.84 \mathrm{~min}$.

\section{Results and discussion}

The synthetic pathway to get new SubPc species $3, \mathbf{4 , 5}$ and $\mathbf{6}$ is described in Figure 1. The first step was the synthesis of compound $\mathbf{1}$ following a standard cyclotrimerization reaction of phthalonitrile around a Boron atom[16]. The ${ }^{1} \mathrm{H}$ NMR spectrum of this compound shows two signals, as the form of multiplets lying at $7.95 \mathrm{ppm}$ and $8.90 \mathrm{ppm}$, that correspond to SubPc$\mathrm{H} \beta$ and SubPc-H $\alpha$ protons, respectively (Fig. S1-1). The low solubility of compound $\mathbf{1}$ in common organic solvents did not allow us to get a ${ }^{13} \mathrm{C}$ NMR spectrum. Compound 2 was obtained upon reduction of 1-pyrenecarboxaldehyde with $\mathrm{NaBH}_{4}$. The formation of the desired product was confirmed by the emergence of a signal at $5.40 \mathrm{ppm}$ in the ${ }^{1} \mathrm{H}$ NMR spectrum, which corresponds to $-\mathrm{OC}_{2}-$ protons (Fig. S1-2).

SubPc Species 3, 4 and $\mathbf{6}$ were successfully synthesized by reacting the antenna with SubPc $\mathbf{1}$ without addition of a base. Target compounds 3,4 and 6 were identified by ${ }^{1} \mathrm{H}-\mathrm{NMR}$ and ${ }^{13} \mathrm{C}-$ NMR and by HRMS spectrometry. X-Rays diffraction of SubPc $\mathbf{4}$ and $\mathbf{6}$ were also performed, as shown in Figure 2. Judging from these structures, the conic shape of SubPc unit appears to be easily noticeable. The bonds angle between boron, oxygen and carbon atoms slightly changes from $117^{\circ}$ in SubPc 4 to $126^{\circ}$ in SubPc 6. It appears that, in the same conditions of temperature and concentration, the antenna 2 took five days to achieve quantitative substitution of the axial chorine atom in $\mathbf{1}$, while the reaction was completed in two days for the others antenna. The lowest reactivity of aliphatic alcohols, compared to phenolic substrates, might be the reason for such a difference in reaction time. 
The synthesis of SubPc 5 was achieved using phenylmagnesium bromide as a base[17] on acidic 1-ethynylpyrene to afford the corresponding ylide that was subsequently reacted with SubPc 1.

As an example, the ${ }^{1} \mathrm{H}$ NMR spectrum of compound $\mathbf{6}$ is depicted in Figure 3. As mentioned before, signals showing up at $7.92 \mathrm{ppm}$ and at $8.87 \mathrm{ppm}$ correspond to the protons of the SubPc unit. The two doublets with a $9.4 \mathrm{~Hz}$ coupling constant, lying at $7.36 \mathrm{ppm}$ and at $6.08 \mathrm{ppm}$, correspond to the $-\mathrm{CH}=\mathrm{C} \underline{H}-$ protons sitting next to the lactone function of the coumarine. The three remaining signals, lying at $5.27 \mathrm{ppm}, 5.33 \mathrm{ppm}$ and $6.83 \mathrm{ppm}$ correspond to the benzylic protons of the coumarine unit. The $2.2 \mathrm{~Hz}$ coupling constant is associated with the protons from either side of the ether function.

Signal assignment in the ${ }^{1} \mathrm{H}$ NMR spectra of compounds $\mathbf{3 , 4}$ and $\mathbf{5}$ were more complicated to achieve, due to the presence of multiple overlayed aromatic signals (Fig. S1-4, 6, 8).

\section{Photophysical properties}

\subsection{Photophysical properties}

Absorption and fluorescence properties of subphthalocyanines 1, 3-6 were studied by UVVisible spectroscopy and are gathered in Table 1. The absorption and emission spectra of compound 1, 3-6 were recorded in toluene, tetrahydrofuran, chloroform, dimethyl sulfoxide and methanol, from an aprotic apolar to a protic polar solvent. Although highest values of absorption/emission maxima were obtained when the compounds were in solution in DMSO, no solvatochromism was noticeable. Also, no aggregation was observed on spectra, due to the three-dimensional design of molecules.

All compounds possess maximum absorption wavelengths between 560 and $572 \mathrm{~nm}$ (subphthalocyanine partner) and UV-blue absorption bands between 250 and $370 \mathrm{~nm}$ (pyrene or coumarine partners) (Figure 4). Associated maximum emission wavelengths were measured with a Stokes shift around $10 \mathrm{~nm}$. Introduction of the pyrenyl antenna linked to a triple bond in subphthalocyanine 5 seams to red-shift both absorption and emission maxima by ca. $5 \mathrm{~nm}$. The observation of distinct absorbance peaks with no (or small) shifts in the absorption values indicate that chromophores do not interact between each other.

Functionalization of the boron atom with aryloxy/alkoxy moieties upon substitution of the chlorine atom lowers the fluorescence quantum yield of the molecule by a factor 2 , resulting in compounds with fluorescence quantum yields ranging from 0.11 to 0.25 , depending on the solvent (highest values are obtained for aprotic apolar solvents), except for subphthalocyanine 4, which did not appear to fluoresce.

\subsection{Energy transfer studies}


Energy transfer properties of antenna-subphthalocyanine conjugates were investigated by fluorescence spectroscopy and are gathered in Table 1 . The fluorescence emission spectra of compounds 3-6 were investigated using an excitation wavelength of $345 \mathrm{~nm}$ for compounds $\mathbf{3}$ and 4, $360 \mathrm{~nm}$ for compound 5 and $305 \mathrm{~nm}$ for compound $\mathbf{6}$, at $25^{\circ} \mathrm{C}$ in various solvents (Fig. S5-1, 2). Unfortunately, no energy transfer between the pyrenyl unit and the subphthalocyanine platform seems to occur in compound 4. Also, even if any residual fluorescence of the coumarine unit could not be observed upon excitation at the antenna and subsequent energy transfer in compound 6 (corresponding to an efficient energy transfer), it was not possible to determine the energy transfer efficiency (E.T.E.) due to the absorption wavelength of the antenna, located right in the absorption of the subphthalocyanine. On the other hand, compounds 3 and $\mathbf{5}$ did show efficient energy transfer processes, ranging from $36 \%$ to $84 \%$ in 3 and from $84 \%$ to $96 \%$ in $\mathbf{5}$. In both cases, a strong emission peak around $575 \mathrm{~nm}$ was observed upon excitation in the UV-blue region of the spectrum, with residual fluorescence of the pyrenyl antenna for compound 3. The high E.T.E. values obtained with compound $\mathbf{5}$ does indicate a really good energy transfer process between the pyrenyl unit linked to the subphthalocyanine platform through a triple bond. At this stage $t$ whether the energy transfer takes place through the triple bond or through space is a question left opened.

\section{Conclusion}

This work showed that the introduction of antenna at the axial position of subphthalocyanine $\mathbf{1}$ was successfully performed whatever the nature of the linker. These new conjugates were fully characterized by ${ }^{1} \mathrm{H}-\mathrm{NMR}$ and ${ }^{13} \mathrm{C}$-NMR, mass spectrometry, UV-Vis, fluorescence and $\mathrm{X}$-ray diffraction for compounds 4 and 6. Absorption and emission measurements showed that an efficient energy transfer occurred in compounds 3, 5 and 6, with E.T.E. values reaching 95\% for compound 5. These new dyads appeared as promising molecular constructs used for applications requiring such energy transfers, such as photovoltaics, molecular probes.

\section{Acknowledgment}

We acknowledge Canceropôle Est and FEDER for Funding (RD) and the French Ministry of Higher Education, Research and Innovation for a fellowship (VL). PACSMUB platform is acknowledged for allowing access to all spectrometers to perform the analyses (NMR, Mass). Dr Kévin Renault is acknowledged for discussion and advices regarding fluorescence studies.

\section{References}

[1] Balzani V, Credi A, Venturi M. Photochemical conversion of solar energy. ChemSusChem. 2008;1(1-2):26-58.

[2] Shrestha D, Jenei A, Nagy P, Vereb G, Szollosi J. Understanding FRET as a research tool for cellular studies. Int J Mol Sci. 2015;16(4):6718-56. 
[3] Rowland CE, Brown CW, Medintz IL, Delehanty JB. Intracellular FRET-based probes: a review. Methods Appl Fluoresc. 2015;3(4):042006.

[4] Chitta R, Sandanayaka ASD, Schumacher AL, D'Souza L, Araki Y, Ito O, et al. DonorAcceptor Nanohybrids of Zinc Naphthalocyanine or Zinc Porphyrin Noncovalently

Linked to Single-Wall Carbon Nanotubes for Photoinduced Electron Transfer. J Phys Chem. 2007;111:6947-55.

[5] Lazarides T, Charalambidis G, Vuillamy A, Reglier M, Klontzas E, Froudakis G, et al. Promising fast energy transfer system via an easy synthesis: Bodipy-porphyrin dyads connected via a cyanuric chloride bridge, their synthesis, and electrochemical and photophysical investigations. Inorg Chem. 2011;50(18):8926-36.

[6] Bizet F, Ipuy M, Bernhard Y, Lioret V, Winckler P, Goze C, et al. Cellular imaging using BODIPY-, pyrene- and phthalocyanine-based conjugates. Bioorg Med Chem. 2018;26(2):41320.

[7] Klaus D, Knecht R, DragÃăsser A, Keil C, Schlettwein D. (Photo-)conduction measurements during the growth of evaporated bulk heterojunctions of a subphthalocyanine donor and a perfluorinated phthalocyanine acceptor. physica status solidi (a). 2009:NA-NA.

[8] Winckel E, Mascaraque M, Zamarrón A, Juarranz de la Fuente Á, Torres T, Escosura A. Dual Role of Subphthalocyanine Dyes for Optical Imaging and Therapy of Cancer. Advanced Functional Materials. 2018;28(24):1705938.

[9] Del Rey B, Keller U, Torres T, Rojo G, Agullo-Lopez F, Nonell S, et al. Synthesis and Nonlinear Optical, Photophysical, and Electrochemical

Properties of Subphthalocyanines. J Am Chem Soc. 1998;120:12808-17.

[10] Martin G, Rojo G, Agullo-Lopez F, Ferro VR, Garcia de la Vega JM, Martinez-Diaz MV, et al. Subphthalocyanines and Subnaphthalocyanines: Nonlinear Quasi-Planar Octupolar Systems with Permanent Polarity. J phys Chem B. 2002;106:13139-45.

[11] a) El-Khouly ME, El-Refaey A, Nam W, Fukuzumi S, Goktug O, Durmus M. A subphthalocyanine-pyrene dyad: electron transfer and singlet oxygen generation. Photochem Photobiol Sci. 2017;16(10):1512-8; b) Gotfredsen H, Kilde MD, Santella M, Kadziola A, Nielsen MB. Fluorescence switching with subphthalocyanine- dihydroazulene dyads. Mol. Syst. Des. Eng., 2019, (4): 199-205.

[12] Claessens Christian G, González-Rodríguez D, del Rey B, Torres T, Mark G, Schuchmann H-P, et al. Highly Efficient Synthesis of Chloro- and Phenoxy-Substituted Subphthalocyanines. European Journal of Organic Chemistry. 2003;2003(14):2547-51.

[13] Ziessel R, Ulrich G, Elliott KJ, Harriman A. Electronic energy transfer in molecular dyads built around boron-ethyne-substituted subphthalocyanines. Chemistry. 2009;15(20):4980-4.

[14] $\mathrm{Xu} \mathrm{H}, \mathrm{Ng} \mathrm{DK}$. Preparation, spectroscopic properties, and stability of water-soluble subphthalocyanines. Chem Asian J. 2009;4(1):104-10.

[15] Bernhard Y, Winckler P, Chassagnon R, Richard P, Gigot E, Perrier-Cornet JM, et al. Subphthalocyanines: addressing water-solubility, nano-encapsulation, and activation for optical imaging of B16 melanoma cells. Chem Commun (Camb). 2014;50(90):13975-8.

[16] Morse GE, Paton AS, Lough A, Bender TP. Chloro boron subphthalocyanine and its derivatives: dyes, pigments or somewhere in between? Dalton Trans. 2010;39(16):3915-22.

[17] Camerel F, Ulrich G, Retailleau P, Ziessel R. Ethynyl-boron subphthalocyanines displaying efficient cascade energy transfer and large Stokes shifts. Angew Chem Int Ed Engl. 2008;47(46):8876-80. 

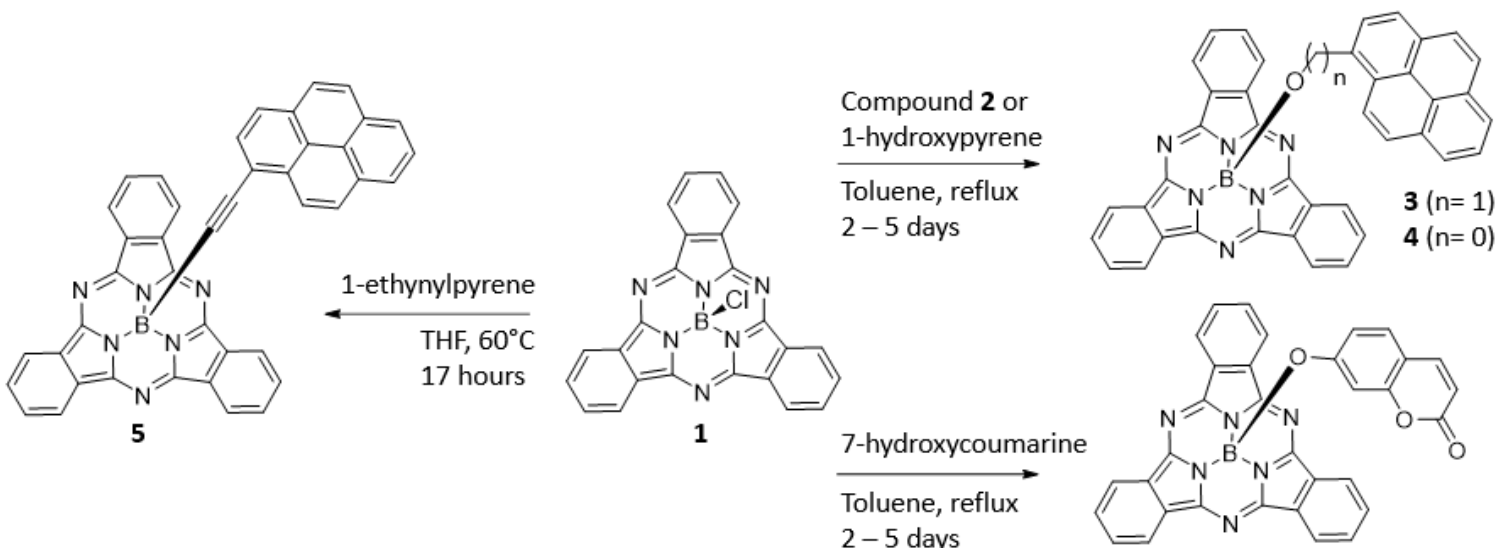

Figure 1: Synthetic pathway to compounds $3,4,5$ and $\mathbf{6}$
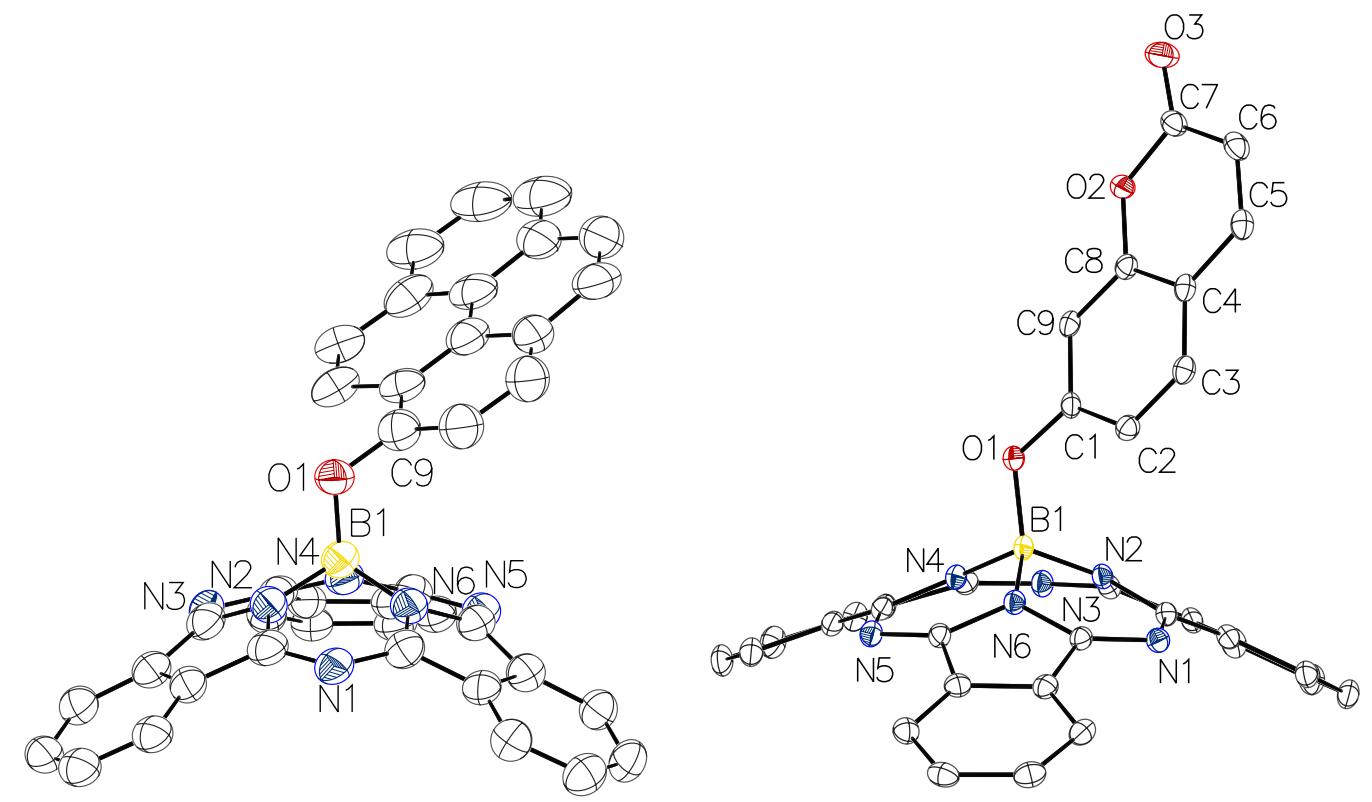

Figure 2: ORTEP view of compounds 4 (left) and 6 (right). Thermal ellipsoids are drawn at $50 \%$ probability plot. 


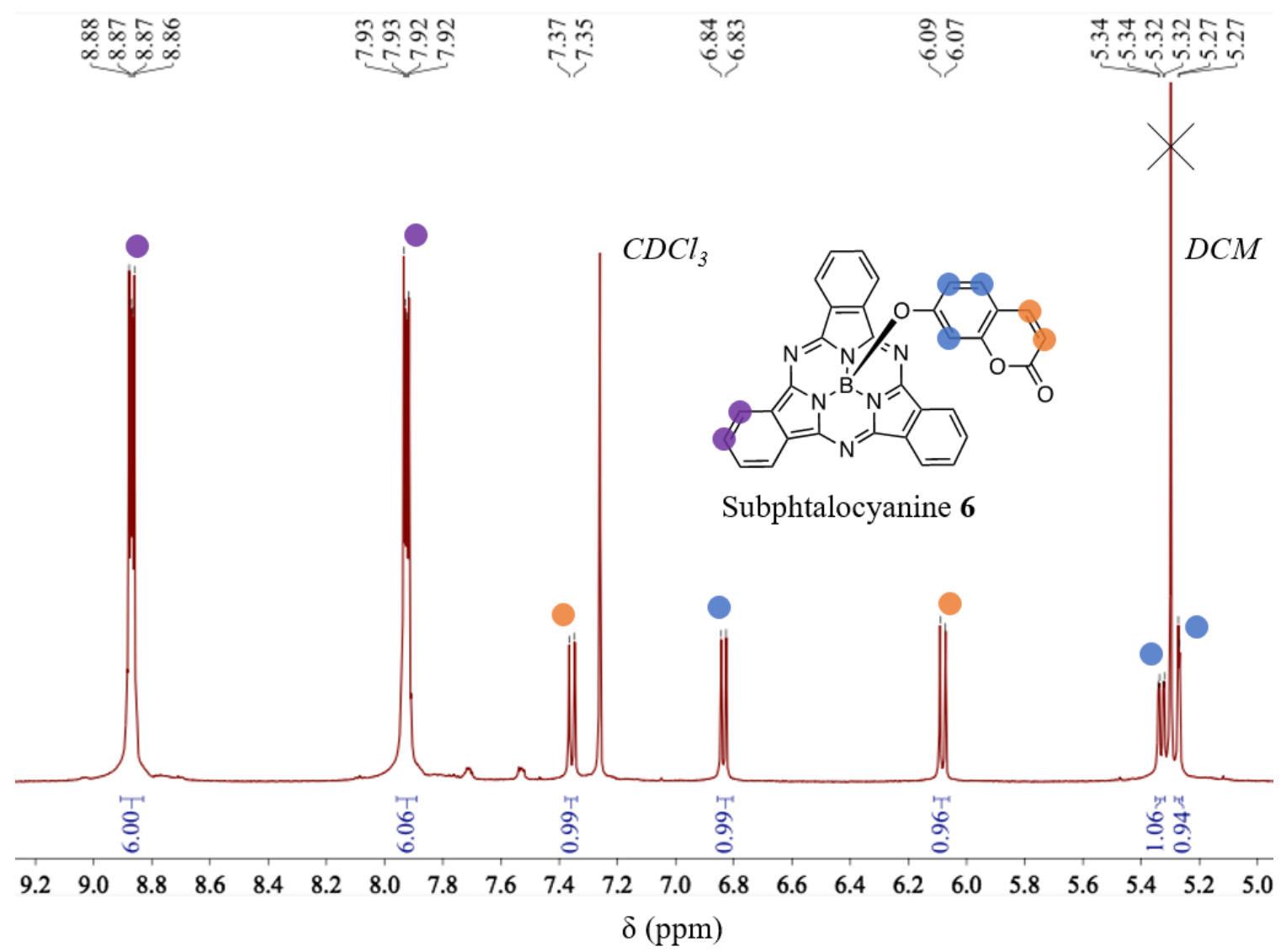

Figure 3: ${ }^{1} \mathrm{H}$ NMR spectrum of compound 6 measured in $\mathrm{CDCl}_{3}(500 \mathrm{MHz})$

\begin{tabular}{|c|c|c|c|c|c|}
\hline Cpd & Solvent & $\lambda_{\mathrm{Abs} / \mathrm{Em}}(\mathrm{nm})$ & $\begin{array}{c}\varepsilon \\
\left(\mathrm{L} \cdot \mathrm{mol}^{-1} \cdot \mathrm{cm}^{-1}\right)\end{array}$ & Q. Y. & E. T. E. \\
\hline \multirow{5}{*}{1} & Toluene & $565 / 572$ & 63000 & 0.48 & \multirow{5}{*}{ / } \\
\hline & THF & $562 / 572$ & n. d. & 0.32 & \\
\hline & $\mathrm{CHCl}_{3}$ & $565 / 571$ & 67500 & 0.32 & \\
\hline & DMSO & $569 / 578$ & n. d. & 0.37 & \\
\hline & $\mathrm{MeOH}$ & $562 / 572$ & n. d. & 0.27 & \\
\hline \multirow{5}{*}{3} & Toluene & $563 / 574$ & 50900 & 0.23 & n. d. \\
\hline & THF & $560 / 572$ & 44000 & 0.18 & $36 \%$ \\
\hline & $\mathrm{CHCl}_{3}$ & $563 / 576$ & 46000 & 0.17 & $78 \%$ \\
\hline & DMSO & $567 / 578$ & 45000 & 0.21 & $84 \%$ \\
\hline & $\mathrm{MeOH}$ & $562 / 576$ & 39100 & 0.13 & $43 \%$ \\
\hline \multirow{5}{*}{4} & Toluene & $563 / 572$ & 76600 & 0.01 & \multirow{5}{*}{1} \\
\hline & THF & $562 / 574$ & 58600 & $<0.01$ & \\
\hline & $\mathrm{CHCl}_{3}$ & $564 / 574$ & 78200 & $<0.01$ & \\
\hline & DMSO & $566 / 576$ & 77700 & $<0.01$ & \\
\hline & $\mathrm{MeOH}$ & $560 / 570$ & 66700 & $<0.01$ & \\
\hline
\end{tabular}




\begin{tabular}{cccccc}
\hline & Toluene & $568 / 576$ & 96000 & 0.20 & $84 \%$ \\
& EtOAc & $564 / 574$ & 88700 & 0.16 & n. d. \\
& $\mathbf{5 H F}$ & $566 / 576$ & 70000 & 0.22 & $93 \%$ \\
& $\mathrm{CHCl}_{3}$ & $568 / 578$ & 90800 & 0.18 & $96 \%$ \\
& $\mathrm{MeCN}^{2}$ & $565 / 576$ & 81100 & 0.18 & n. d. \\
& $\mathrm{DMSO}$ & $572 / 582$ & 84300 & 0.20 & $94 \%$ \\
& $\mathrm{MeOH}$ & $565 / 576$ & 79300 & 0.11 & $95 \%$ \\
\hline & $\mathrm{Toluene}$ & $564 / 574$ & 68400 & 0.25 & \\
& $\mathrm{THF}$ & $562 / 572$ & 62000 & 0.19 & \\
& $\mathrm{CHCl}$ & $564 / 574$ & 65000 & 0.19 & \\
& $\mathrm{DMSO}$ & $567 / 578$ & 66600 & 0.23 & \\
& $\mathrm{MeOH}$ & $561 / 574$ & 59200 & 0.17 &
\end{tabular}

Table 1: spectroscopic properties of synthetized subphthalocyanines

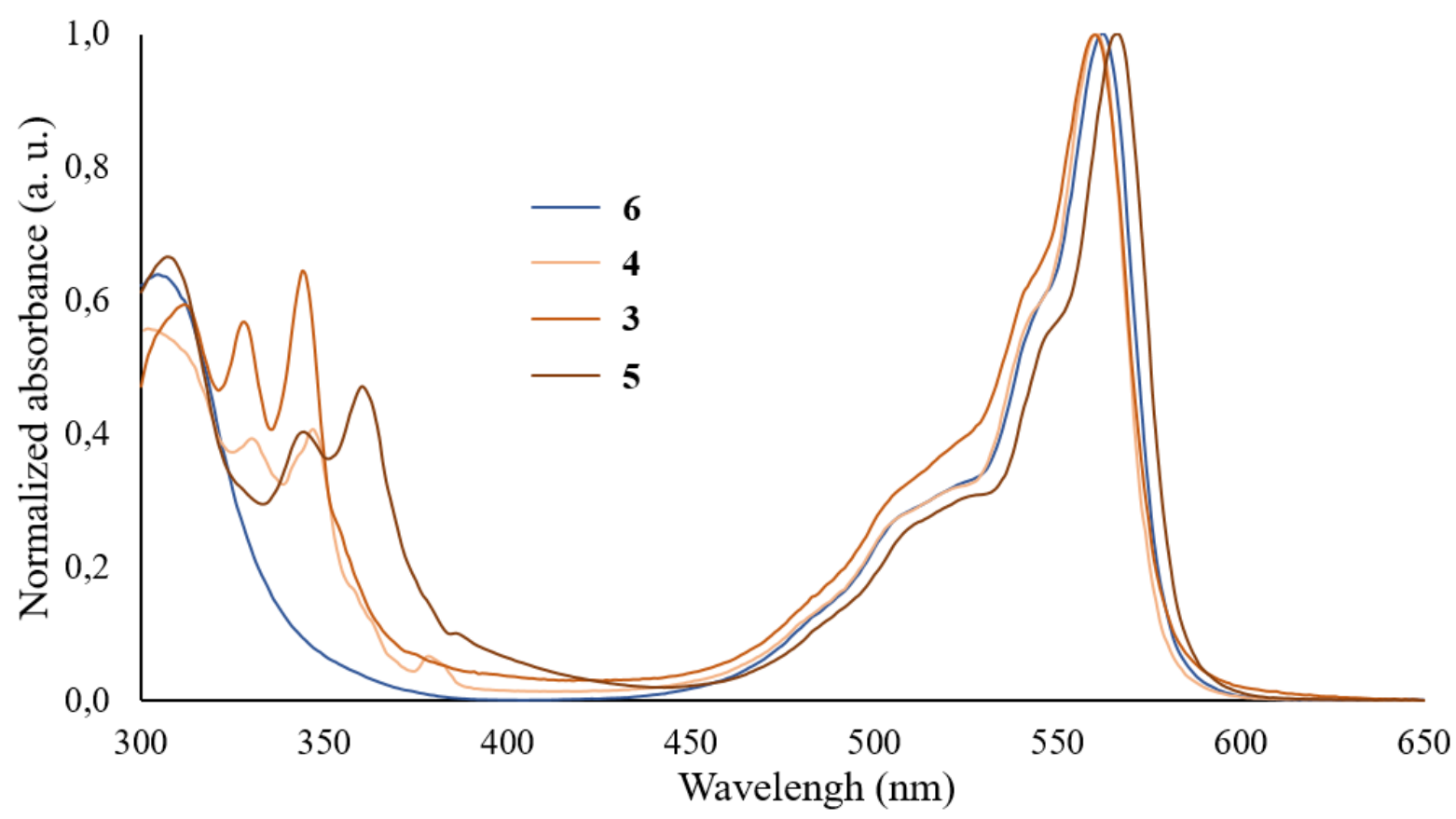

Figure 4: Absorption spectra of compounds 3, 4,5 and 6 measured in THF 


\section{checkCIF/PLATON report}

You have not supplied any structure factors. As a result the full set of tests cannot be run.

THIS REPORT IS FOR GUIDANCE ONLY. IF USED AS PART OF A REVIEW PROCEDURE FOR PUBLICATION, IT SHOULD NOT REPLACE THE EXPERTISE OF AN EXPERIENCED CRYSTALLOGRAPHIC REFEREE.

No syntax errors found. CIF dictionary Interpreting this report

\section{Datablock: compound_4}

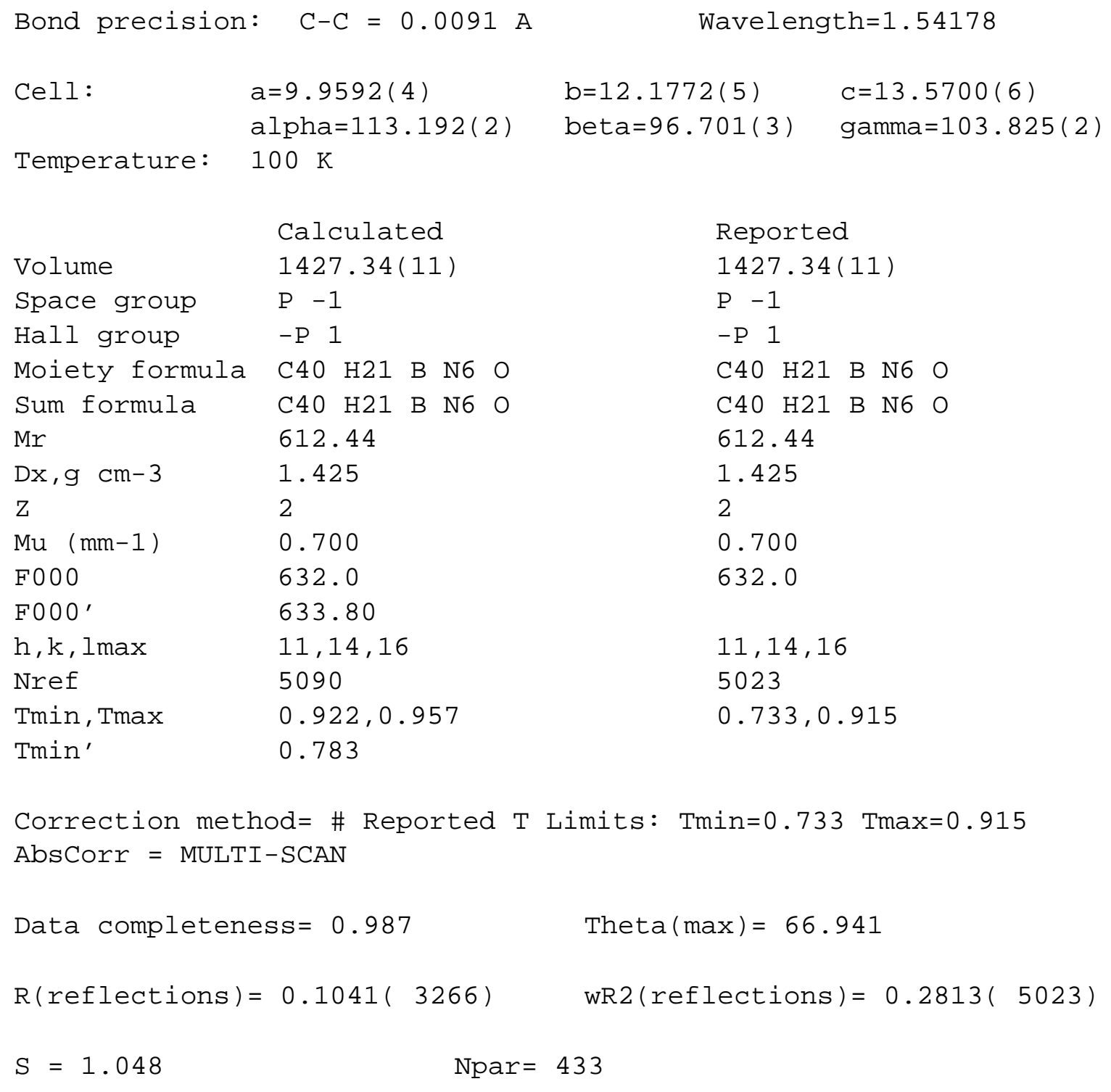


Alert level C

PLAT084_ALERT_3_C

PLAT230_ALERT_2_C

Hirshfeld Test Diff for C21
Large Hirshfeld Difference

21
15
16

$\ldots \ldots \ldots \ldots$

$-\mathrm{C} 24$

$-\mathrm{C} 16$.

PLAT234_ALERT_4_C Large Hirshfeld Difference C1

$-\mathrm{C} 17$

PLAT340_ALERT_3_C Low Bond Precision on C-C Bonds ............ 0.00914 Ang.
0.28 Report
$6.2 \mathrm{s.u}$.
0.18 Ang.
0.18 Ang.

Alert level $\mathbf{G}$

PLAT012_ALERT_1_G No _shelx_res_checksum Found in CIF ......

Please Check

PLAT072_ALERT_2_G SHELXL First Parameter in WGHT Unusually Large

PLAT335_ALERT_2_G Check Large C6 Ring C-C Range C12 -C15

PLAT432_ALERT_2_G Short Inter X...Y Contact C6B

. $\mathrm{C} 6 \mathrm{~B}$

0.12 Report

0.17 Ang.

3.19 Ang.

$$
1-\mathrm{x}, 1-\mathrm{y},-\mathrm{z}=2 \_665 \mathrm{Check}
$$

\footnotetext{
0 ALERT level $\mathbf{A}=$ Most likely a serious problem - resolve or explain

0 ALERT level $\mathbf{B}=\mathrm{A}$ potentially serious problem, consider carefully

5 ALERT level $\mathbf{C}=$ Check. Ensure it is not caused by an omission or oversight

4 ALERT level $\mathbf{G}=$ General information/check it is not something unexpected

1 ALERT type 1 CIF construction/syntax error, inconsistent or missing data

4 ALERT type 2 Indicator that the structure model may be wrong or deficient

2 ALERT type 3 Indicator that the structure quality may be low

2 ALERT type 4 Improvement, methodology, query or suggestion

0 ALERT type 5 Informative message, check
}

\section{Datablock: compound_6}

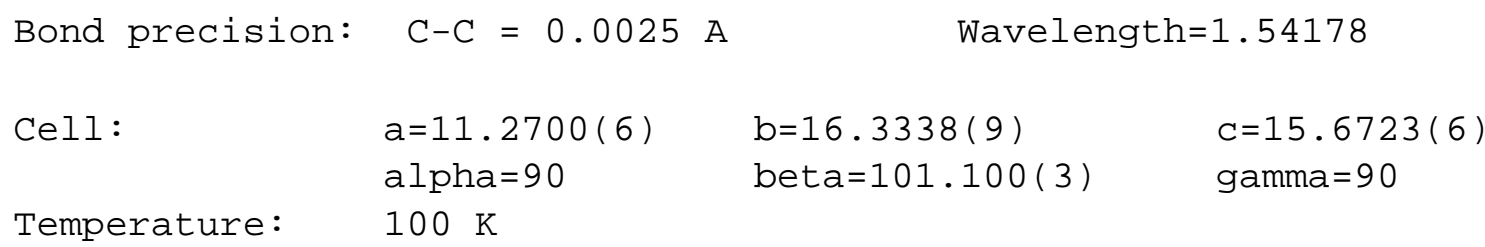

Calculated

Volume

Space group

Hall group

Moiety formula

Sum formula

$\mathrm{Mr}$

$\mathrm{Dx}, \mathrm{g} \mathrm{cm-3}$

$\mathrm{Z}$

$\mathrm{Mu}(\mathrm{mm}-1)$

F000

F000'

$h, k, l \max$

Nref

Tmin, Tmax

Tmin'
$2831.0(2)$

P $21 / \mathrm{C}$

-P 2ybc

C33 H17 B N6 03, C H2 Cl2

C34 H19 B Cl2 N6 O3

641.26

1.505

4

2.478

1312.0

1318.52

$13,19,18$

5029

$0.520,0.788$

0.276
Reported

$2831.0(2)$

P $121 / \mathrm{C} 1$

-P $2 \mathrm{ybc}$

C33 H17 B N6 O3, C H2 Cl2

C34 H19 B Cl2 N6 O3

641.26

1.505

4

2.478

1312.0

$13,19,18$

5018

$0.447,0.621$ 
Correction method= \# Reported $\mathrm{T}$ Limits: Tmin=0.447 Tmax=0.621

AbsCorr = MULTI-SCAN

Data completeness $=0.998 \quad$ Theta $(\max )=66.797$

$R($ reflections $)=0.0354(4461) \quad$ wR2 (reflections $)=0.0895(5018)$

$\mathrm{S}=1.069 \quad$ Npar $=415$

The following ALERTS were generated. Each ALERT has the format test-name_ALERT_alert-type_alert-level.

Click on the hyperlinks for more details of the test.

Alert level G

PLAT012_ALERT_1_G No__shelx_res_checksum Found in CIF ..... Please Check

0 ALERT level $\mathbf{A}=$ Most likely a serious problem - resolve or explain

0 ALERT level B $=$ A potentially serious problem, consider carefully

0 ALERT level $\mathbf{C}=$ Check. Ensure it is not caused by an omission or oversight

1 ALERT level $\mathbf{G}=$ General information/check it is not something unexpected

1 ALERT type 1 CIF construction/syntax error, inconsistent or missing data

0 ALERT type 2 Indicator that the structure model may be wrong or deficient

0 ALERT type 3 Indicator that the structure quality may be low

0 ALERT type 4 Improvement, methodology, query or suggestion

0 ALERT type 5 Informative message, check 
It is advisable to attempt to resolve as many as possible of the alerts in all categories. Often the minor alerts point to easily fixed oversights, errors and omissions in your CIF or refinement strategy, so attention to these fine details can be worthwhile. In order to resolve some of the more serious problems it may be necessary to carry out additional measurements or structure refinements. However, the purpose of your study may justify the reported deviations and the more serious of these should normally be commented upon in the discussion or experimental section of a paper or in the "special_details" fields of the CIF. checkCIF was carefully designed to identify outliers and unusual parameters, but every test has its limitations and alerts that are not important in a particular case may appear. Conversely, the absence of alerts does not guarantee there are no aspects of the results needing attention. It is up to the individual to critically assess their own results and, if necessary, seek expert advice.

\section{Publication of your CIF in IUCr journals}

A basic structural check has been run on your CIF. These basic checks will be run on all CIFs submitted for publication in IUCr journals (Acta Crystallographica, Journal of Applied Crystallography, Journal of Synchrotron Radiation); however, if you intend to submit to Acta Crystallographica Section C or E or IUCrData, you should make sure that full publication checks are run on the final version of your CIF prior to submission.

\section{Publication of your CIF in other journals}

Please refer to the Notes for Authors of the relevant journal for any special instructions relating to CIF submission.

\section{PLATON version of 22/04/2020; check.def file version of 09/03/2020}


Datablock compound_4 - ellipsoid plot

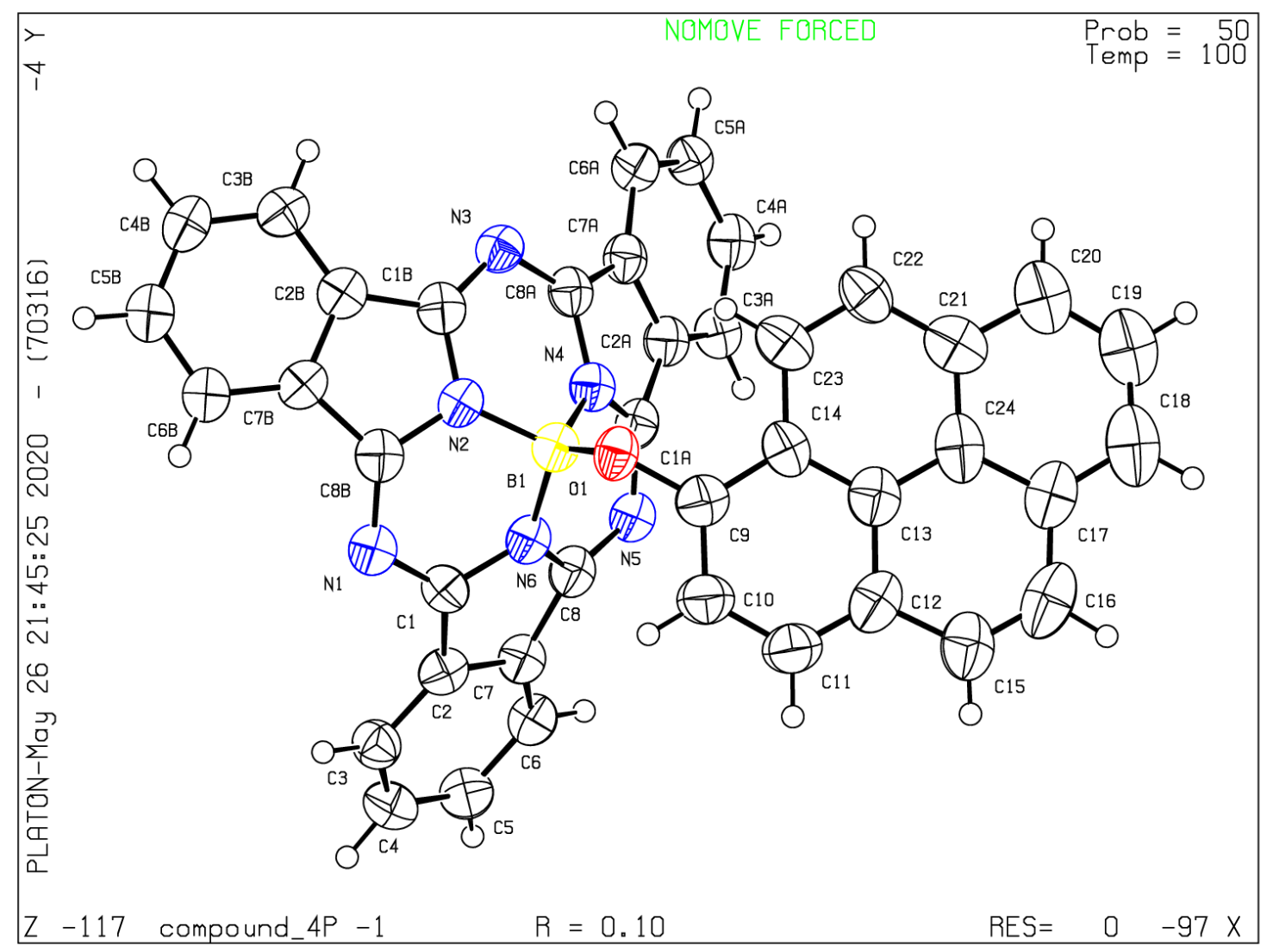


Datablock compound_6 - ellipsoid plot

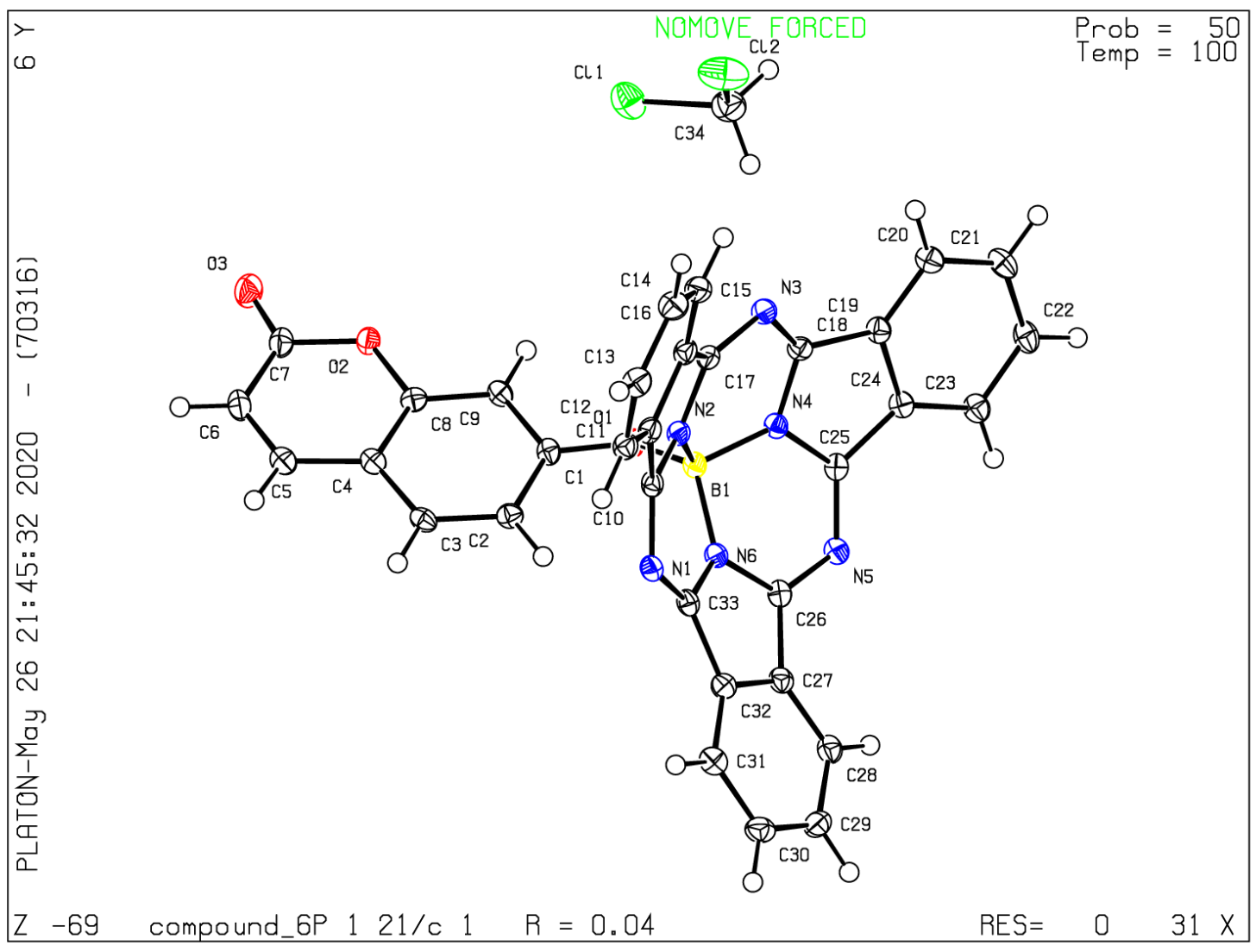




\section{Declaration of interests}

$\bigotimes$ The authors declare that they have no known competing financial interests or personal relationships that could have appeared to influence the work reported in this paper.

$\square$ The authors declare the following financial interests/personal relationships which may be considered as potential competing interests: 
Pyrene/coumarine-subphthalocyanine conjugates as light harvesting systems with intramolecular energy transfer

Vivian Lioret ${ }^{\mathrm{a}}$, Yoann Rousselin ${ }^{\mathrm{a}}$, Richard A. Decréau ${ }^{\mathrm{*}}$

\section{SUPPORTING INFORMATIONS}

OUTLINE

I. ${ }^{1} \mathrm{H}$ and ${ }^{13} \mathrm{C}$ NMR spectra

II. RP-HPLC elution profiles of compounds 01, 03, 04, 05 and $06 \quad$ S-8

III. HRMS analysis $\quad \mathrm{S}-11$

IV. Absorbance, excitation and emission spectra of compounds 01, 03, 04, 05

and 06 in different solvents

V. Energy Transfer Efficiency studies of compounds 03 and 05 in different solvents

VI. X-Ray diffraction informations for compounds $\mathbf{4}$ and $\mathbf{6}$ 
I. ${ }^{1} \mathrm{H}$ and ${ }^{13} \mathrm{C}$ NMR spectra

Figure S1-1: ${ }^{1} \mathrm{H}$ NMR spectrum of compound 01 recorded in $\mathrm{CDCl}_{3}$ at $500 \mathrm{MHz}$ and $300 \mathrm{~K}$

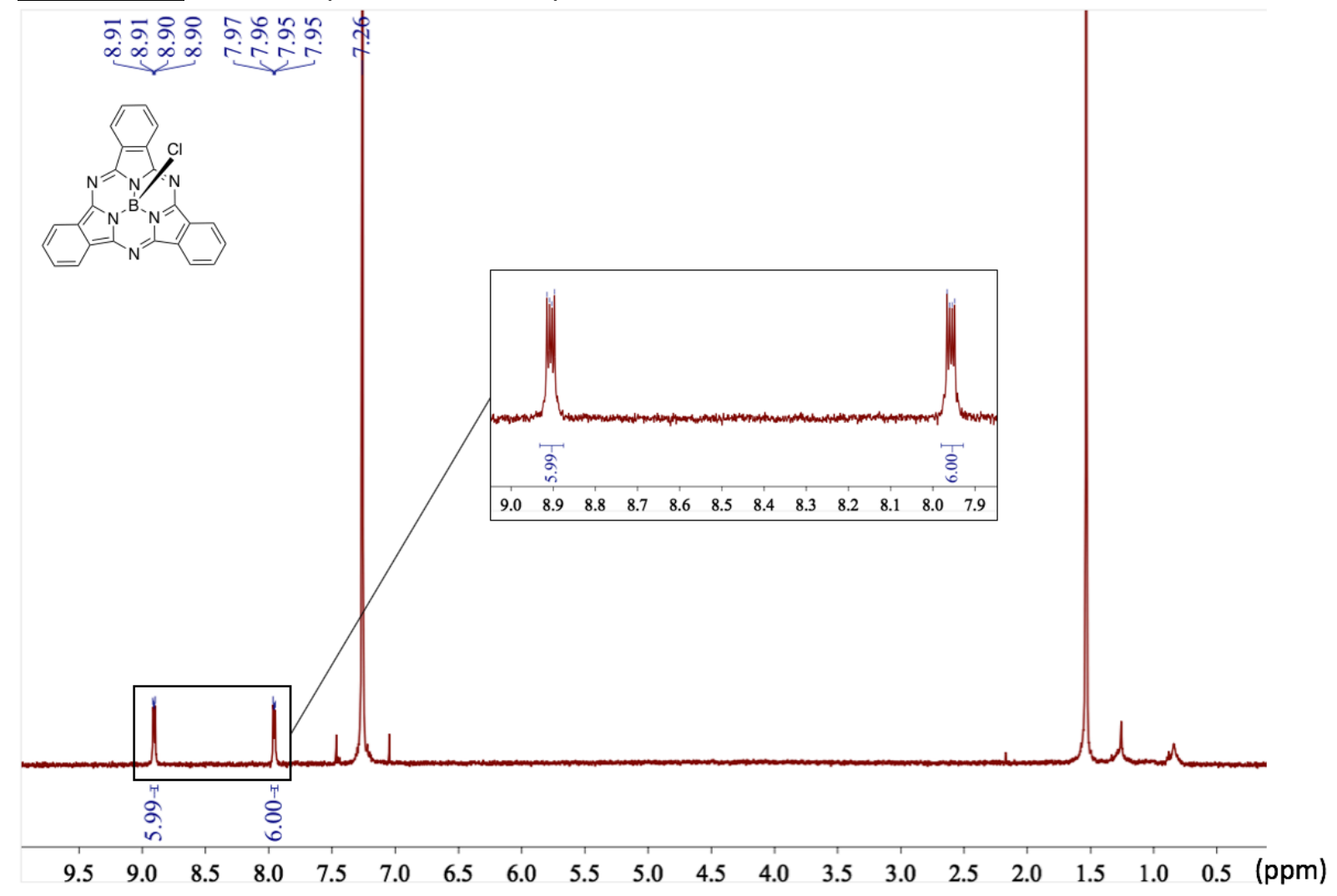


Figure S1-2: ${ }^{1} \mathrm{H}$ NMR spectrum of compound 02 recorded in $\mathrm{CDCl}_{3}$ at $500 \mathrm{MHz}$ and $300 \mathrm{~K}$

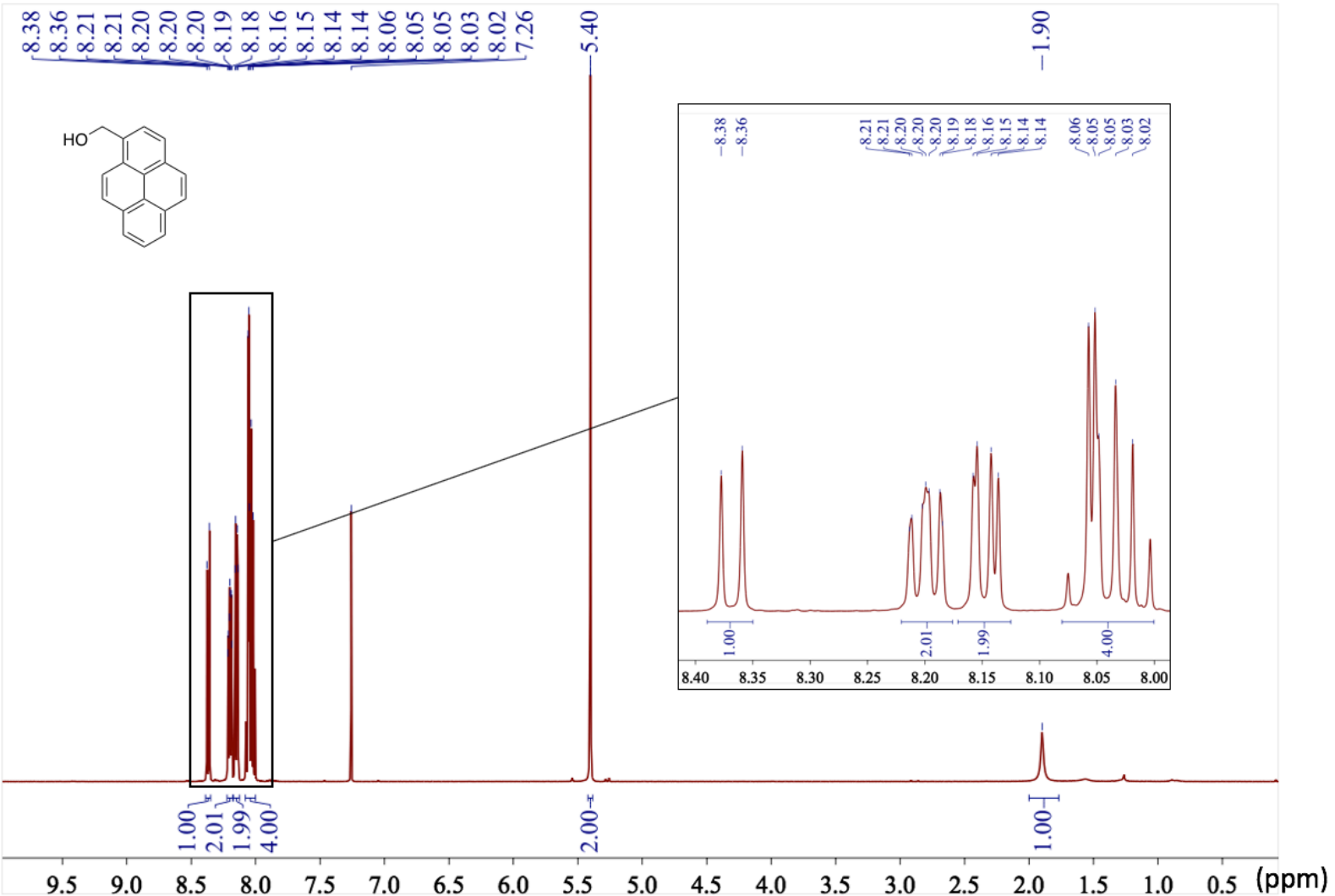

Figure S1-3: ${ }^{13} \mathrm{C}$ NMR spectrum of compound 02 recorded in $\mathrm{CDCl}_{3}$ at $125 \mathrm{MHz}$ and $300 \mathrm{~K}$

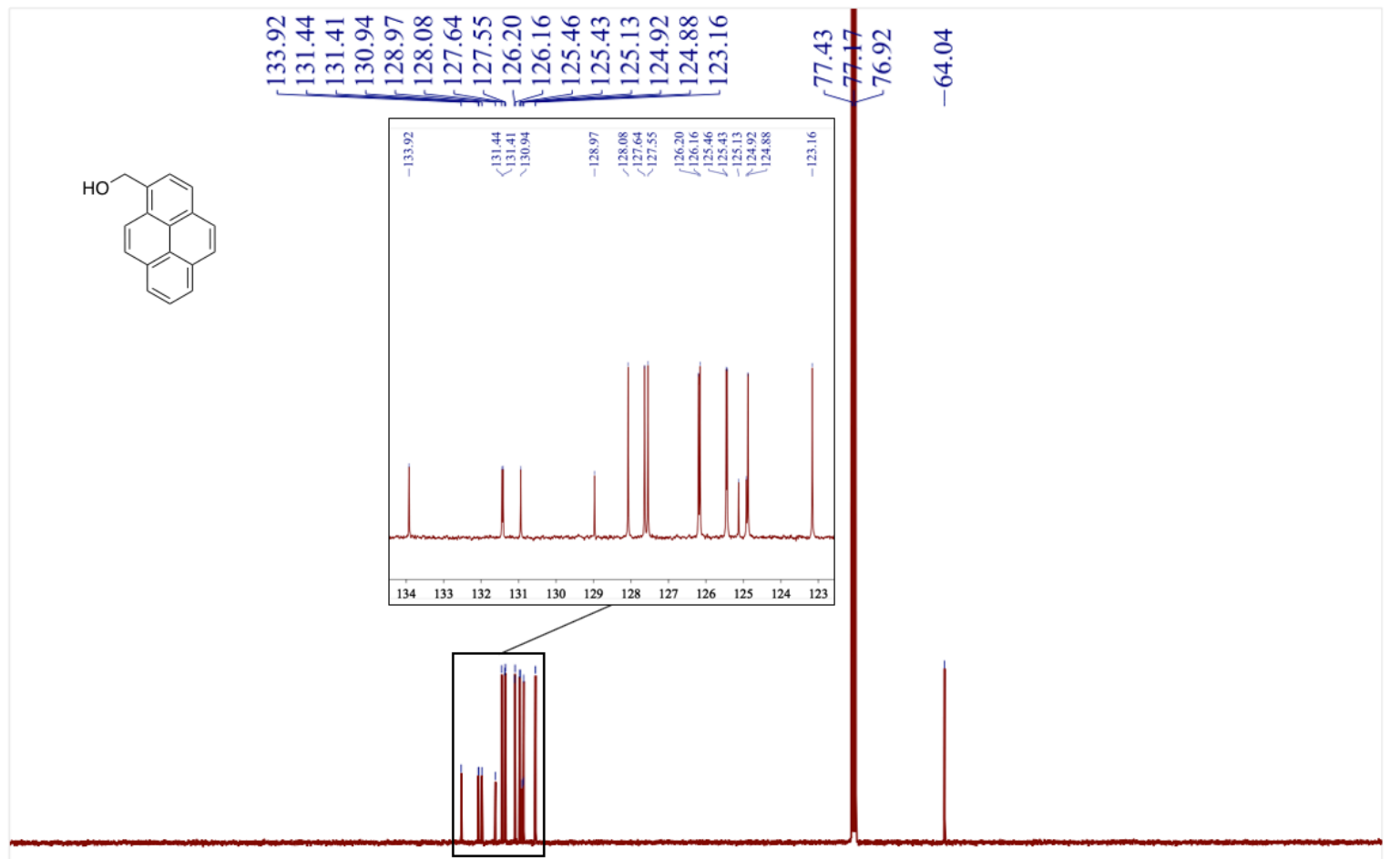

$\begin{array}{llllllllllllllllllll}190 & 180 & 170 & 160 & 150 & 140 & 130 & 120 & 110 & 100 & 90 & 80 & 70 & 60 & 50 & 40 & 30 & 20 & 10 & (\mathrm{ppm})\end{array}$ 
Figure S1-4: ${ }^{1} \mathrm{H}$ NMR spectrum of compound 03 recorded in $\mathrm{CDCl}_{3}$ at $500 \mathrm{MHz}$ and $300 \mathrm{~K}$

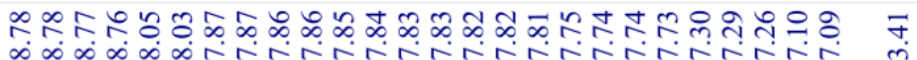

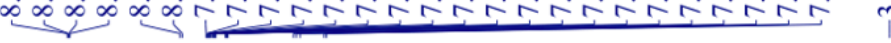

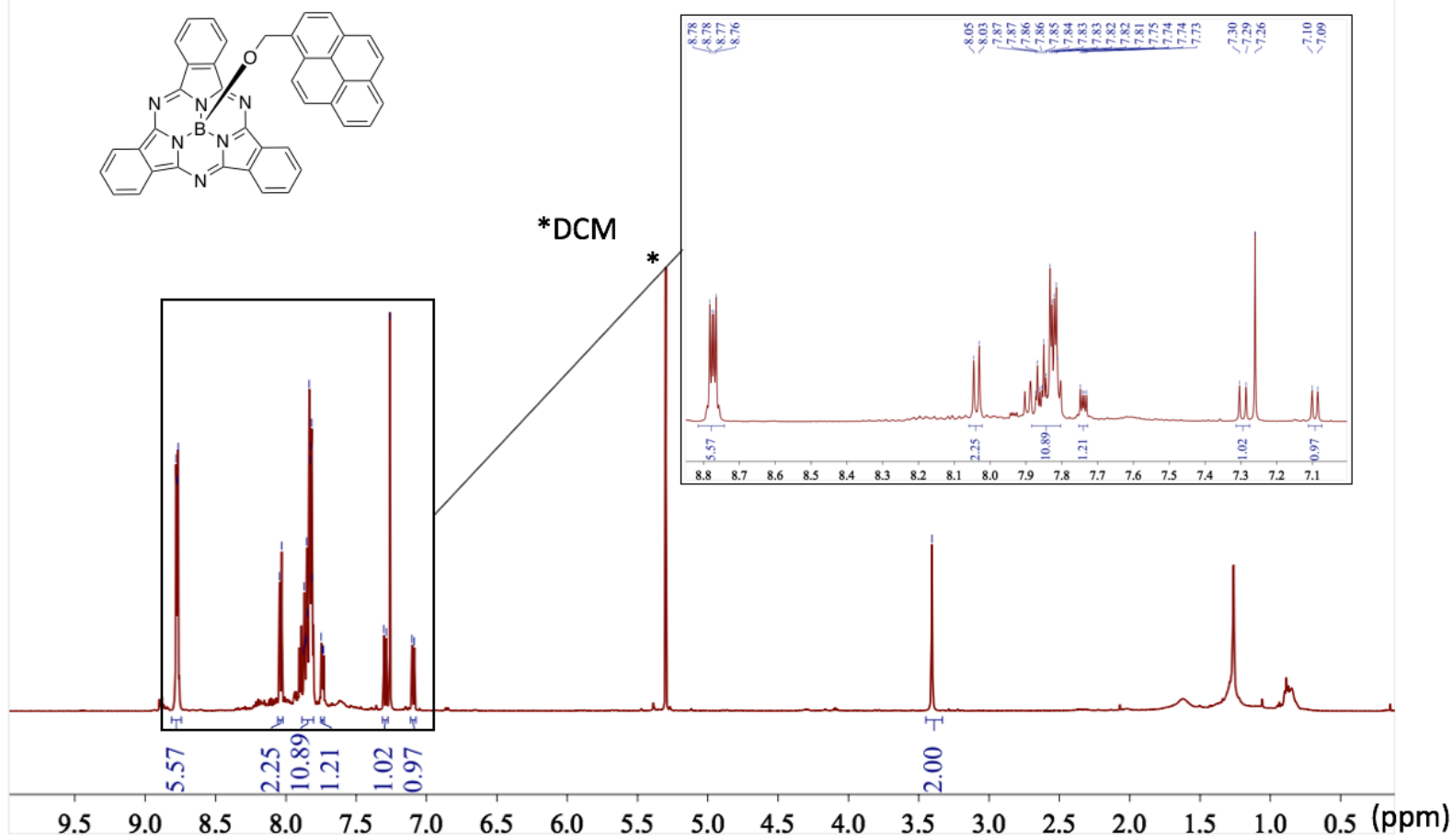

Figure S1-5: ${ }^{13} \mathrm{C}$ NMR spectrum of compound 03 recorded in $\mathrm{CDCl}_{3}$ at $125 \mathrm{MHz}$ and $300 \mathrm{~K}$

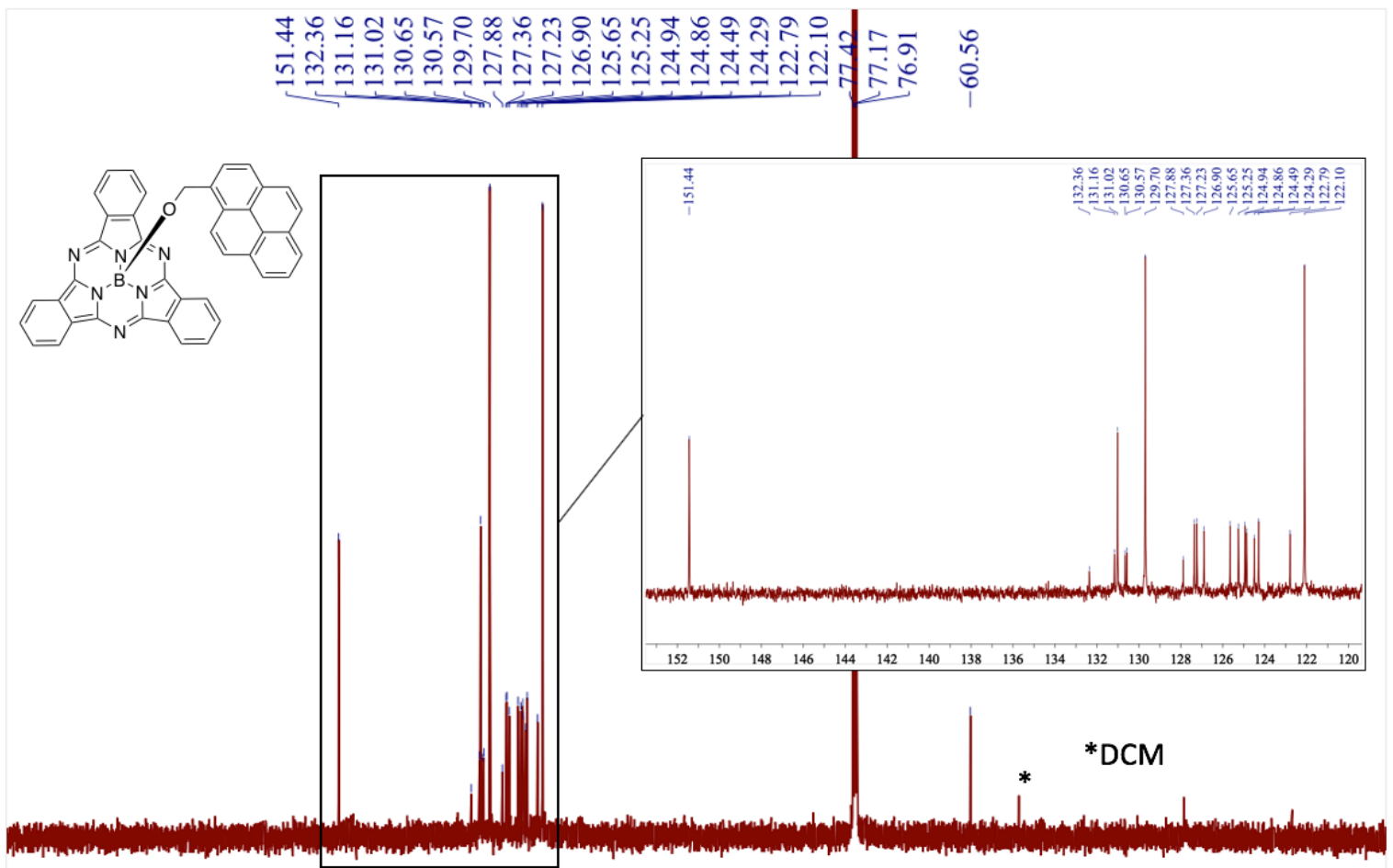

$\begin{array}{llllllllllllllllllll}190 & 180 & 170 & 160 & 150 & 140 & 130 & 120 & 110 & 100 & 90 & 80 & 70 & 60 & 50 & 40 & 30 & 20 & 10 & \text { (ppm) }\end{array}$ 
Figure S1-6: ${ }^{1} \mathrm{H}$ NMR spectrum of compound 04 recorded in $\mathrm{CDCl}_{3}$ at $500 \mathrm{MHz}$ and $300 \mathrm{~K}$ क

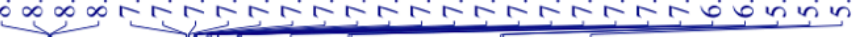

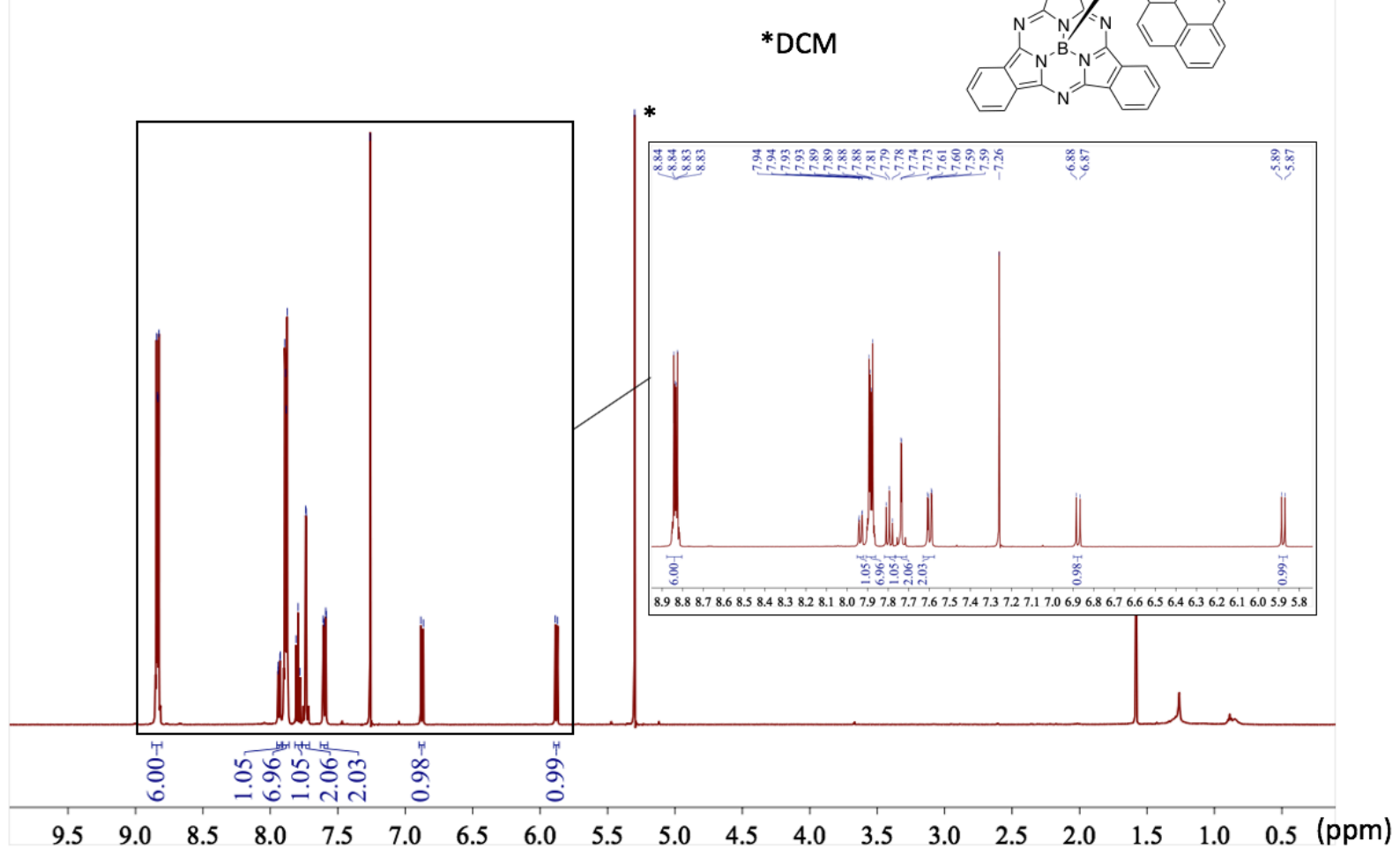

Figure S1-7: ${ }^{13} \mathrm{C}$ NMR spectrum of compound 04 recorded in $\mathrm{CDCl}_{3}$ at $125 \mathrm{MHz}$ and $300 \mathrm{~K}$

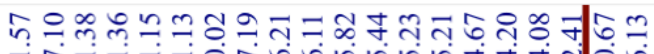

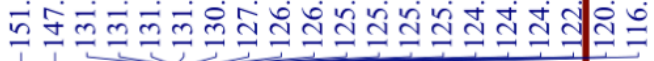
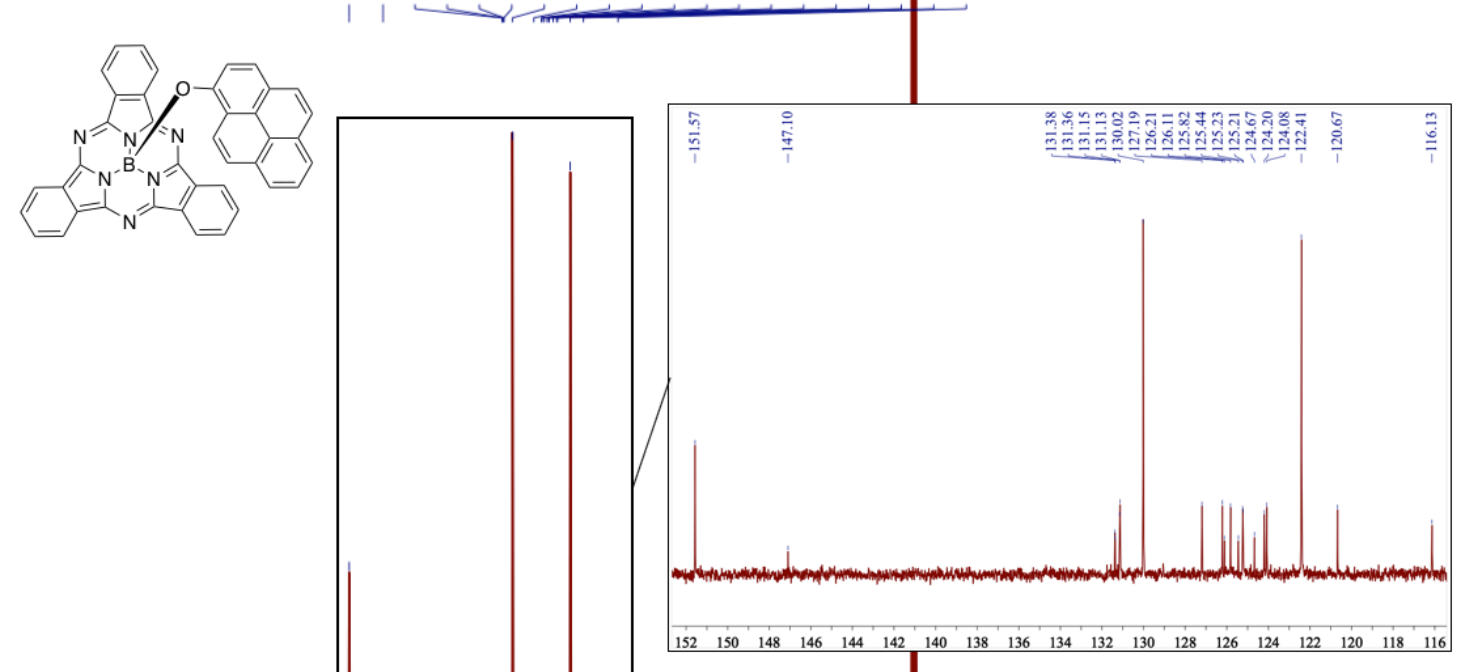

*DCM

$\begin{array}{llllllllllllllllllll}190 & 180 & 170 & 160 & 150 & 140 & 130 & 120 & 110 & 100 & 90 & 80 & 70 & 60 & 50 & 40 & 30 & 20 & 10 & (\mathrm{ppm})\end{array}$ 
Figure S1-8: ${ }^{1} \mathrm{H}$ NMR spectrum of compound 05 recorded in $\mathrm{CDCl}_{3}$ at $500 \mathrm{MHz}$ and $300 \mathrm{~K}$

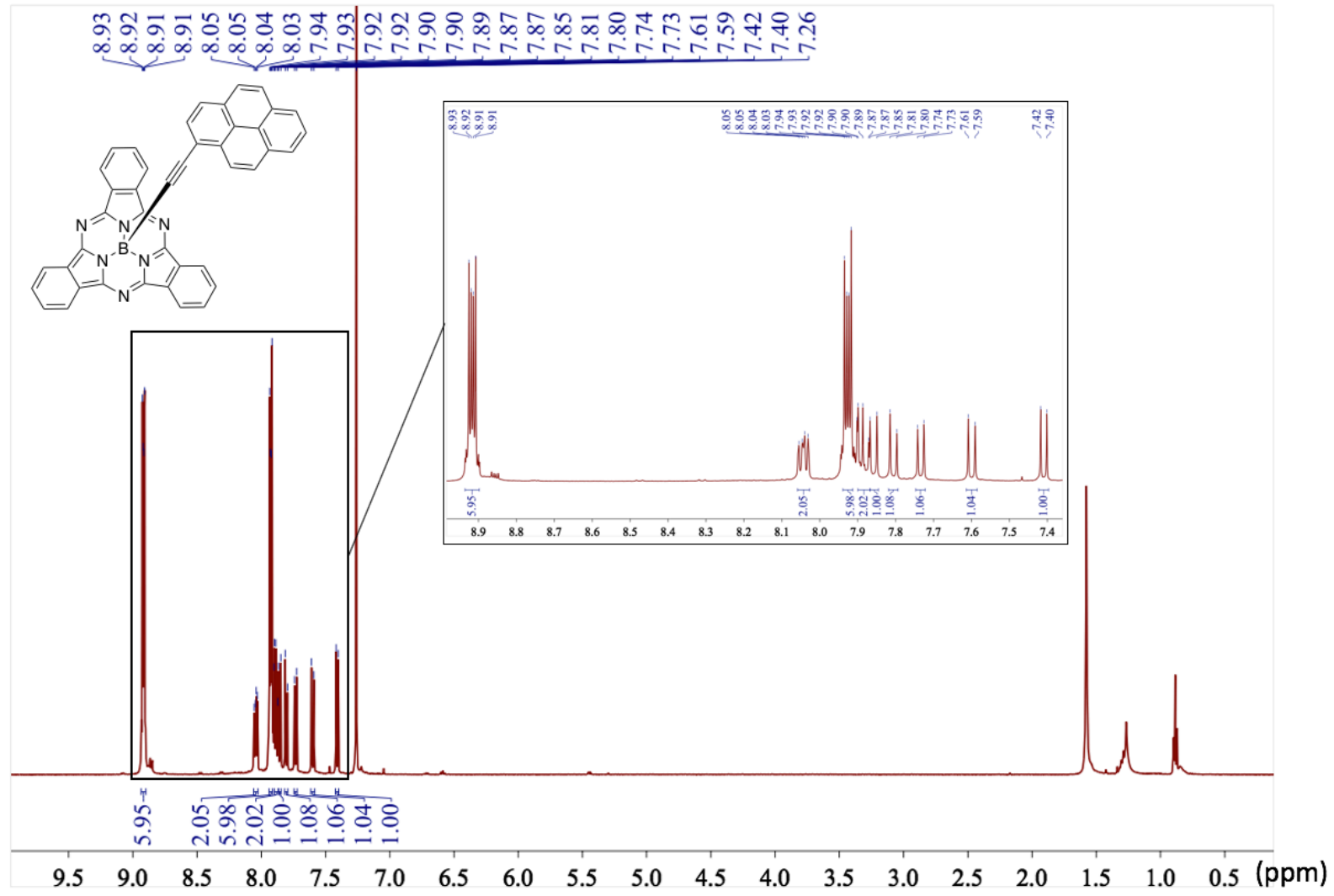

Figure S1-9: ${ }^{13} \mathrm{C}$ NMR spectrum of compound 05 recorded in $\mathrm{CDCl}_{3}$ at $125 \mathrm{MHz}$ and $300 \mathrm{~K}$

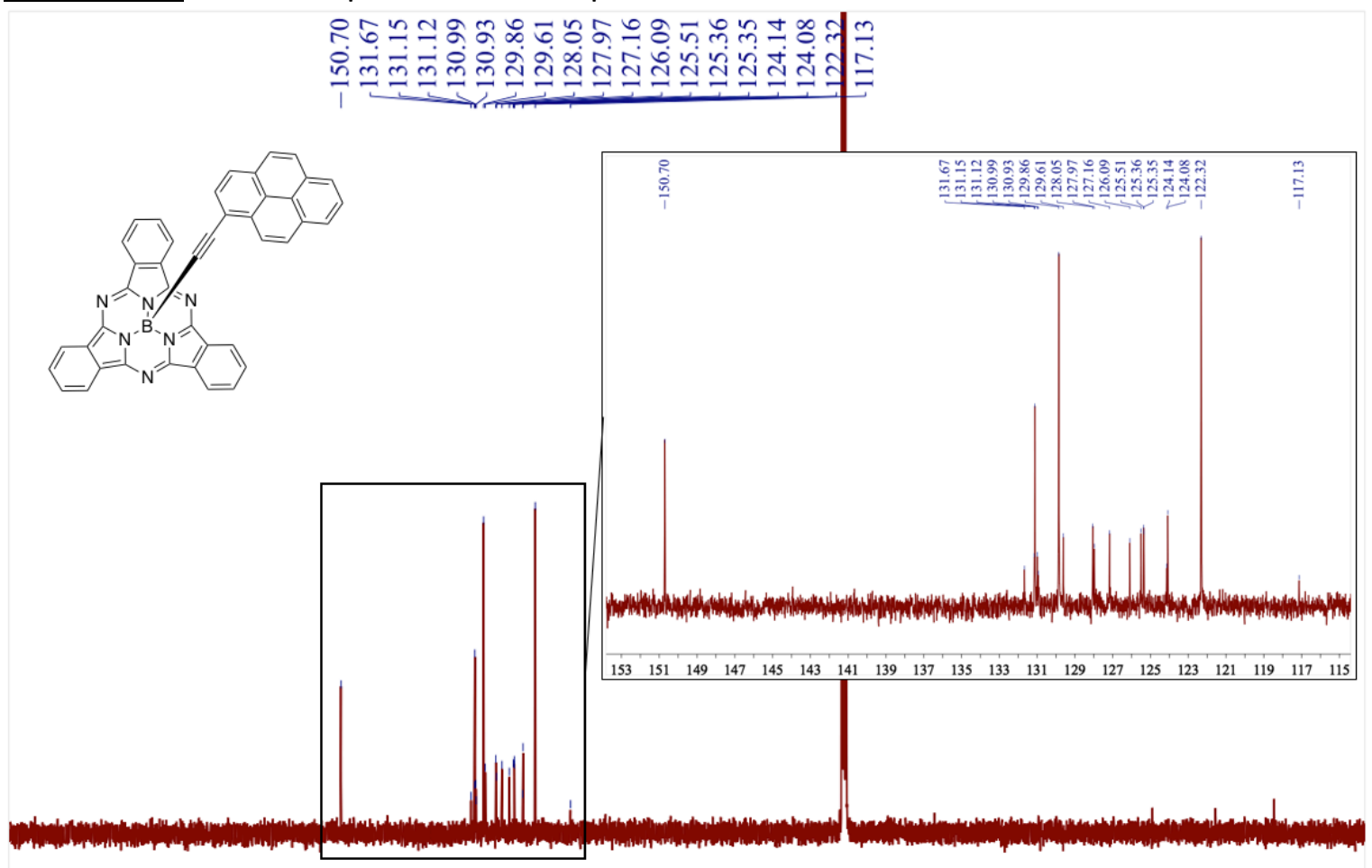

$\begin{array}{llllllllllllllllllll}190 & 180 & 170 & 160 & 150 & 140 & 130 & 120 & 110 & 100 & 90 & 80 & 70 & 60 & 50 & 40 & 30 & 20 & 10 & \text { (ppm) }\end{array}$ 
Figure S1-10: ${ }^{1} \mathrm{H}$ NMR spectrum of compound 06 recorded in $\mathrm{CDCl}_{3}$ at $500 \mathrm{MHz}$ and $300 \mathrm{~K}$

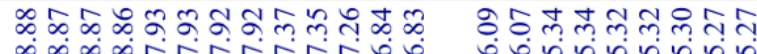

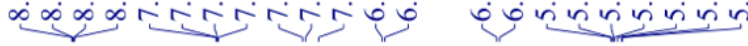

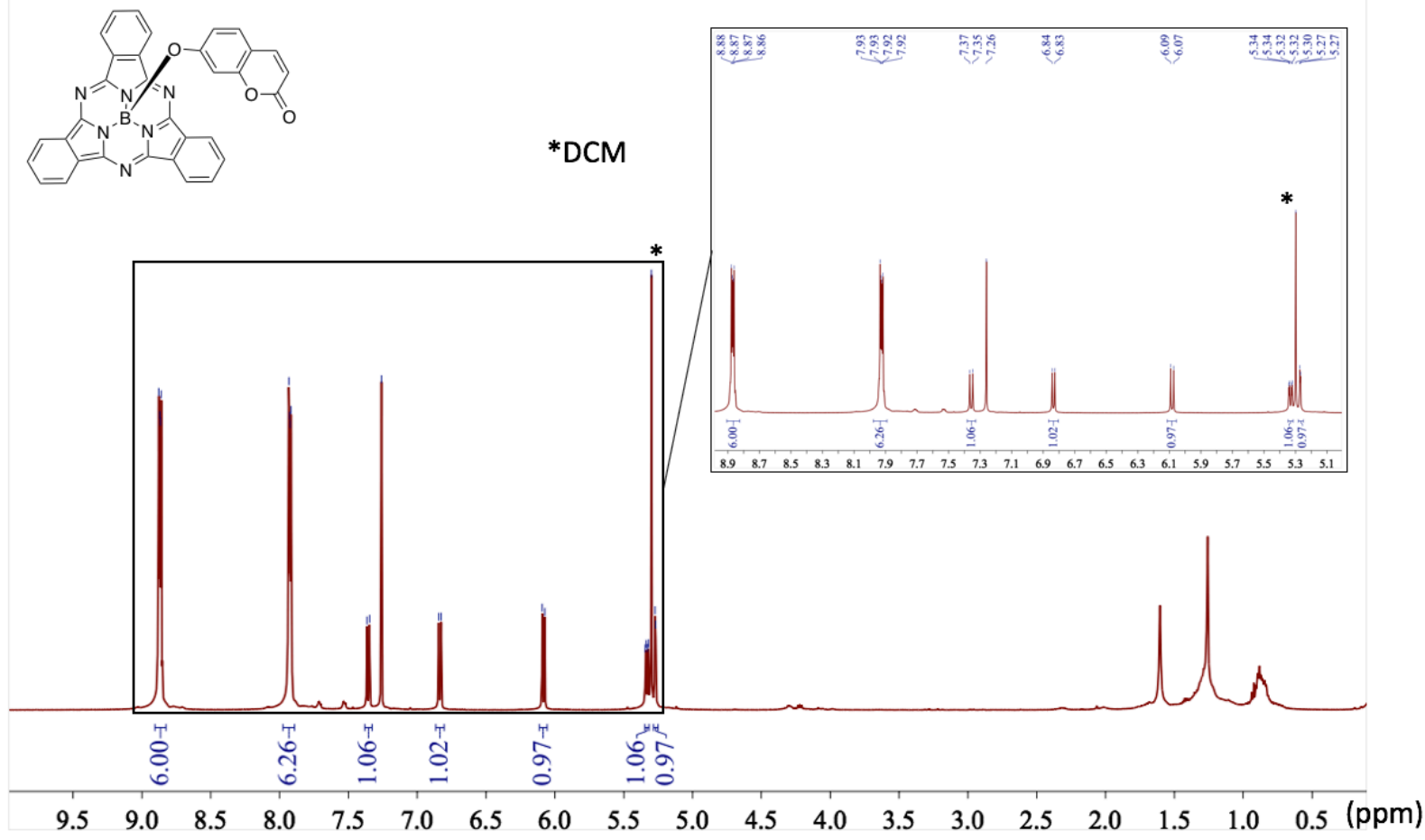

Figure S1-11: ${ }^{13} \mathrm{C}$ NMR spectrum of compound 06 recorded in $\mathrm{CDCl}_{3}$ at $125 \mathrm{MHz}$ and $300 \mathrm{~K}$

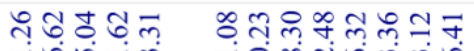

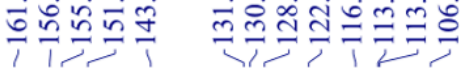
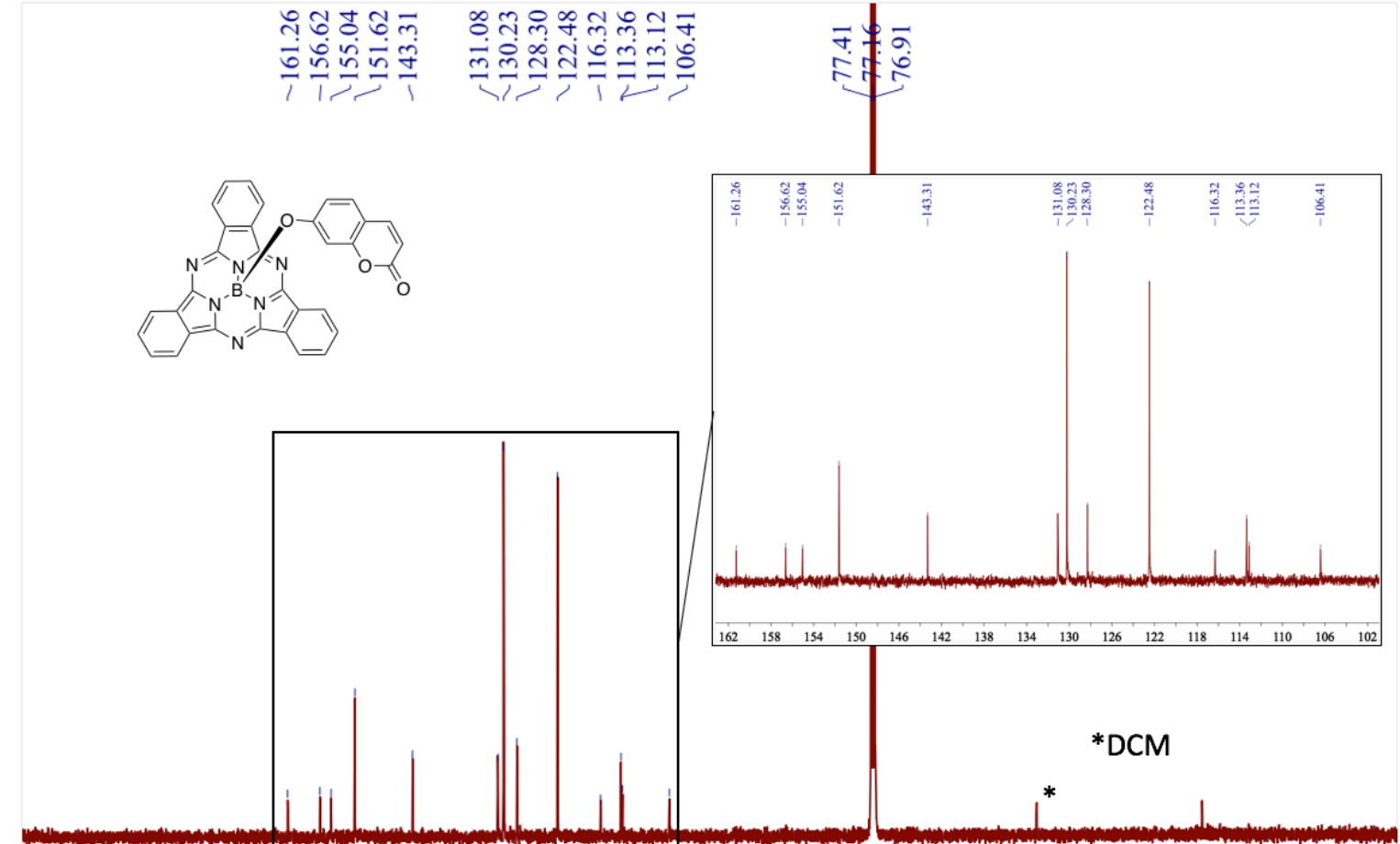

$\begin{array}{lllllllllllllllllll}190 & 180 & 170 & 160 & 150 & 140 & 130 & 120 & 110 & 100 & 90 & 80 & 70 & 60 & 50 & 40 & 30 & 20 & 10\end{array}$ 


\section{RP-HPLC elution profiles of compounds $01,03,04,05$ and 06}

HPLC-MS analyses were performed on a Thermo-Dionex Ultimate 3000 instrument equipped with a diode array detector (Thermo-Dionex, FLD 3400-RS).

HPLC system used: RP-HPLC-MS (Phenomenex Kinetex $\mathrm{C}_{18}$ column, $2.6 \mu \mathrm{m}, 2.1 \times 50 \mathrm{~mm}$ ) with $\mathrm{MeCN}(+0.1 \% \mathrm{FA})$ and $0.1 \%$ aq. formic acid (aq. FA, $\mathrm{pH} 2.7$ ) as eluents [5\% MeCN (0.1 min) followed by linear gradient from $5 \%$ to $100 \%$ ( $5 \mathrm{~min}$ ) of $\mathrm{MeCN}$ and maintained at $100 \%$ during 3 $\mathrm{min}$ ] at a flow rate of $0.5 \mathrm{~mL} \mathrm{~min}^{-1}$. UV-visible detection was achieved at 220, 260 and $560 \mathrm{~nm} \mathrm{(+}$ DAD in the range $220-700 \mathrm{~nm}$ ). Low resolution ESI-MS detection in the positive/negative mode (full scan, 100-1000 a.m.u., data type: centroid, needle voltage: $3.0 \mathrm{kV}$, probe temperature: 350 ${ }^{\circ} \mathrm{C}$, cone voltage: $75 \mathrm{~V}$ and scan time: $1 \mathrm{~s}$ ).

Figure S2-1: RP-HPLC elution profile of compound 01 at $560 \mathrm{~nm}$

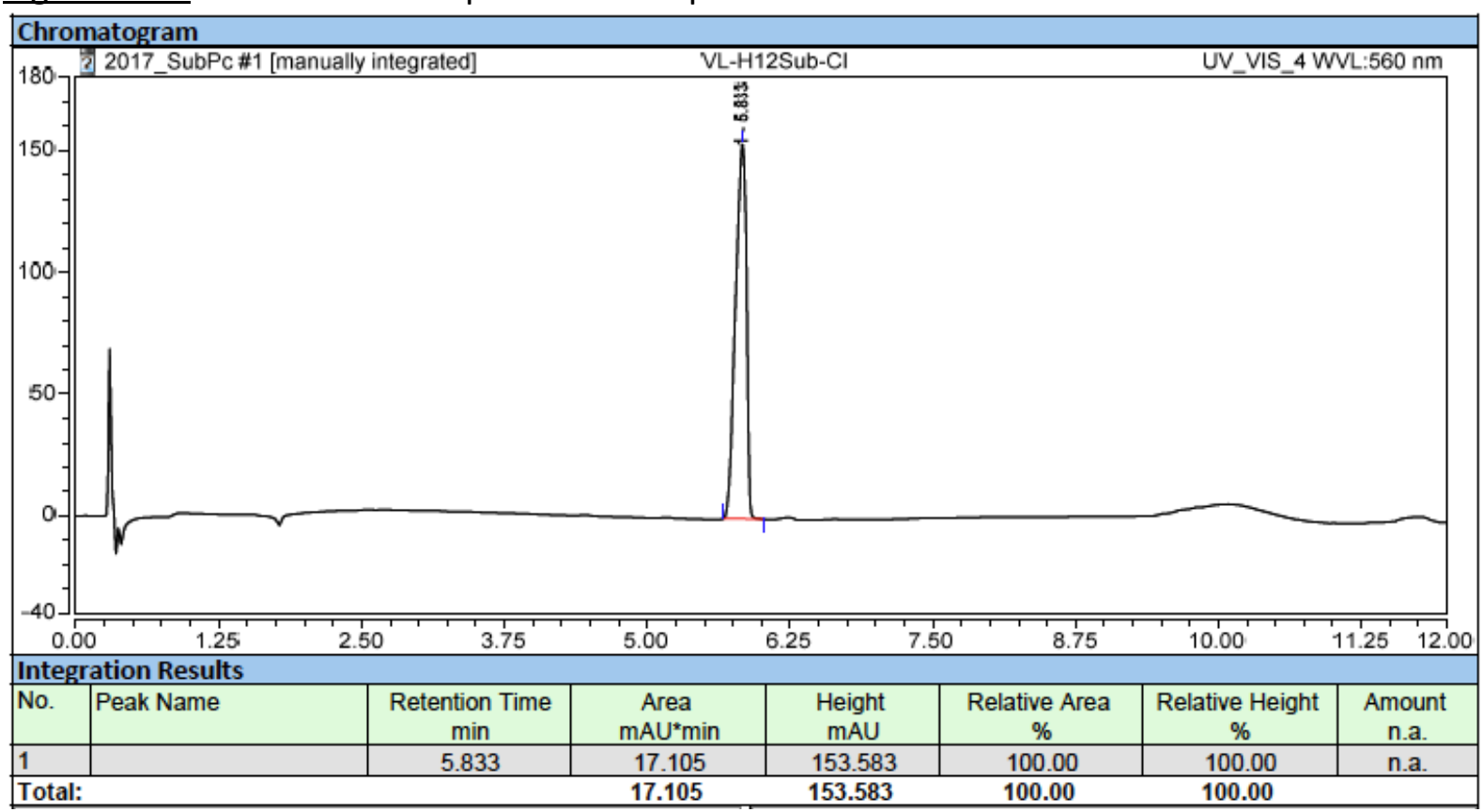

Figure S2-2: RP-HPLC elution profile of compound 03 at $560 \mathrm{~nm}$

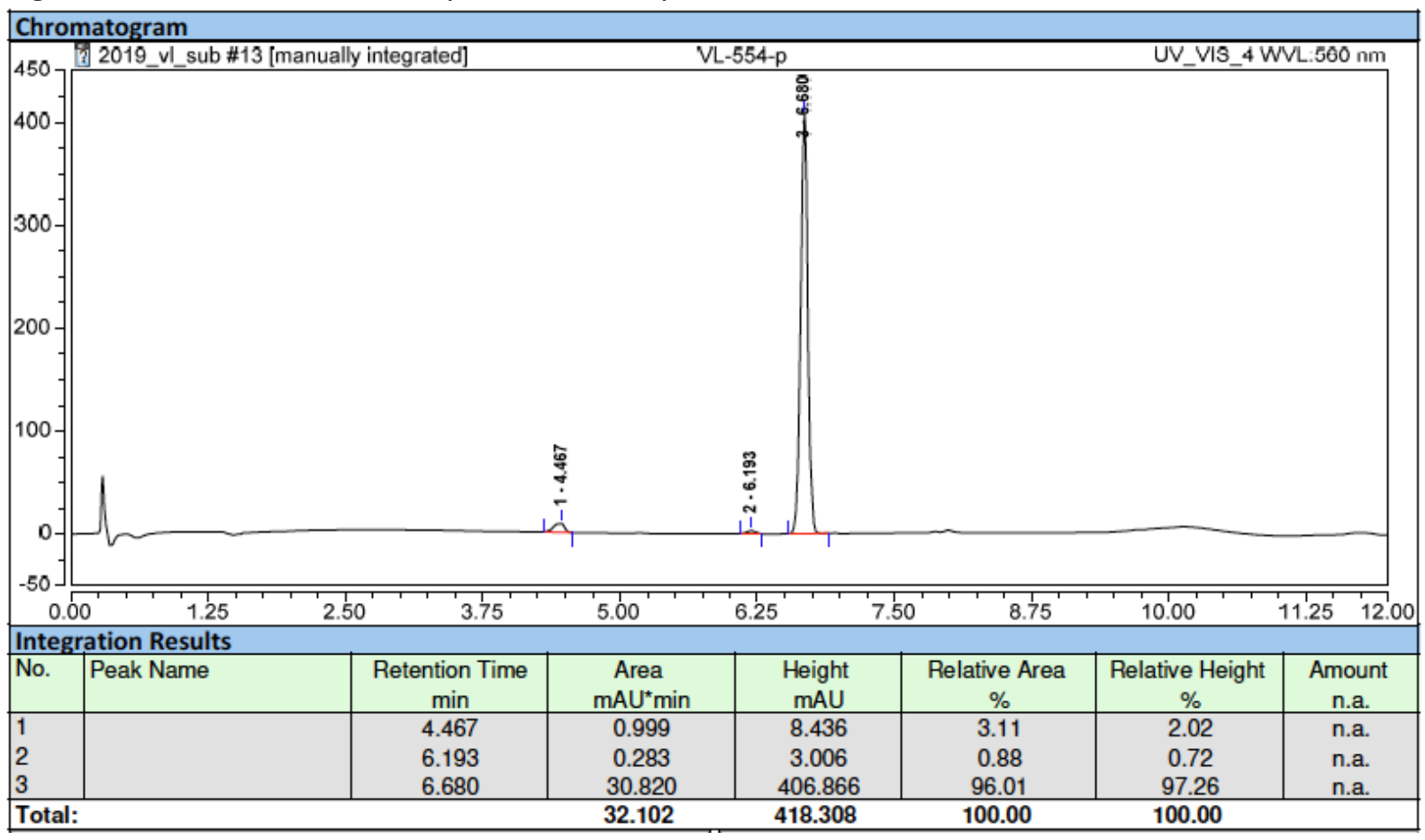


Figure S2-3: RP-HPLC elution profile of compound 04 at $560 \mathrm{~nm}$

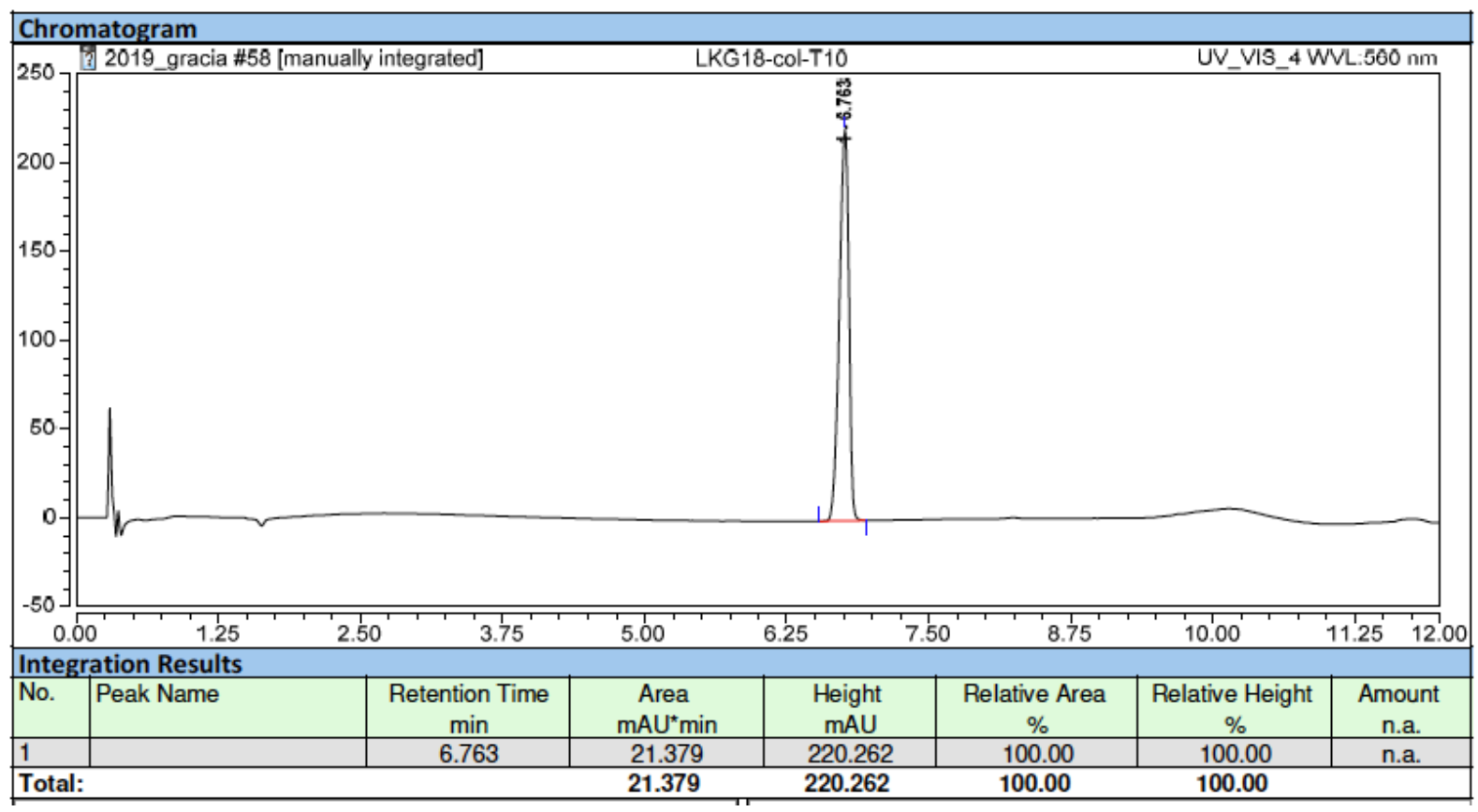

Figure S2-4: RP-HPLC elution profile of compound 05 at $560 \mathrm{~nm}$

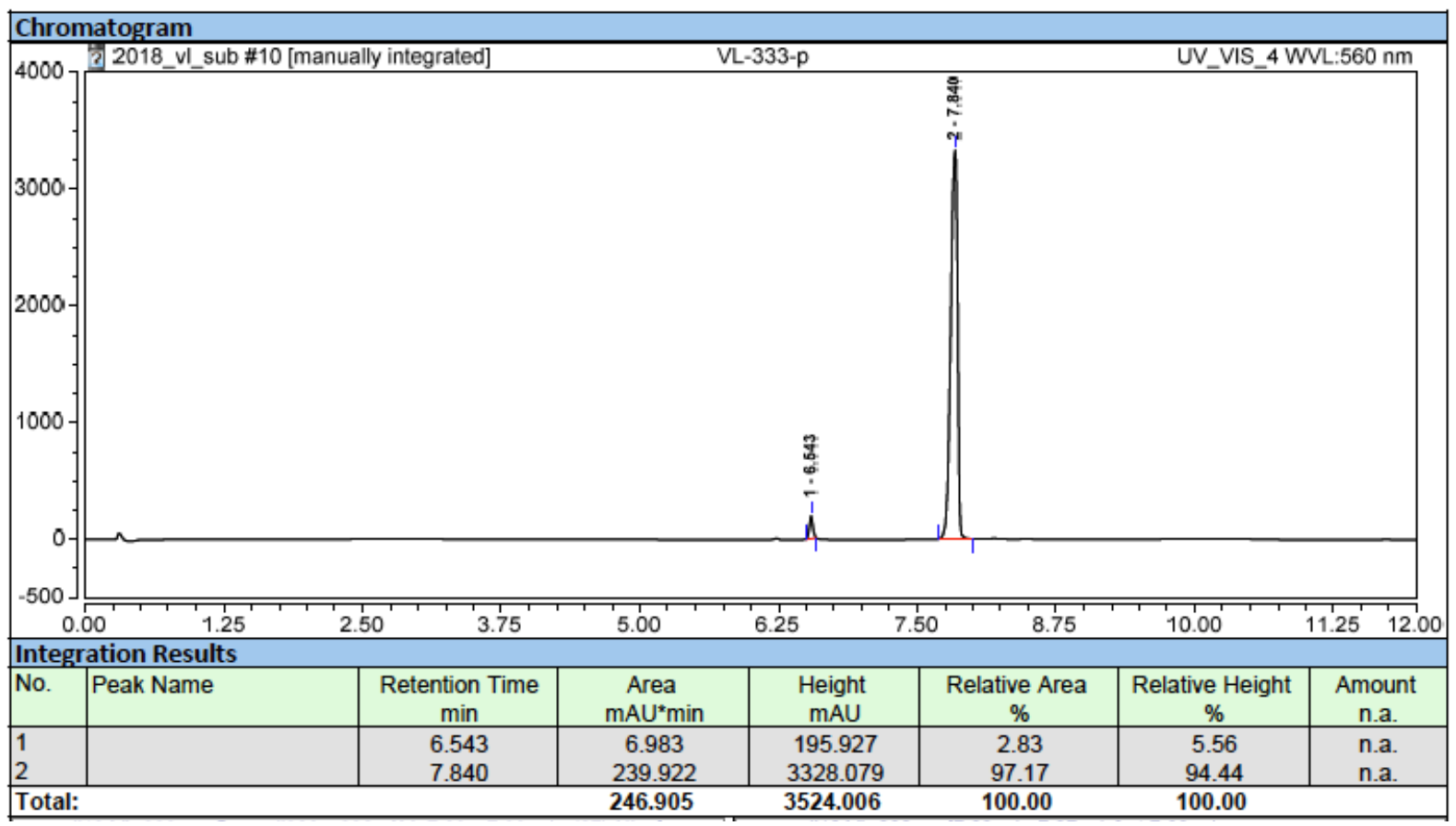


Figure S2-5: RP-HPLC elution profile of compound 06 at $560 \mathrm{~nm}$

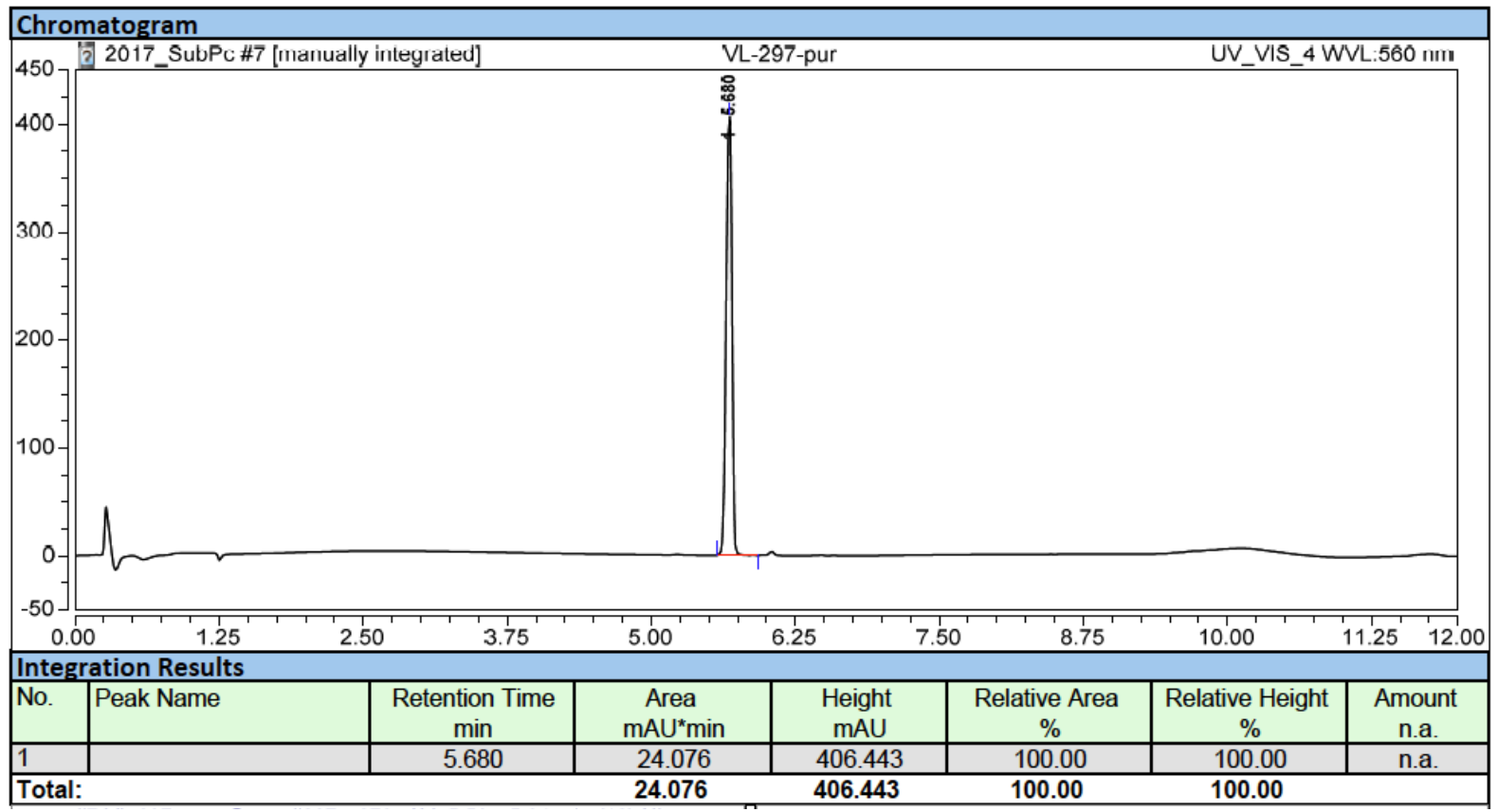




\section{HRMS analysis}

Figure S3-1: HRMS spectrum of compound 01

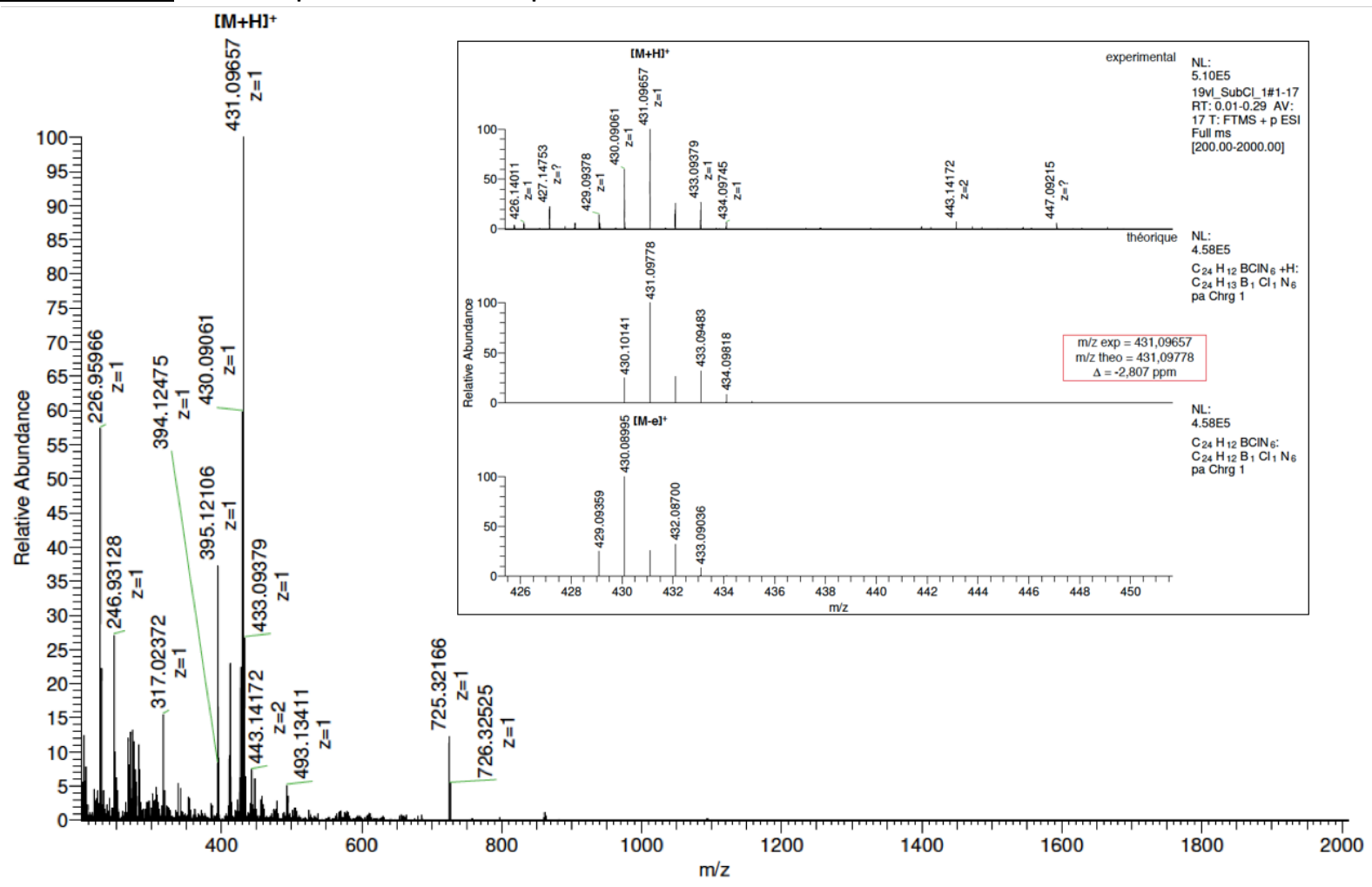

Figure S3-2: HRMS spectrum of compound 02

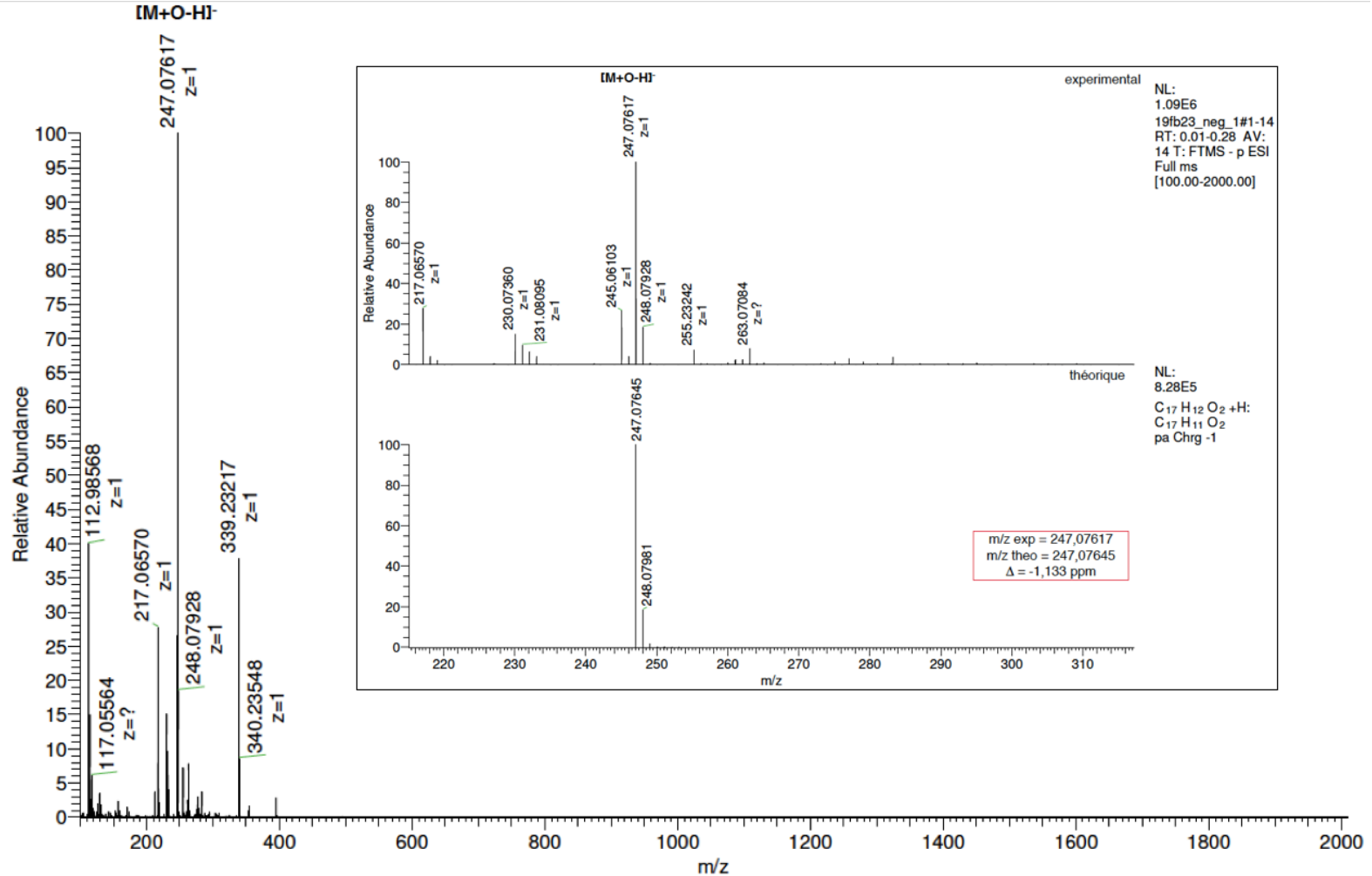


Figure S3-3: HRMS spectrum of compound $\mathbf{0 3}$

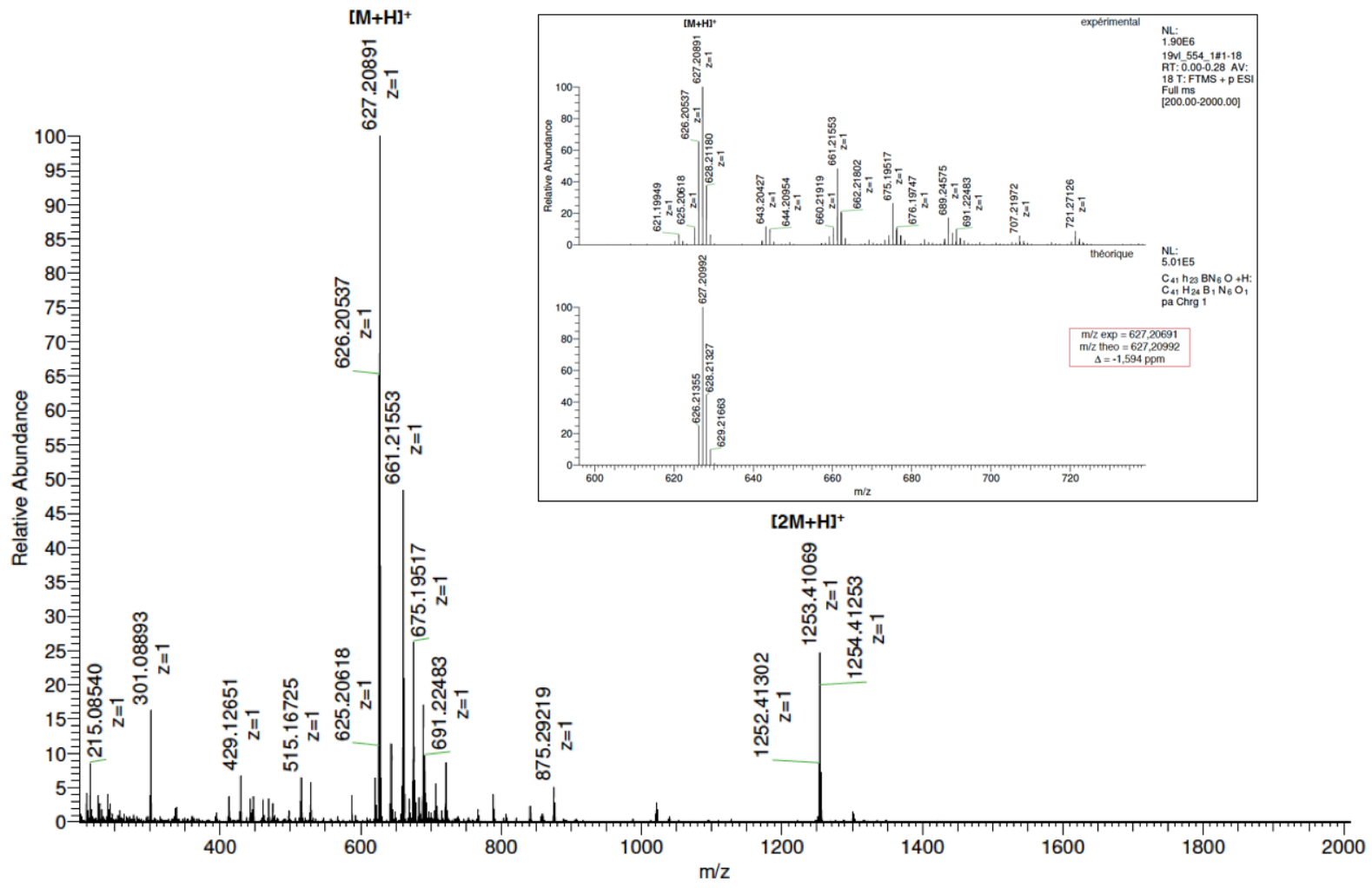

Figure S3-4: HRMS spectrum of compound 04

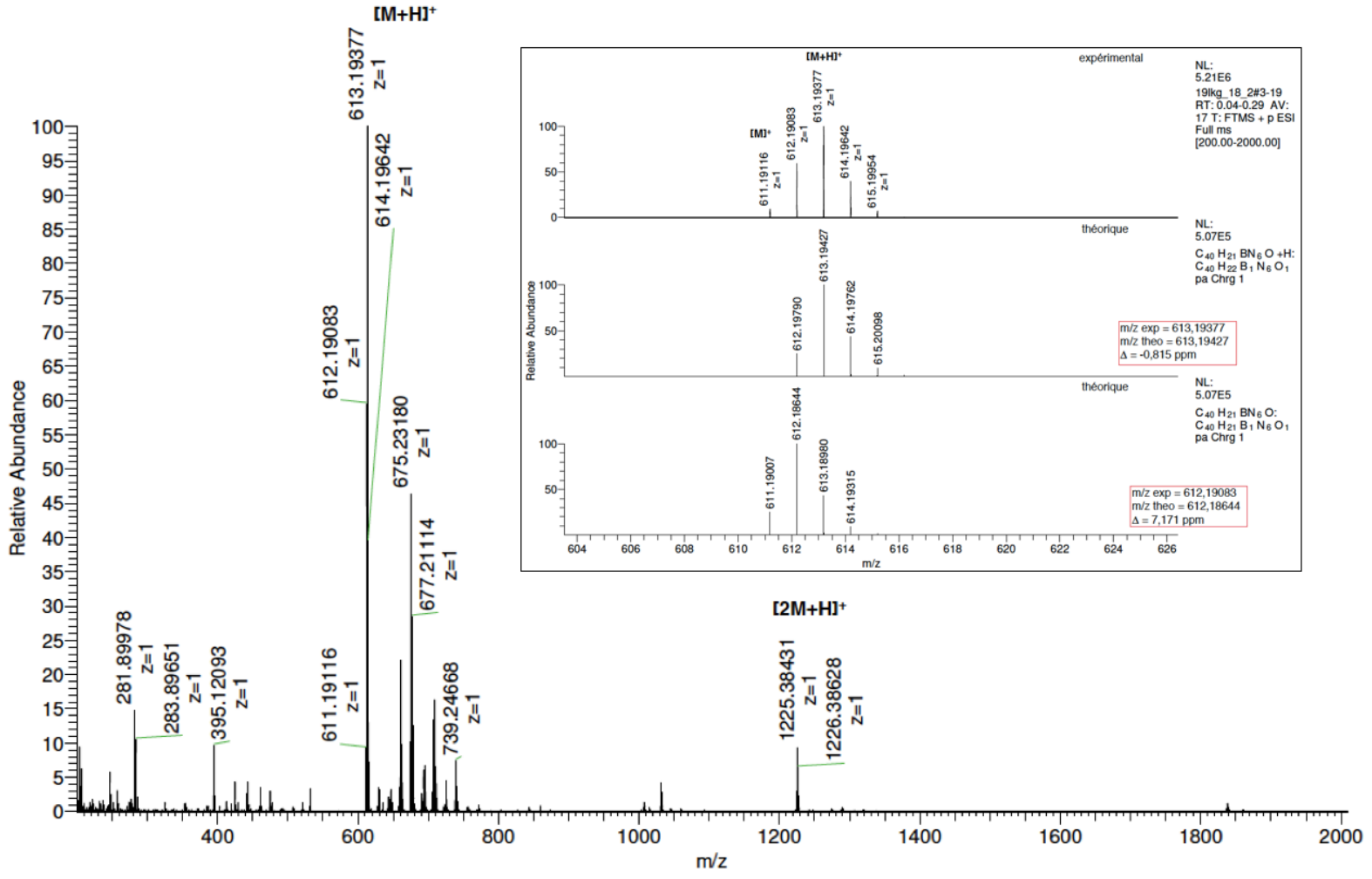


Figure S3-5: HRMS spectrum of compound 05

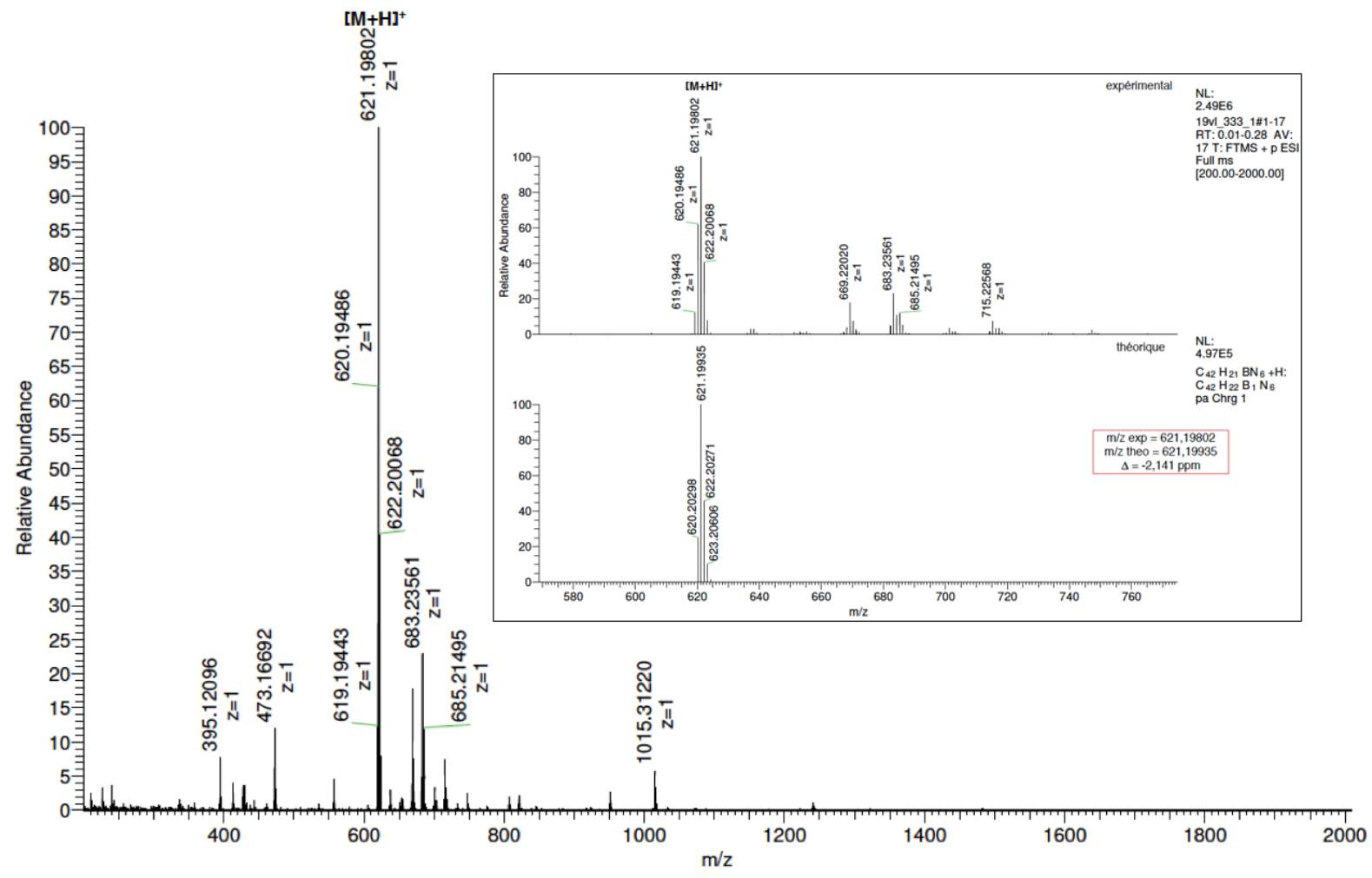

Figure S3-6: HRMS spectrum of compound 06

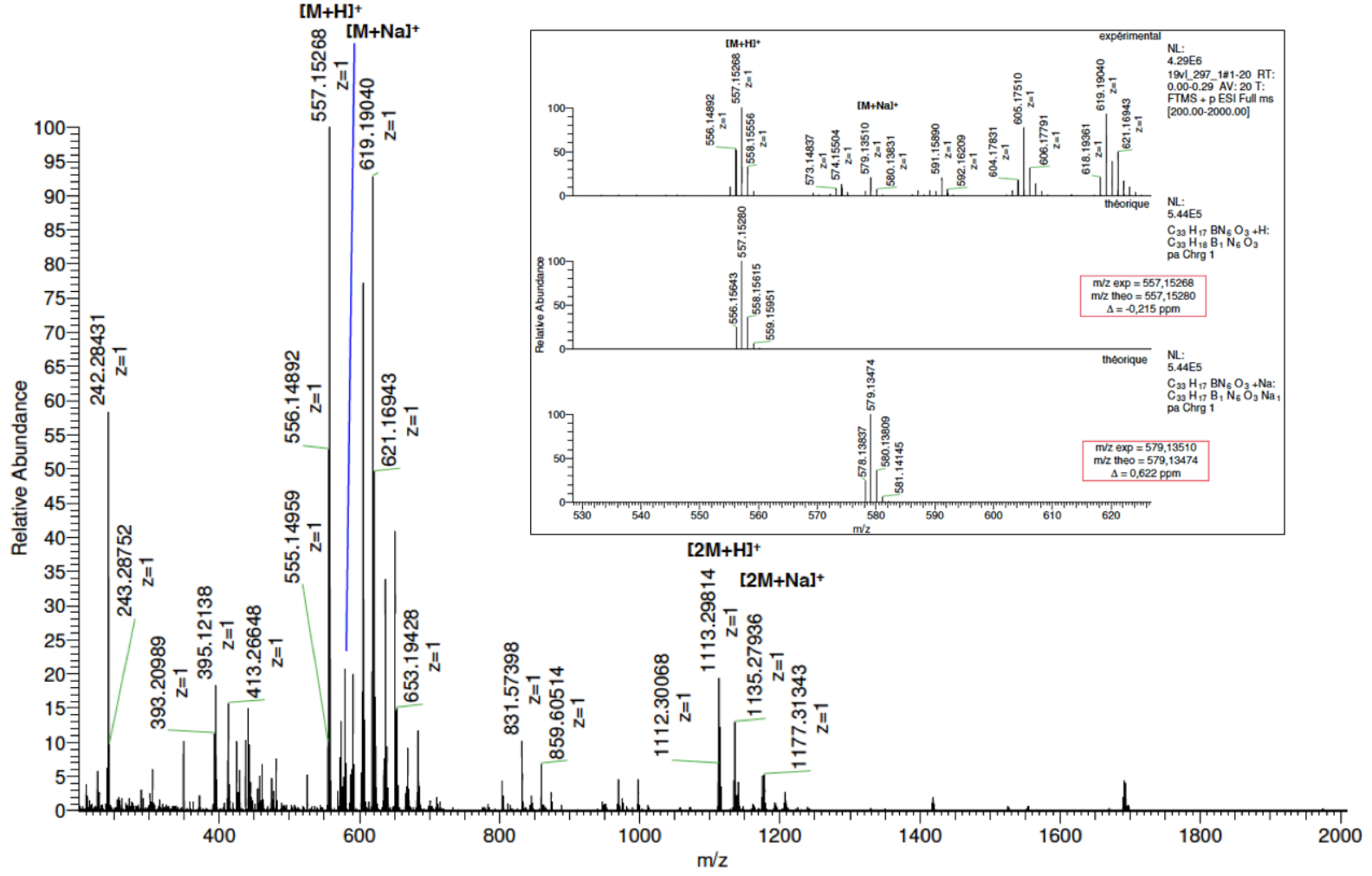


IV. Absorbance, excitation and emission spectra of compounds 01, 03, 04, 05 and 06 in different solvents

Figure S4-1: Absorbance, excitation $\left(\lambda_{\mathrm{em}}=630 \mathrm{~nm}\right)$ and emission $\left(\lambda_{\mathrm{ex}}=488 \mathrm{~nm}\right)$ spectra of compound $\mathbf{0 1}$ in different solvents
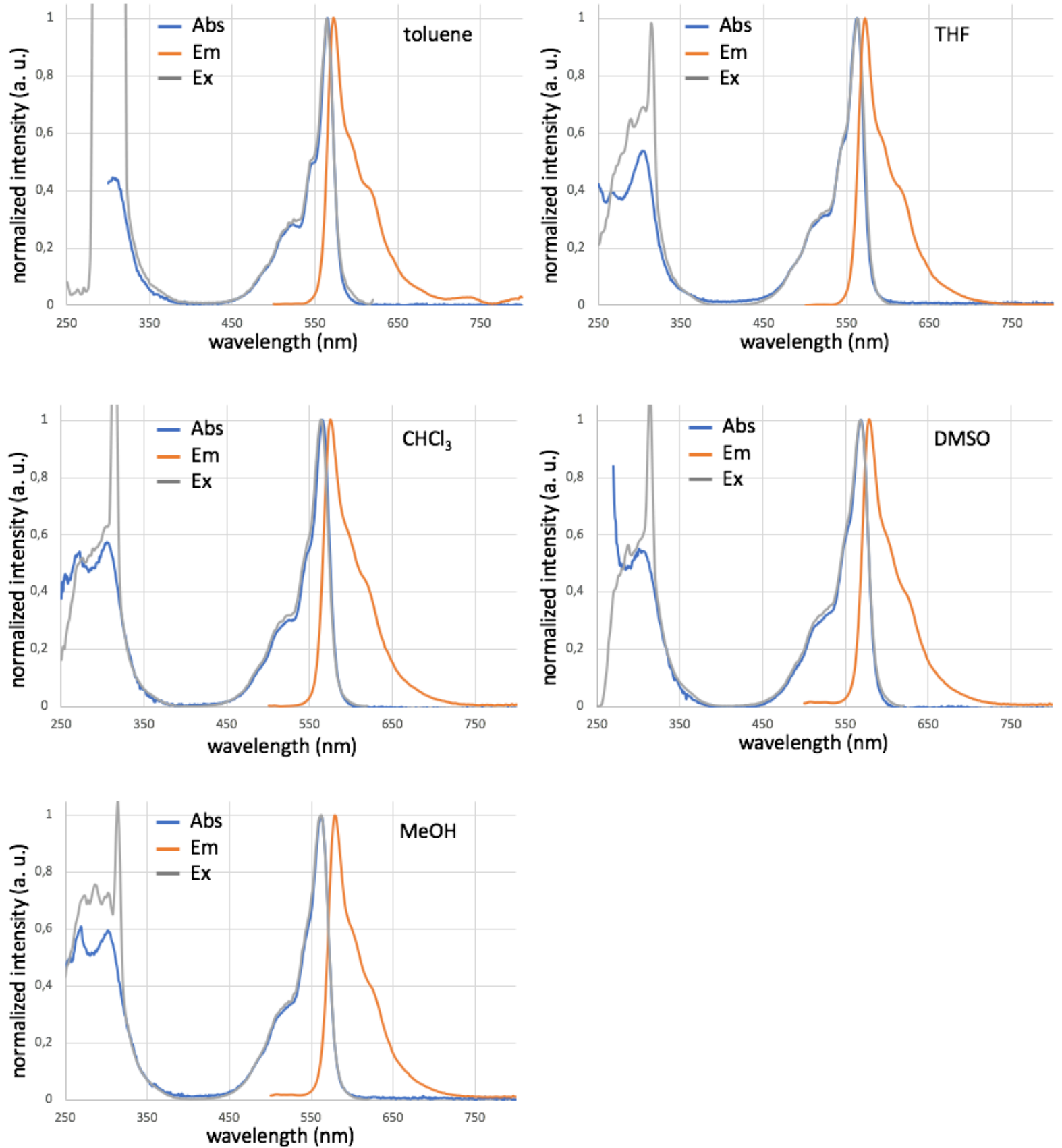
Figure S4-2: Absorbance, excitation $\left(\lambda_{\mathrm{em}}=630 \mathrm{~nm}\right)$ and emission $\left(\lambda_{\mathrm{ex}}=488 \mathrm{~nm}\right)$ spectra of compound $\mathbf{0 3}$ in different solvents
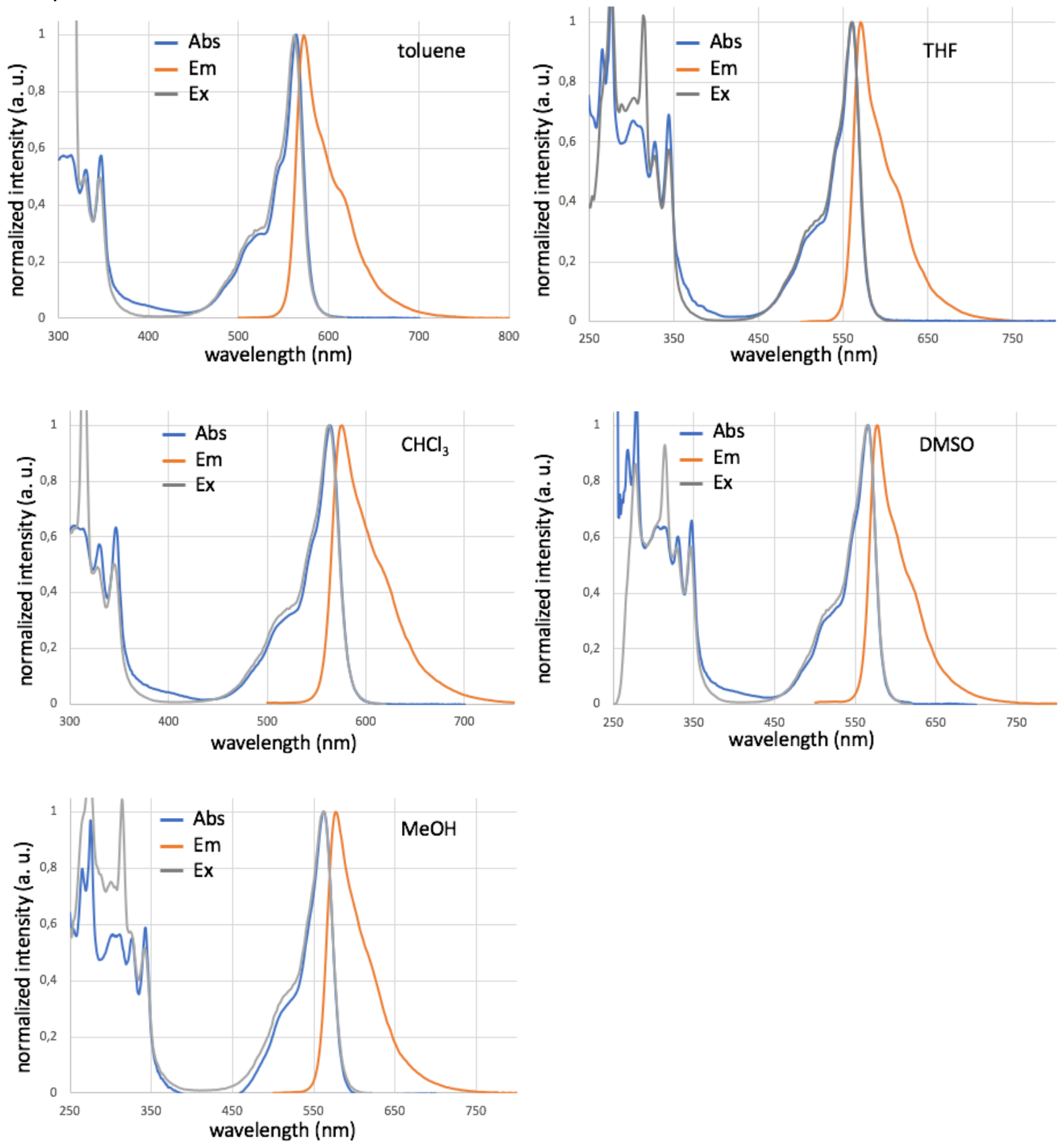
Figure S4-3: Absorbance, excitation $\left(\lambda_{\mathrm{em}}=630 \mathrm{~nm}\right)$ and emission $\left(\lambda_{\mathrm{ex}}=488 \mathrm{~nm}\right)$ spectra of compound 04 in different solvents
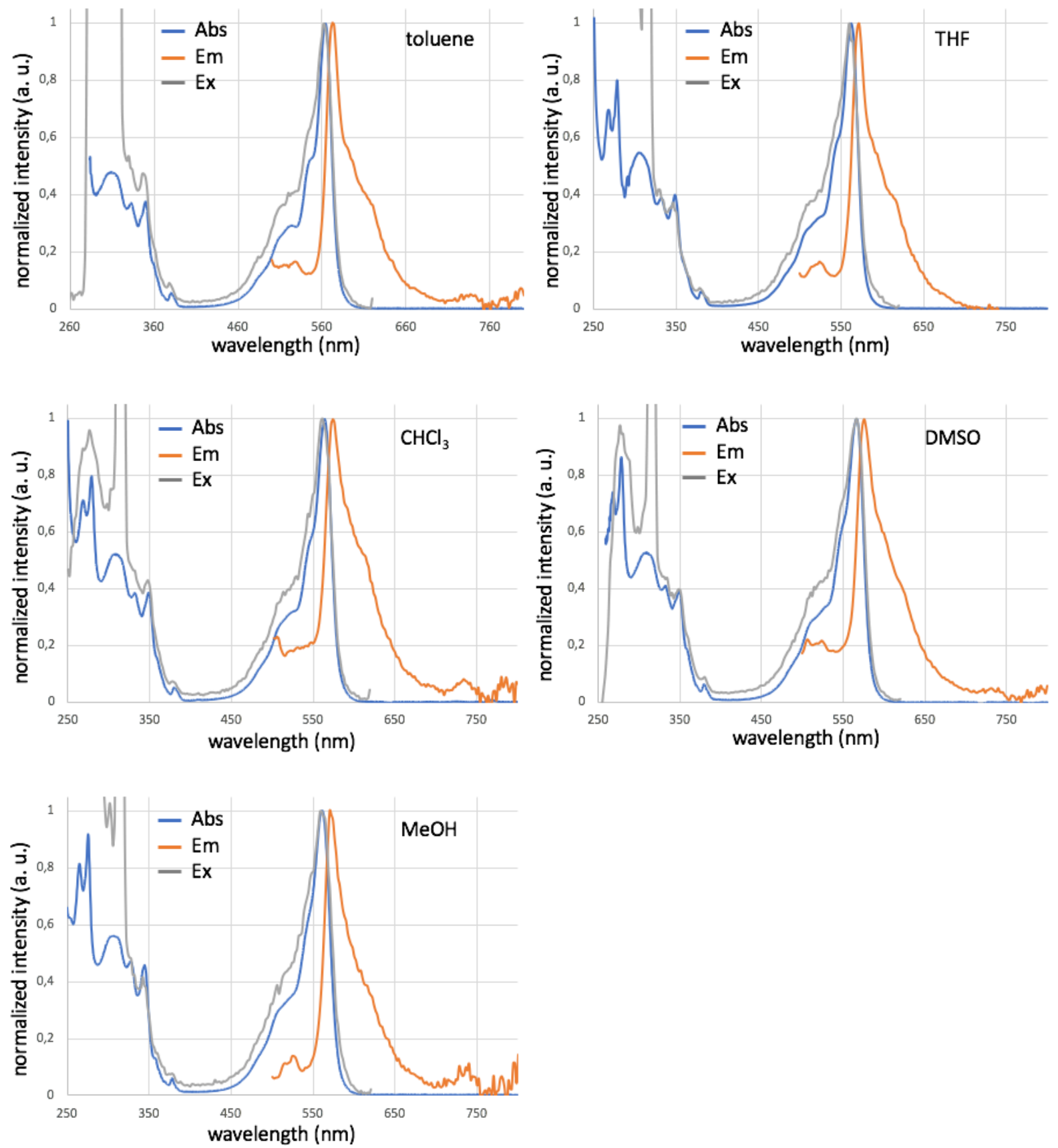
Figure S4-4: Absorbance, excitation $\left(\lambda_{\mathrm{em}}=630 \mathrm{~nm}\right)$ and emission $\left(\lambda_{\mathrm{ex}}=488 \mathrm{~nm}\right)$ spectra of compound 05 in different solvents
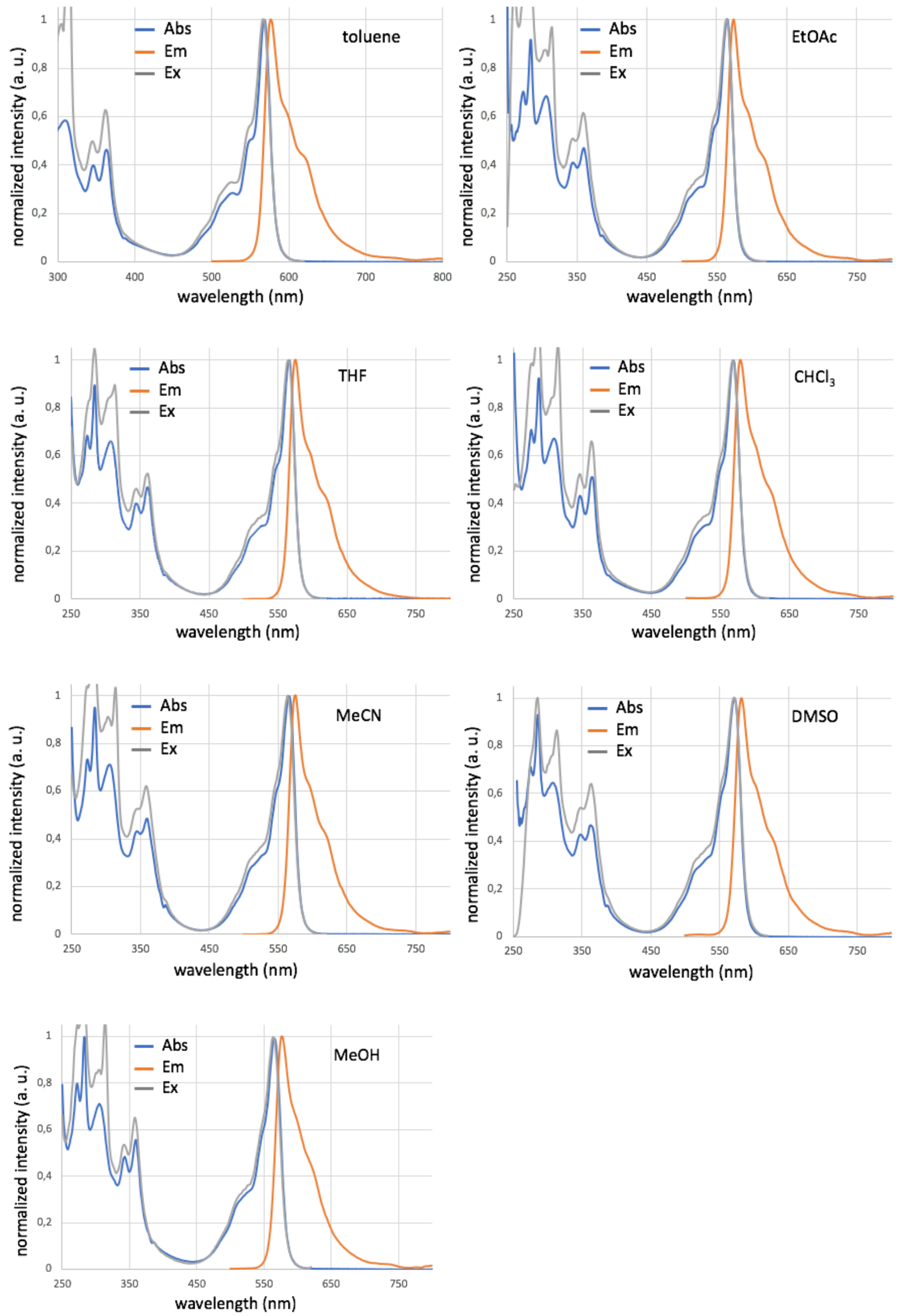
Figure S4-5: Absorbance, excitation $\left(\lambda_{\mathrm{em}}=630 \mathrm{~nm}\right)$ and emission $\left(\lambda_{\mathrm{ex}}=488 \mathrm{~nm}\right)$ spectra of compound 06 in different solvents
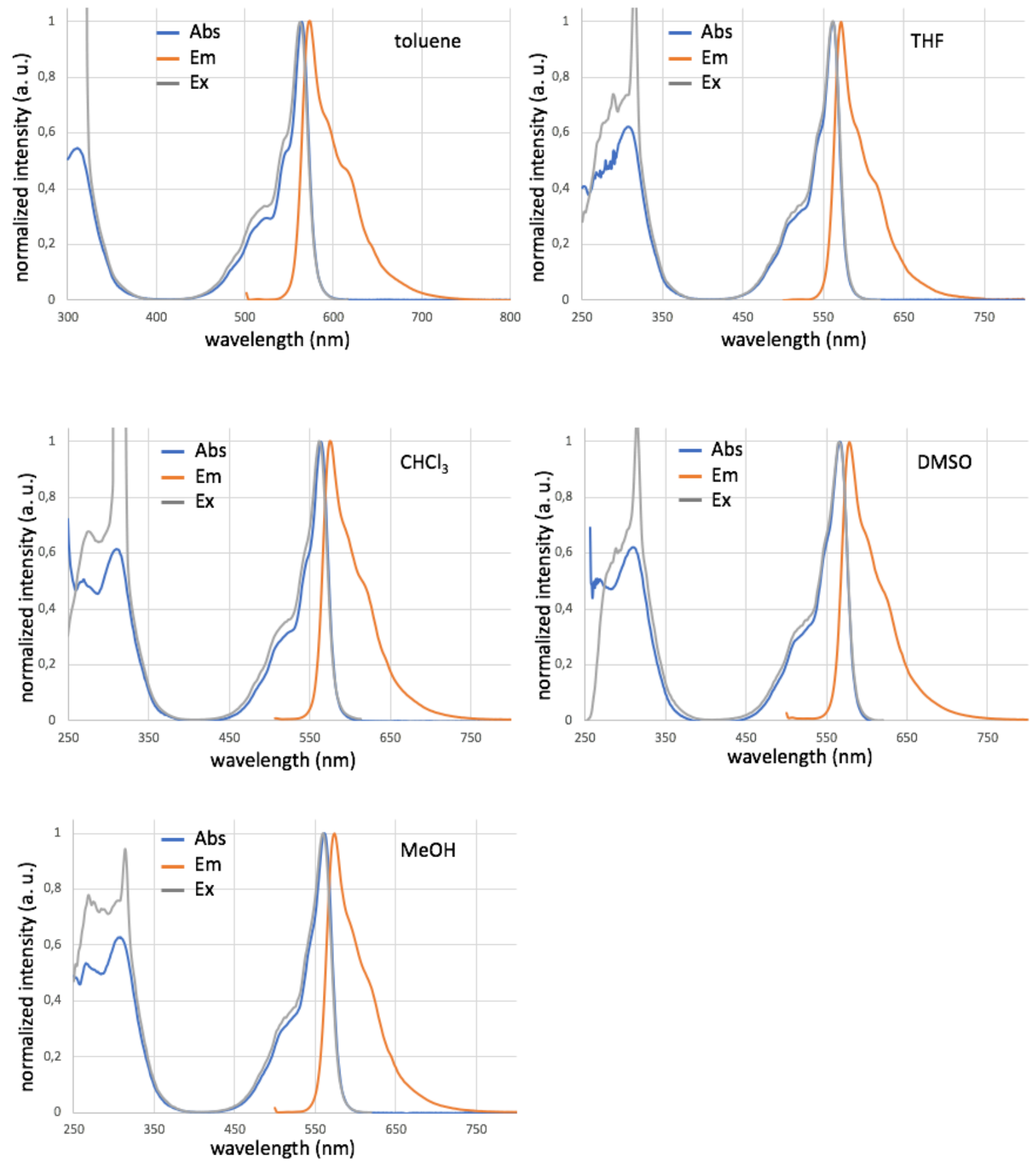


\section{Energy Transfer Efficiency studies of compounds 03 and 05 in different solvents}

Figure S5-1: Energy transfer efficiency of compound $\mathbf{0 3}$ in different solvents
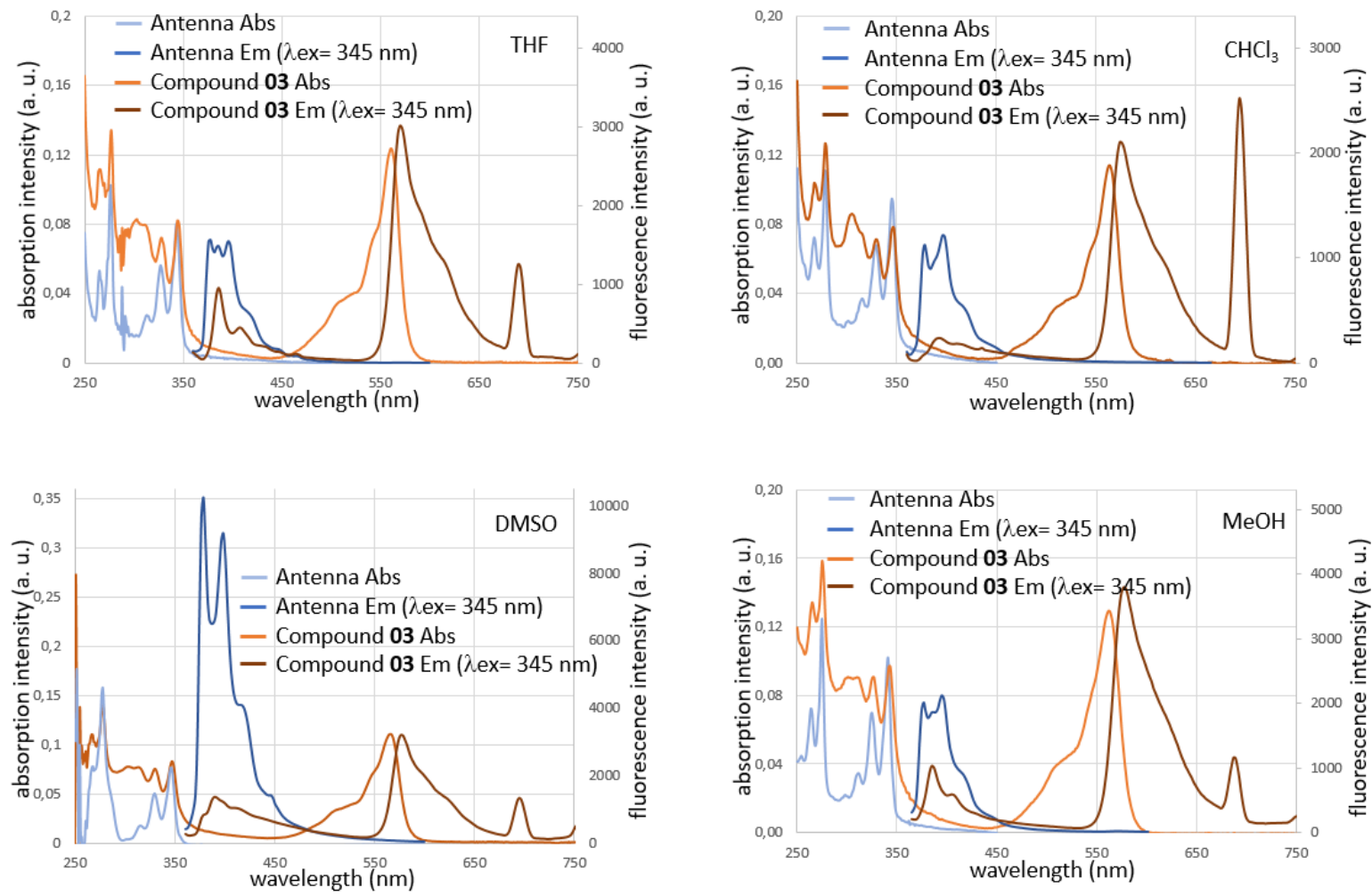
Figure S5-2: Energy transfer efficiency of compound 05 in different solvents
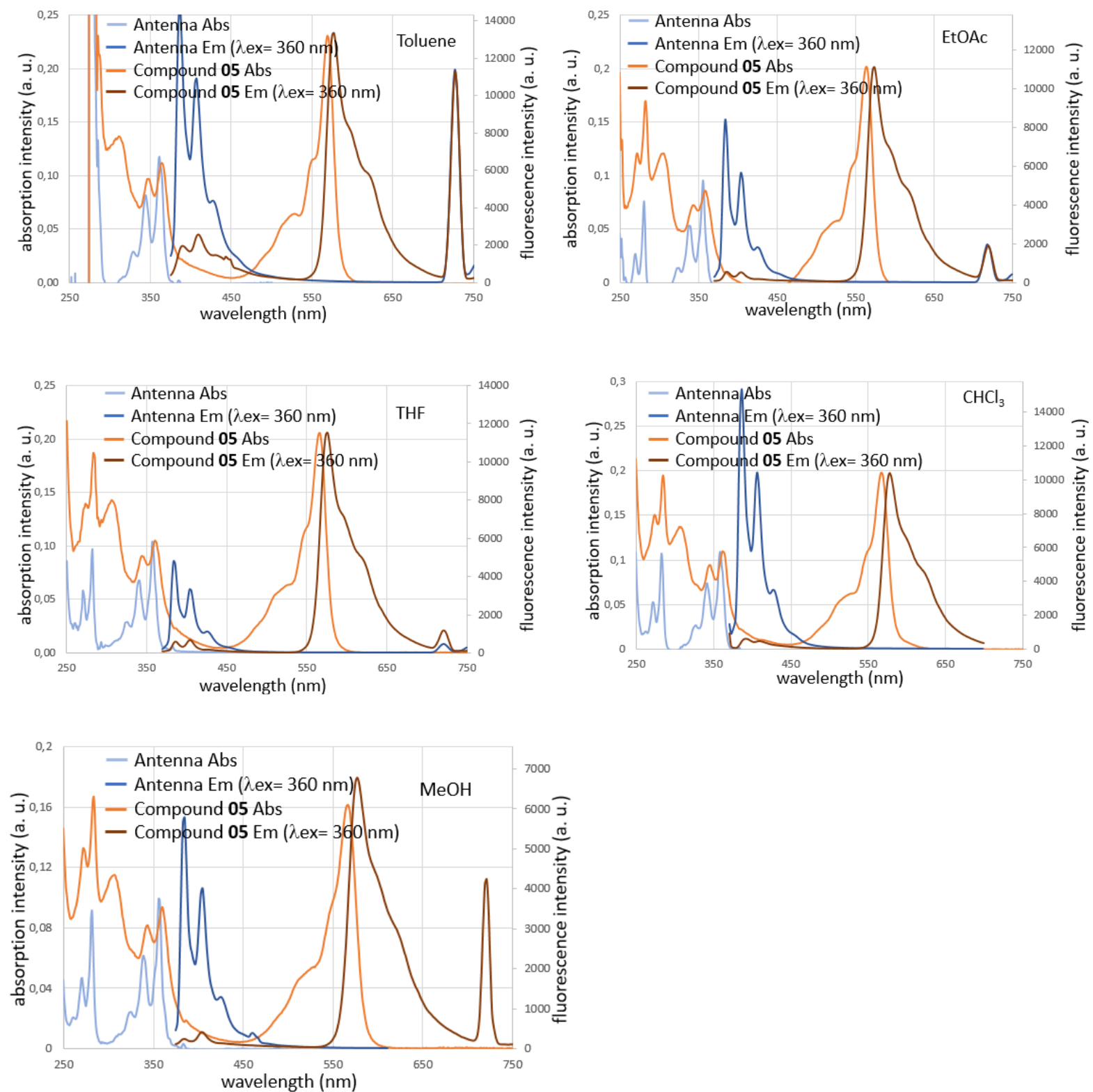


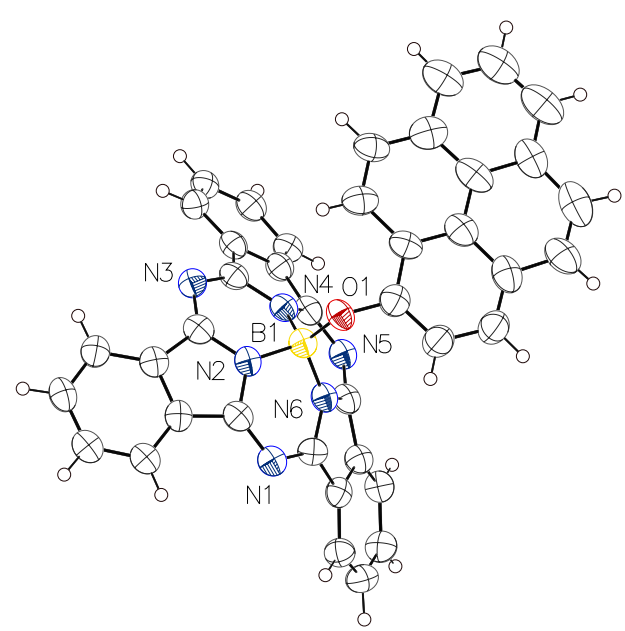

Experimental. Single clear light red plate-shaped crystals of compound $\mathbf{4}$ were recrystallized from a mixture of DCM and cyclohexane by slow evaporation. A suitable crystal $0.35 \times 0.10 \times 0.06 \mathrm{~mm}^{3}$ was selected and mounted on a MITIGEN holder oil on a Bruker D8 Venture diffractometer. The crystal was kept at a steady $T=$ 100.0(1) K during data collection. The structure was solved with the ShelXT (Sheldrick, 2015) structure solution program using the Intrinsic Phasing solution method and by using 0lex2 (Dolomanov et al., 2009) as the graphical interface. The model was refined with version 2018/3 of ShelXL (Sheldrick, 2015) using Least Squares minimization.

Crystal Data. $\mathrm{C}_{40} \mathrm{H}_{21} \mathrm{BN}_{6} \mathrm{O}, M_{r}=612.44$, triclinic, $P-1$ (No. 2), $\mathrm{a}=9.9592(4) \AA \AA, \mathrm{b}=12.1772(5) \AA, \mathrm{c}=13.5700(6) \AA, \alpha=$ $113.192(2)^{\circ}, \quad \beta=96.701(3)^{\circ}, \quad \gamma=103.825(2)^{\circ}, \quad V=$ 1427.34(11) $\AA^{3}, T=100.0(1) \mathrm{K}, Z=2, Z^{\prime}=1, \mu\left(\mathrm{CuK}_{\alpha}\right)=$ $0.700,18696$ reflections measured, 5023 unique $\left(R_{\text {int }}=\right.$ $0.1053)$ which were used in all calculations. The final $w R_{2}$ was 0.2813 (all data) and $R_{1}$ was 0.1041 (I > 2(I)).

\begin{tabular}{|c|c|}
\hline Compound & 4 \\
\hline CCDC & 2005981 \\
\hline Internal Reference & $\begin{array}{l}\text { 20191125VLS4bOP } \\
\mathrm{y}\end{array}$ \\
\hline Formula & $\mathrm{C}_{40} \mathrm{H}_{21} \mathrm{BN}_{6} \mathrm{O}$ \\
\hline$D_{\text {calc. }} / \mathrm{g} \mathrm{cm}^{-3}$ & 1.425 \\
\hline$\mu / \mathrm{mm}^{-1}$ & 0.700 \\
\hline Formula Weight & 612.44 \\
\hline Color & clear light red \\
\hline Shape & plate \\
\hline Size $/ \mathrm{mm}^{3}$ & $0.35 \times 0.10 \times 0.06$ \\
\hline$T / \mathrm{K}$ & $100.0(1)$ \\
\hline Crystal System & triclinic \\
\hline Space Group & $P-1$ \\
\hline$a / \AA ̊$ & $9.9592(4)$ \\
\hline$b / \AA$ & $12.1772(5)$ \\
\hline$c / \AA ̊$ & $13.5700(6)$ \\
\hline$\alpha /^{\circ}$ & $113.192(2)$ \\
\hline$\beta /^{\circ}$ & $96.701(3)$ \\
\hline$\gamma /^{\circ}$ & $103.825(2)$ \\
\hline $\mathrm{V} / \AA^{3}$ & $1427.34(11)$ \\
\hline$Z$ & 2 \\
\hline$Z^{\prime}$ & 1 \\
\hline Wavelength/Å & 1.541840 \\
\hline Radiation type & $\mathrm{CuK}_{\alpha}$ \\
\hline$\Theta_{\min } /^{\circ}$ & 3.647 \\
\hline$\Theta_{\max } /^{\circ}$ & 66.941 \\
\hline Measured Refl. & 18696 \\
\hline Independent Refl. & 5023 \\
\hline $\begin{array}{l}\text { Reflections with I > } \\
2(\mathrm{I})\end{array}$ & 3266 \\
\hline$R_{\text {int }}$ & 0.1053 \\
\hline Parameters & 433 \\
\hline Restraints & 0 \\
\hline Largest Peak & 0.468 \\
\hline Deepest Hole & -0.359 \\
\hline GooF & 1.048 \\
\hline$w R_{2}$ (all data) & 0.2813 \\
\hline$w R_{2}$ & 0.2523 \\
\hline$R_{1}$ (all data) & 0.1462 \\
\hline
\end{tabular}




\section{Structure Quality Indicators}

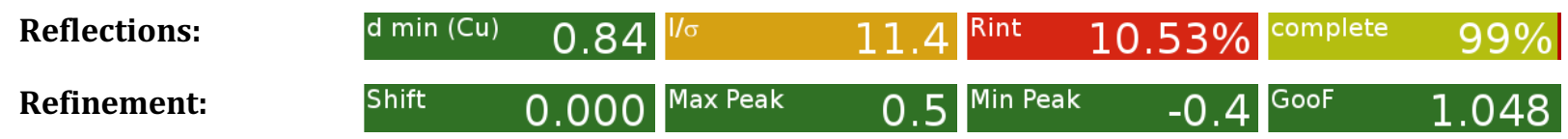

A clear light red plate-shaped crystal with dimensions $0.35 \times 0.10 \times 0.06 \mathrm{~mm}^{3}$ was mounted on a MITIGEN holder oil. Data were collected using a Bruker D8 Venture diffractometer equipped with an Oxford Cryosystems low-temperature device operating at $T=100.0(1) \mathrm{K}$. Data were measured using $\phi$ and $\omega$ scans' using $\mathrm{CuK}_{\alpha}$ radiation. The total number of runs and images was based on the strategy calculation from the program APEX3 (Bruker, 2015) The maximum resolution that was achieved was $\Theta=66.941^{\circ}$ $(0.84 \AA)$. The diffraction pattern was indexed. The total number of runs and images was based on the strategy calculation from the program APEX3 (Bruker, 2015) and the unit cell was refined using SAINT (Bruker, V8.40A, after 2013) on 4970 reflections, $27 \%$ of the observed reflections. Data reduction, scaling and absorption corrections were performed using SAINT (Bruker, V8.40A, after 2013). The final completeness is $98.70 \%$ out to $66.941^{\circ}$ in $\Theta$. A multi-scan absorption correction was performed using SADABS-2016/2 (Bruker,2016) was used for absorption correction. $w R_{2}$ (int) was 0.1218 before and 0.0935 after correction. The Ratio of minimum to maximum transmission is 0.8010 . The absorption coefficient $\mu$ of this material is $0.700 \mathrm{~mm}^{-1}$ at this wavelength $(\lambda=1.542 \AA)$ and the minimum and maximum transmissions are 0.733 and 0.915 . The structure was solved and the space group $P-1$ (\# 2) determined by the ShelXT (Sheldrick, 2015) structure solution program using Intrinsic Phasing and refined by Least Squares using version 2018/3 of ShelXL (Sheldrick, 2015). All non-hydrogen atoms were refined anisotropically. Hydrogen atom positions were calculated geometrically and refined using the riding model. Hydrogen atom positions were calculated geometrically and refined using the riding model. There is a single molecule in the asymmetric unit, which is represented by the reported sum formula. In other words: $\mathrm{Z}$ is 2 and $\mathrm{Z}^{\prime}$ is 1 .

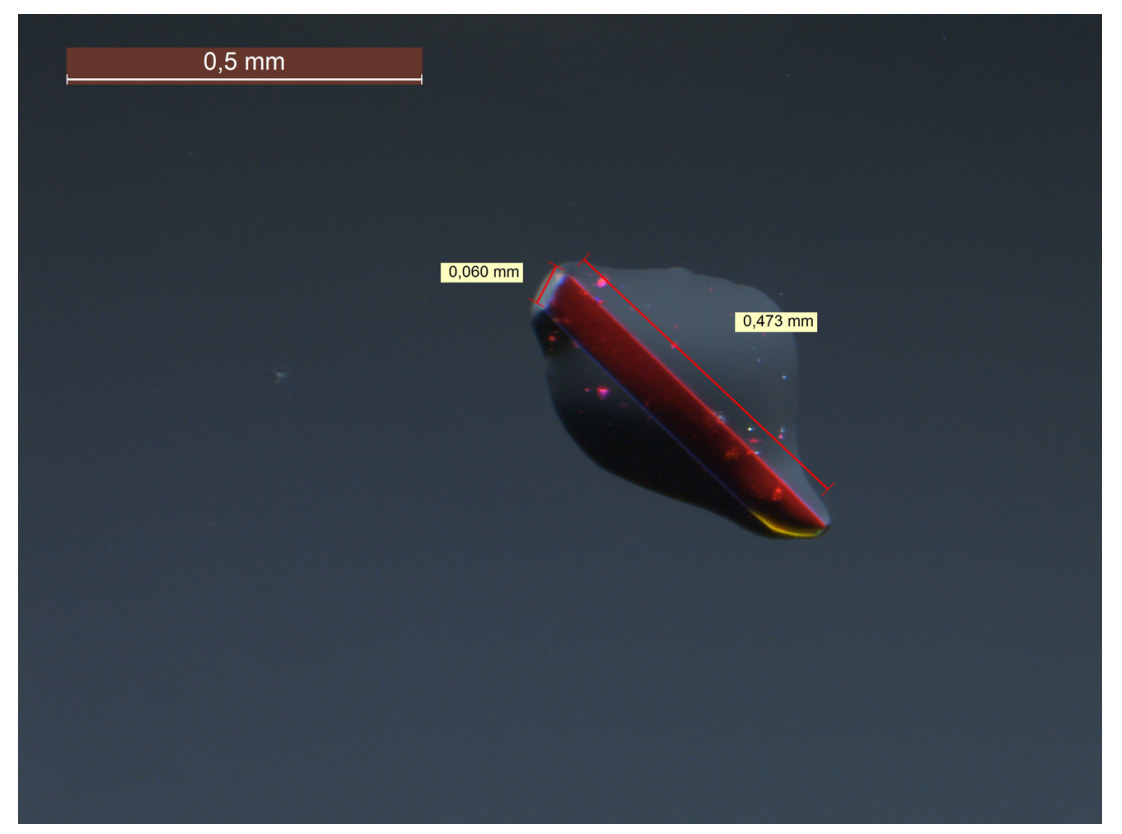

Figure 1: View of selected sample. 
Table 1: Bond Lengths in Å for compound 4.

\begin{tabular}{lll}
\hline Atom & Atom & Length/Å \\
\hline O1 & C9 & $1.374(7)$ \\
O1 & B1 & $1.430(7)$ \\
N1 & C1 & $1.355(6)$ \\
N1 & C8B & $1.342(7)$ \\
N2 & C1B & $1.358(7)$ \\
N2 & C8B & $1.372(7)$ \\
N2 & B1 & $1.496(7)$ \\
N3 & C1B & $1.353(7)$ \\
N3 & C8A & $1.346(6)$ \\
N4 & C1A & $1.357(6)$ \\
N4 & C8A & $1.365(6)$ \\
N4 & B1 & $1.499(7)$ \\
N5 & C1A & $1.339(7)$ \\
N5 & C8 & $1.351(7)$ \\
N6 & C1 & $1.372(6)$ \\
N6 & C8 & $1.368(6)$ \\
N6 & B1 & $1.499(7)$ \\
C1 & C2 & $1.456(7)$ \\
C1A & C2A & $1.459(7)$ \\
C1B & C2B & $1.443(7)$ \\
C2 & C3 & $1.395(7)$ \\
C2 & C7 & $1.433(7)$ \\
C2A & C3A & $1.386(7)$ \\
C2A & C7A & $1.426(7)$ \\
C2B & C3B & $1.398(7)$ \\
C2B & C7B & $1.426(7)$ \\
C3 & C4 & $1.381(8)$ \\
C3A & C4A & $1.388(7)$ \\
C3B & C4B & $1.385(8)$ \\
C4 & C5 & $1.396(8)$ \\
& &
\end{tabular}

\begin{tabular}{lll}
\hline Atom & Atom & Length/Å \\
\hline C4A & C5A & $1.404(7)$ \\
C4B & C5B & $1.386(8)$ \\
C5 & C6 & $1.392(7)$ \\
C5A & C6A & $1.389(7)$ \\
C5B & C6B & $1.380(8)$ \\
C6 & C7 & $1.386(7)$ \\
C6A & C7A & $1.405(7)$ \\
C6B & C7B & $1.387(7)$ \\
C7 & C8 & $1.458(7)$ \\
C7A & C8A & $1.452(7)$ \\
C7B & C8B & $1.472(7)$ \\
C9 & C10 & $1.379(8)$ \\
C9 & C14 & $1.397(8)$ \\
C10 & C11 & $1.392(9)$ \\
C11 & C12 & $1.349(9)$ \\
C12 & C13 & $1.470(9)$ \\
C12 & C15 & $1.422(9)$ \\
C13 & C14 & $1.402(8)$ \\
C13 & C24 & $1.392(8)$ \\
C14 & C23 & $1.474(8)$ \\
C15 & C16 & $1.312(9)$ \\
C16 & C17 & $1.483(10)$ \\
C17 & C18 & $1.354(9)$ \\
C17 & C24 & $1.434(8)$ \\
C18 & C19 & $1.373(11)$ \\
C19 & C20 & $1.385(10)$ \\
C20 & C21 & $1.401(9)$ \\
C21 & C22 & $1.442(9)$ \\
C21 & C24 & $1.446(9)$ \\
C22 & C23 & $1.347(8)$ \\
& &
\end{tabular}

Table 2: Bond Angles in ${ }^{\circ}$ for compound 04.

\begin{tabular}{llll}
\hline Atom & Atom & Atom & Angle $^{\circ}$ \\
\hline C9 & O1 & B1 & $117.0(4)$ \\
C8B & N1 & C1 & $117.0(4)$ \\
C1B & N2 & C8B & $112.6(4)$ \\
C1B & N2 & B1 & $122.6(4)$ \\
C8B & N2 & B1 & $123.3(4)$ \\
C8A & N3 & C1B & $115.9(4)$ \\
C1A & N4 & C8A & $113.4(4)$ \\
C1A & N4 & B1 & $123.7(4)$ \\
C8A & N4 & B1 & $122.2(4)$ \\
C1A & N5 & C8 & $115.9(4)$ \\
C1 & N6 & B1 & $123.3(4)$ \\
C8 & N6 & C1 & $112.3(4)$ \\
C8 & N6 & B1 & $123.0(4)$ \\
N1 & C1 & N6 & $122.1(5)$ \\
N1 & C1 & C2 & $129.3(5)$ \\
N6 & C1 & C2 & $106.5(4)$ \\
N4 & C1A & C2A & $105.8(4)$ \\
N5 & C1A & N4 & $122.9(5)$ \\
N5 & C1A & C2A & $129.8(5)$ \\
N2 & C1B & C2B & $107.0(4)$ \\
N3 & C1B & N2 & $123.4(5)$ \\
N3 & C1B & C2B & $128.0(5)$ \\
C3 & C2 & C1 & $132.4(5)$ \\
C3 & C2 & C7 & $120.2(5)$
\end{tabular}

\begin{tabular}{llll}
\hline Atom & Atom & Atom & Angle $^{\circ}$ \\
\hline C7 & C2 & C1 & $106.7(5)$ \\
C3A & C2A & C1A & $132.5(5)$ \\
C3A & C2A & C7A & $121.0(5)$ \\
C7A & C2A & C1A & $106.4(4)$ \\
C3B & C2B & C1B & $132.6(5)$ \\
C3B & C2B & C7B & $119.9(5)$ \\
C7B & C2B & C1B & $107.3(5)$ \\
C4 & C3 & C2 & $117.6(5)$ \\
C2A & C3A & C4A & $118.0(5)$ \\
C4B & C3B & C2B & $117.9(5)$ \\
C3 & C4 & C5 & $122.5(5)$ \\
C3A & C4A & C5A & $121.6(5)$ \\
C3B & C4B & C5B & $121.5(5)$ \\
C6 & C5 & C4 & $120.6(5)$ \\
C6A & C5A & C4A & $121.1(5)$ \\
C6B & C5B & C4B & $122.0(5)$ \\
C7 & C6 & C5 & $118.2(5)$ \\
C5A & C6A & C7A & $117.9(5)$ \\
C5B & C6B & C7B & $117.6(5)$ \\
C2 & C7 & C8 & $106.9(4)$ \\
C6 & C7 & C2 & $120.8(5)$ \\
C6 & C7 & C8 & $132.0(5)$ \\
C2A & C7A & C8A & $107.5(5)$ \\
C6A & C7A & C2A & $120.3(5)$
\end{tabular}




\begin{tabular}{lllr}
\hline Atom & Atom & Atom & Angle $^{\circ}$ \\
\hline C6A & C7A & C8A & $131.9(5)$ \\
C2B & C7B & C8B & $106.4(5)$ \\
C6B & C7B & C2B & $121.1(5)$ \\
C6B & C7B & C8B & $132.0(5)$ \\
N5 & C8 & N6 & $123.3(5)$ \\
N5 & C8 & C7 & $128.2(5)$ \\
N6 & C8 & C7 & $106.5(4)$ \\
N3 & C8A & N4 & $123.1(5)$ \\
N3 & C8A & C7A & $130.7(5)$ \\
N4 & C8A & C7A & $105.2(4)$ \\
N1 & C8B & N2 & $122.6(5)$ \\
N1 & C8B & C7B & $129.7(5)$ \\
N2 & C8B & C7B & $105.5(4)$ \\
01 & C9 & C10 & $119.7(6)$ \\
01 & C9 & C14 & $120.1(5)$ \\
C10 & C9 & C14 & $120.2(6)$ \\
C9 & C10 & C11 & $120.5(6)$ \\
C12 & C11 & C10 & $121.7(6)$ \\
C11 & C12 & C13 & $119.0(6)$ \\
C11 & C12 & C15 & $125.1(7)$ \\
C15 & C12 & C13 & $115.8(6)$ \\
C14 & C13 & C12 & $118.2(5)$ \\
C24 & C13 & C12 & $119.5(6)$ \\
C24 & C13 & C14 & $122.3(6)$ \\
C9 & C14 & C13 & $120.2(5)$
\end{tabular}

\begin{tabular}{lllr}
\hline Atom & Atom & Atom & Angle/ \\
\hline C9 & C14 & C23 & $120.9(5)$ \\
C13 & C14 & C23 & $118.8(5)$ \\
C16 & C15 & C12 & $125.0(7)$ \\
C15 & C16 & C17 & $121.6(6)$ \\
C18 & C17 & C16 & $123.4(7)$ \\
C18 & C17 & C24 & $121.8(7)$ \\
C24 & C17 & C16 & $114.7(6)$ \\
C17 & C18 & C19 & $119.3(8)$ \\
C18 & C19 & C20 & $121.8(7)$ \\
C19 & C20 & C21 & $121.6(8)$ \\
C20 & C21 & C22 & $123.0(6)$ \\
C20 & C21 & C24 & $116.8(7)$ \\
C22 & C21 & C24 & $120.1(6)$ \\
C23 & C22 & C21 & $120.8(6)$ \\
C22 & C23 & C14 & $119.9(6)$ \\
C13 & C24 & C17 & $123.4(7)$ \\
C13 & C24 & C21 & $118.0(6)$ \\
C17 & C24 & C21 & $118.6(6)$ \\
O1 & B1 & N2 & $110.9(4)$ \\
O1 & B1 & N4 & $116.1(5)$ \\
O1 & B1 & N6 & $117.6(5)$ \\
N2 & B1 & N4 & $104.2(4)$ \\
N2 & B1 & N6 & $103.7(4)$ \\
N4 & B1 & N6 & $102.8(4)$ \\
\end{tabular}


Crystal Data and Experimental

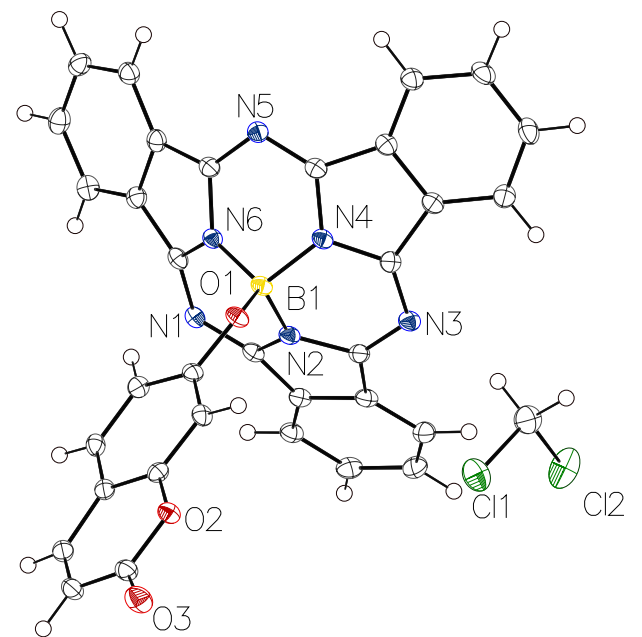

Experimental. Single clear light red prism-shaped crystals of compound $\mathbf{6}$ were recrystallized from DCM by slow evaporation. A suitable crystal $0.50 \times 0.24 \times 0.10 \mathrm{~mm}^{3}$ was selected and mounted on a MITIGEN holder oil on a Bruker D8 Venture diffractometer. The crystal was kept at a steady $T=100.0(1) \mathrm{K}$ during data collection. The structure was solved with the ShelXT (Sheldrick, 2015) structure solution program using the Intrinsic Phasing solution method and by using Olex2 (Dolomanov et al., 2009 ) as the graphical interface. The model was refined with version 2018/3 of ShelXL (Sheldrick, 2015) using Least Squares minimization.

Crystal Data. $\mathrm{C}_{34} \mathrm{H}_{19} \mathrm{BCl}_{2} \mathrm{~N}_{6} \mathrm{O}_{3}, M_{r}=641.26$, monoclinic, $P 2_{1} / c$ (No. 14), $\mathrm{a}=11.2700(6) \AA, \mathrm{b}=16.3338(9) \AA, \mathrm{c}=$ 15.6723(6) $\AA, \quad \beta=101.100(3)^{\circ}, \quad \alpha=\quad \gamma=90^{\circ}, \quad V=$ 2831.0(2) $\AA^{3}, T=100.0(1) \mathrm{K}, Z=4, Z^{\prime}=1, \mu\left(\mathrm{CuK}_{\alpha}\right)=2.478$, 69277 reflections measured, 5018 unique $\left(R_{\text {int }}=0.0599\right)$ which were used in all calculations. The final $w R_{2}$ was 0.0895 (all data) and $R_{1}$ was 0.0354 (I > 2s(I)).

\begin{tabular}{|c|c|}
\hline Compound & 6 \\
\hline CCDC & 2005982 \\
\hline Internal Reference & 20190502VL297 \\
\hline Formula & $\mathrm{C}_{34} \mathrm{H}_{19} \mathrm{BCl}_{2} \mathrm{~N}_{6} \mathrm{O}_{3}$ \\
\hline$D_{\text {calc. }} / \mathrm{g} \mathrm{cm}^{-3}$ & 1.505 \\
\hline$\mu / \mathrm{mm}^{-1}$ & 2.478 \\
\hline Formula Weight & 641.26 \\
\hline Colour & clear light red \\
\hline Shape & prism \\
\hline Size $/ \mathrm{mm}^{3}$ & $0.50 \times 0.24 \times 0.10$ \\
\hline$T / \mathrm{K}$ & $100.0(1)$ \\
\hline Crystal System & monoclinic \\
\hline Space Group & $P 21 / c$ \\
\hline$a / \AA ̊$ & $11.2700(6)$ \\
\hline$b / \AA ̊$ & $16.3338(9)$ \\
\hline$c / \AA ̊$ & $15.6723(6)$ \\
\hline$\alpha /^{\circ}$ & 90 \\
\hline$\beta 1^{\circ}$ & $101.100(3)$ \\
\hline$\gamma /^{\circ}$ & 90 \\
\hline $\mathrm{V} / \AA^{3}$ & $2831.0(2)$ \\
\hline$Z$ & 4 \\
\hline$Z^{\prime}$ & 1 \\
\hline Wavelength/Å & 1.541840 \\
\hline Radiation type & $\mathrm{CuK}_{\alpha}$ \\
\hline$\Theta_{\min } /^{\circ}$ & 3.948 \\
\hline$\Theta_{\max } /^{\circ}$ & 66.797 \\
\hline Measured Refl. & 69277 \\
\hline Independent Refl. & 5018 \\
\hline $\begin{array}{l}\text { Reflections with I > } \\
\text { 2(I) }\end{array}$ & 4461 \\
\hline$R_{\text {int }}$ & 0.0599 \\
\hline Parameters & 415 \\
\hline Restraints & 0 \\
\hline Largest Peak & 0.241 \\
\hline Deepest Hole & -0.391 \\
\hline GooF & 1.069 \\
\hline$w R_{2}$ (all data) & 0.0895 \\
\hline$w R_{2}$ & 0.0861 \\
\hline$R_{1}$ (all data) & 0.0409 \\
\hline$R_{1}$ & 0.0354 \\
\hline
\end{tabular}




\section{Structure Quality Indicators}

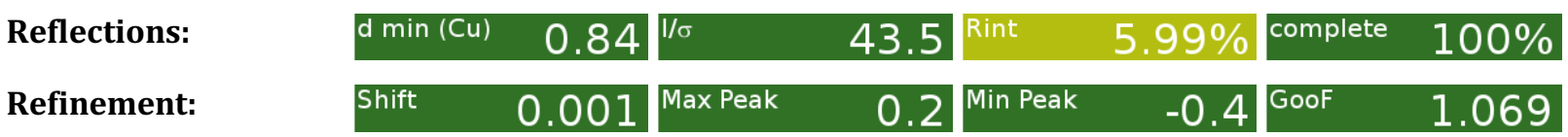

A clear light red prism-shaped crystal with dimensions $0.50 \times 0.24 \times 0.10 \mathrm{~mm}^{3}$ was mounted on a MITIGEN holder oil. Data were collected using a Bruker D8 Venture diffractometer equipped with an Oxford Cryosystems low-temperature device operating at $T=100.0(1) \mathrm{K}$. Data were measured using $\phi$ and $\omega$ scans using $\mathrm{CuK}_{\alpha}$ radiation. The total number of runs and images was based on the strategy calculation from the program APEX3 (Bruker, 2015) The maximum resolution that was achieved was $\Theta=66.797^{\circ}$ $(0.84 \AA)$. The diffraction pattern was indexed. The total number of runs and images was based on the strategy calculation from the program APEX3 (Bruker, 2015) and the unit cell was refined using SAINT (Bruker, V8.38A, after 2013) on 2267 reflections, 3\% of the observed reflections. Data reduction, scaling and absorption corrections were performed using SAINT (Bruker, V8.38A, after 2013). The final completeness is $99.80 \%$ out to $66.797^{\circ}$ in $\Theta$. A multi-scan absorption correction was performed using SADABS-2016/2 (Bruker, 2016) was used for absorption correction. $w R_{2}$ (int) was 0.1162 before and 0.0766 after correction. The Ratio of minimum to maximum transmission is 0.7194 . The absorption coefficient $\mu$ of this material is $2.478 \mathrm{~mm}^{-1}$ at this wavelength $(\lambda=1.542 \AA)$ and the minimum and maximum transmissions are 0.447 and 0.621 . The structure was solved and the space group $P 2_{1} / c$ (\# 14) determined by the ShelXT (Sheldrick, 2015) structure solution program using Intrinsic Phasing and refined by Least Squares using version 2018/3 of ShelXL (Sheldrick, 2015). All non-hydrogen atoms were refined anisotropically. Hydrogen atom positions were calculated geometrically and refined using the riding model. Hydrogen atom positions were calculated geometrically and refined using the riding model. There is a single molecule in the asymmetric unit, which is represented by the reported sum formula. In other words: $\mathrm{Z}$ is 4 and $\mathrm{Z}^{\prime}$ is 1 .

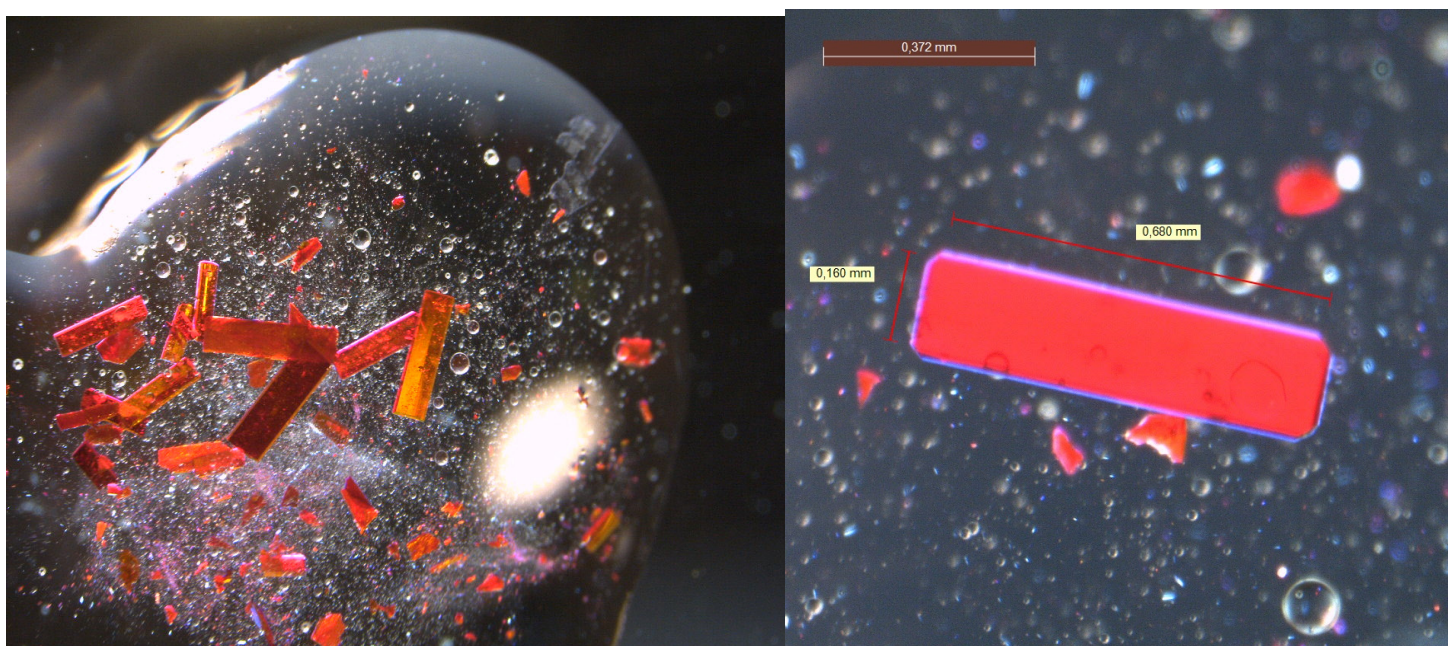

Figure 2: View of sample batch (left) and selected crystal (right).

Table 3: Bond Lengths in $\AA$ for compound 6.

\begin{tabular}{lll}
\hline Atom & Atom & Length/Å \\
\hline $\mathrm{Cl} 1$ & $\mathrm{C} 34$ & $1.775(2)$ \\
$\mathrm{Cl} 2$ & $\mathrm{C} 34$ & $1.767(2)$ \\
$\mathrm{O} 1$ & $\mathrm{C} 1$ & $1.355(2)$ \\
$\mathrm{O} 1$ & $\mathrm{~B} 1$ & $1.449(2)$ \\
$\mathrm{O} 2$ & $\mathrm{C} 7$ & $1.387(2)$ \\
$\mathrm{O} 2$ & $\mathrm{C} 8$ & $1.381(2)$ \\
03 & $\mathrm{C} 7$ & $1.206(2)$
\end{tabular}

\begin{tabular}{lll}
\hline Atom & Atom & Length/Å \\
\hline N1 & C10 & $1.350(2)$ \\
N1 & C33 & $1.343(2)$ \\
N2 & C10 & $1.370(2)$ \\
N2 & C17 & $1.367(2)$ \\
N2 & B1 & $1.496(2)$ \\
N3 & C17 & $1.349(2)$ \\
N3 & C18 & $1.343(2)$
\end{tabular}




\begin{tabular}{lll}
\hline Atom & Atom & Length/Å \\
\hline N4 & C18 & $1.362(2)$ \\
N4 & C25 & $1.364(2)$ \\
N4 & B1 & $1.489(2)$ \\
N5 & C25 & $1.348(2)$ \\
N5 & C26 & $1.342(2)$ \\
N6 & C26 & $1.369(2)$ \\
N6 & C33 & $1.369(2)$ \\
N6 & B1 & $1.495(2)$ \\
C1 & C2 & $1.401(2)$ \\
C1 & C9 & $1.391(2)$ \\
C2 & C3 & $1.380(2)$ \\
C3 & C4 & $1.402(3)$ \\
C4 & C5 & $1.432(2)$ \\
C4 & C8 & $1.396(2)$ \\
C5 & C6 & $1.344(3)$ \\
C6 & C7 & $1.451(3)$ \\
C8 & C9 & $1.380(2)$ \\
C10 & C11 & $1.453(2)$ \\
C11 & C12 & $1.397(2)$ \\
C11 & C16 & $1.425(2)$ \\
C12 & C13 & $1.387(3)$ \\
\end{tabular}

Table 4: Bond Angles in ${ }^{\circ}$ for compound 6.

\begin{tabular}{|c|c|c|c|}
\hline Atom & Atom & Atom & Angle ${ }^{\circ}$ \\
\hline$\overline{\mathrm{Cl} 2}$ & C34 & $\mathrm{Cl} 1$ & $110.90(11)$ \\
\hline C1 & 01 & B1 & $126.22(13)$ \\
\hline $\mathrm{C} 8$ & 02 & $\mathrm{C} 7$ & $122.09(14)$ \\
\hline C33 & N1 & $\mathrm{C} 10$ & $117.38(14)$ \\
\hline C10 & $\mathrm{N} 2$ & B1 & $123.29(14)$ \\
\hline C17 & $\mathrm{N} 2$ & $\mathrm{C} 10$ & $112.74(14)$ \\
\hline C17 & N2 & B1 & $122.08(14)$ \\
\hline C18 & N3 & $\mathrm{C} 17$ & $117.10(15)$ \\
\hline C18 & $\mathrm{N} 4$ & $\mathrm{C} 25$ & $113.89(14)$ \\
\hline C18 & $\mathrm{N} 4$ & B1 & $122.44(14)$ \\
\hline $\mathrm{C} 25$ & $\mathrm{~N} 4$ & B1 & $123.35(15)$ \\
\hline $\mathrm{C} 26$ & N5 & $\mathrm{C} 25$ & $116.68(14)$ \\
\hline $\mathrm{C} 26$ & N6 & C33 & $112.83(14)$ \\
\hline $\mathrm{C} 26$ & N6 & B1 & $122.44(14)$ \\
\hline C33 & N6 & B1 & $123.30(14)$ \\
\hline 01 & $\mathrm{C} 1$ & $\mathrm{C} 2$ & $123.66(16)$ \\
\hline 01 & $\mathrm{C} 1$ & $\mathrm{C} 9$ & $116.14(15)$ \\
\hline C9 & $\mathrm{C} 1$ & $\mathrm{C} 2$ & $120.18(16)$ \\
\hline $\mathrm{C} 3$ & $\mathrm{C} 2$ & $\mathrm{C} 1$ & $119.82(16)$ \\
\hline $\mathrm{C} 2$ & $\mathrm{C} 3$ & $\mathrm{C} 4$ & $121.10(16)$ \\
\hline $\mathrm{C} 3$ & $\mathrm{C} 4$ & $\mathrm{C} 5$ & $124.39(16)$ \\
\hline $\mathrm{C} 8$ & $\mathrm{C} 4$ & $\mathrm{C} 3$ & $117.57(16)$ \\
\hline $\mathrm{C} 8$ & $\mathrm{C} 4$ & $\mathrm{C} 5$ & $118.04(16)$ \\
\hline C6 & $\mathrm{C} 5$ & $\mathrm{C} 4$ & $120.82(17)$ \\
\hline $\mathrm{C} 5$ & $\mathrm{C} 6$ & $\mathrm{C} 7$ & $121.29(16)$ \\
\hline 02 & $\mathrm{C} 7$ & $\mathrm{C} 6$ & $116.83(15)$ \\
\hline 03 & $\mathrm{C} 7$ & 02 & $116.21(16)$ \\
\hline 03 & $\mathrm{C} 7$ & $\mathrm{C} 6$ & $126.96(17)$ \\
\hline 02 & $\mathrm{C} 8$ & $\mathrm{C} 4$ & $120.74(15)$ \\
\hline $\mathrm{C} 9$ & $\mathrm{C} 8$ & 02 & $116.80(15)$ \\
\hline C9 & $\mathrm{C} 8$ & $\mathrm{C} 4$ & $122.46(16)$ \\
\hline $\mathrm{C} 8$ & $\mathrm{C} 9$ & $\mathrm{C} 1$ & $118.84(15)$ \\
\hline $\mathrm{N} 1$ & $\mathrm{C} 10$ & $\mathrm{~N} 2$ & $122.36(15)$ \\
\hline $\mathrm{N} 1$ & C10 & $\mathrm{C} 11$ & $129.76(15)$ \\
\hline $\mathrm{N} 2$ & $\mathrm{C} 10$ & C11 & $105.91(14)$ \\
\hline C12 & C11 & $\mathrm{C} 10$ & $132.11(16)$ \\
\hline C12 & C11 & C16 & $120.65(16)$ \\
\hline
\end{tabular}

\begin{tabular}{lll}
\hline Atom & Atom & Length/A \\
\hline C13 & C14 & $1.403(3)$ \\
C14 & C15 & $1.383(3)$ \\
C15 & C16 & $1.394(3)$ \\
C16 & C17 & $1.455(2)$ \\
C18 & C19 & $1.460(2)$ \\
C19 & C20 & $1.390(2)$ \\
C19 & C24 & $1.426(2)$ \\
C20 & C21 & $1.384(3)$ \\
C21 & C22 & $1.400(3)$ \\
C22 & C23 & $1.386(3)$ \\
C23 & C24 & $1.391(2)$ \\
C24 & C25 & $1.459(2)$ \\
C26 & C27 & $1.458(2)$ \\
C27 & C28 & $1.393(3)$ \\
C27 & C32 & $1.419(2)$ \\
C28 & C29 & $1.389(3)$ \\
C29 & C30 & $1.395(3)$ \\
C30 & C31 & $1.390(3)$ \\
C31 & C32 & $1.392(2)$ \\
C32 & C33 & $1.457(2)$ \\
& &
\end{tabular}

\begin{tabular}{|c|c|c|c|}
\hline Atom & Atom & Atom & Angle $/^{\circ}$ \\
\hline$\overline{\mathrm{C} 16}$ & C11 & C10 & $107.07(15)$ \\
\hline C13 & C12 & C11 & $117.92(16)$ \\
\hline C12 & C13 & C14 & $121.41(16)$ \\
\hline C15 & C14 & C13 & $121.21(17)$ \\
\hline C14 & C15 & C16 & $118.39(17)$ \\
\hline C11 & C16 & C17 & $107.09(15)$ \\
\hline C15 & C16 & C11 & $120.38(16)$ \\
\hline C15 & C16 & C17 & $132.29(16)$ \\
\hline N2 & C17 & C16 & $105.91(14)$ \\
\hline N3 & C17 & N2 & $122.77(15)$ \\
\hline N3 & C17 & C16 & $129.53(16)$ \\
\hline N3 & C18 & N4 & $122.23(15)$ \\
\hline N3 & C18 & C19 & $130.74(16)$ \\
\hline N4 & C18 & C19 & $105.52(14)$ \\
\hline $\mathrm{C} 20$ & C19 & C18 & $132.51(16)$ \\
\hline C20 & C19 & C24 & $120.66(16)$ \\
\hline C24 & C19 & C18 & $106.79(15)$ \\
\hline C21 & $\mathrm{C} 20$ & C19 & 117.91(17) \\
\hline C20 & $\mathrm{C} 21$ & C22 & $121.56(17)$ \\
\hline $\mathrm{C} 23$ & $\mathrm{C} 22$ & C21 & $121.21(17)$ \\
\hline C22 & $\mathrm{C} 23$ & C24 & $117.99(17)$ \\
\hline C19 & $\mathrm{C} 24$ & C25 & $107.45(15)$ \\
\hline C23 & $\mathrm{C} 24$ & C19 & $120.61(16)$ \\
\hline $\mathrm{C} 23$ & $\mathrm{C} 24$ & C25 & $131.89(16)$ \\
\hline N4 & $\mathrm{C} 25$ & C24 & $105.21(14)$ \\
\hline N5 & $\mathrm{C} 25$ & N4 & $122.00(15)$ \\
\hline N5 & $\mathrm{C} 25$ & C24 & $131.43(16)$ \\
\hline N5 & $\mathrm{C} 26$ & N6 & $123.12(16)$ \\
\hline N5 & $\mathrm{C} 26$ & $\mathrm{C} 27$ & $129.91(16)$ \\
\hline N6 & $\mathrm{C} 26$ & $\mathrm{C} 27$ & $105.51(14)$ \\
\hline C28 & $\mathrm{C} 27$ & C26 & $131.91(16)$ \\
\hline C28 & $\mathrm{C} 27$ & C32 & $120.59(16)$ \\
\hline C32 & $\mathrm{C} 27$ & C26 & $107.40(15)$ \\
\hline C29 & $\mathrm{C} 28$ & C27 & $117.94(17)$ \\
\hline C28 & $\mathrm{C} 29$ & C30 & $121.27(17)$ \\
\hline C31 & C30 & C29 & $121.60(17)$ \\
\hline C30 & C31 & C32 & $117.57(17)$ \\
\hline
\end{tabular}




\begin{tabular}{|c|c|c|c|c|c|c|c|}
\hline Atom & Atom & Atom & Angle ${ }^{\circ}$ & Atom & Atom & Atom & Angle ${ }^{\circ}$ \\
\hline$\overline{\mathrm{C} 27}$ & $\mathrm{C} 32$ & C33 & $107.01(15)$ & $\overline{01}$ & B1 & N2 & $116.52(15)$ \\
\hline $\mathrm{C} 31$ & $\mathrm{C} 32$ & $\mathrm{C} 27$ & $120.96(16)$ & 01 & B1 & $\mathrm{N} 4$ & $107.80(14)$ \\
\hline $\mathrm{C} 31$ & $\mathrm{C} 32$ & C33 & $131.95(16)$ & 01 & B1 & N6 & $118.25(15)$ \\
\hline N1 & C33 & N6 & $122.45(16)$ & $\mathrm{N} 4$ & B1 & $\mathrm{N} 2$ & $104.57(14)$ \\
\hline $\mathrm{N} 1$ & $\mathrm{C} 33$ & $\mathrm{C} 32$ & $130.20(16)$ & $\mathrm{N} 4$ & B1 & N6 & $103.66(14)$ \\
\hline N6 & C33 & C32 & $105.74(14)$ & N6 & B1 & $\mathrm{N} 2$ & $104.52(14)$ \\
\hline
\end{tabular}

\section{Citations}

O.V. Dolomanov and L.J. Bourhis and R.J. Gildea and J.A.K. Howard and H. Puschmann, Olex2: A complete structure solution, refinement and analysis program, J. Appl. Cryst., (2009), 42, 339-341.

Sheldrick, G.M., Crystal structure refinement with ShelXL, Acta Cryst., (2015), C71, 3-8.

Sheldrick, G.M., ShelXT-Integrated space-group and crystal-structure determination, Acta Cryst., (2015), A71, 3-8.

Software for the Integration of CCD Detector System Bruker Analytical X-ray Systems, Bruker AXS, Madison, WI (after 2013). 